\title{
Another beauty of analytical chemistry: chemical analysis of inorganic pigments of art and archaeological objects
}

\author{
María Teresa Doménech-Carbó ${ }^{1} \cdot$ Laura Osete-Cortina $^{1}$
}

Received: 16 February 2016/Accepted: 28 July 2016/Published online: 26 August 2016

(C) Springer International Publishing Switzerland 2016

\begin{abstract}
This lecture text shows what fascinating tasks analytical chemists face in Art Conservation and Archaeology, and it is hoped that students reading it will realize that passions for science, arts or history are by no means mutually exclusive. This study describes the main analytical techniques used since the eighteenth century, and in particular, the instrumental techniques developed throughout the last century for analyzing pigments and inorganic materials, in general, which are found in cultural artefacts, such as artworks and archaeological remains. The lecture starts with a historical review on the use of analytical methods for the analysis of pigments from archaeological and art objects. Three different periods can be distinguished in the history of the application of the Analytical Chemistry in Archaeometrical and Art Conservation
\end{abstract}

studies: (a) the "Formation" period (eighteenth century1930), (b) the "Maturing" period (1930-1970), and (c) the "Expansion" period (1970-nowadays). A classification of analytical methods specifically established in the fields of Archaeometry and Conservation Science is also provided. After this, some sections are devoted to the description of a number of analytical techniques, which are most commonly used in routine analysis of pigments from cultural heritage. Each instrumental section gives the fundamentals of the instrumental technique, together with relevant analytical data and examples of applications.

Keywords Artists' pigments · Archaeometry · Voltammetry of microparticles · Microscopy techniques · Spectroscopic techniques $\cdot$ Spot tests
Electronic supplementary material The online version of this article (doi:10.1007/s40828-016-0033-5) contains supplementary material, which is available to authorized users.

\footnotetext{
María Teresa Doménech-Carbó

tdomenec@crbc.upv.es

1 Institut de Restauració del Patrimoni, Universitat Politècnica de València, Cami de Vera s/n, 46022 Valencia, Spain
} 


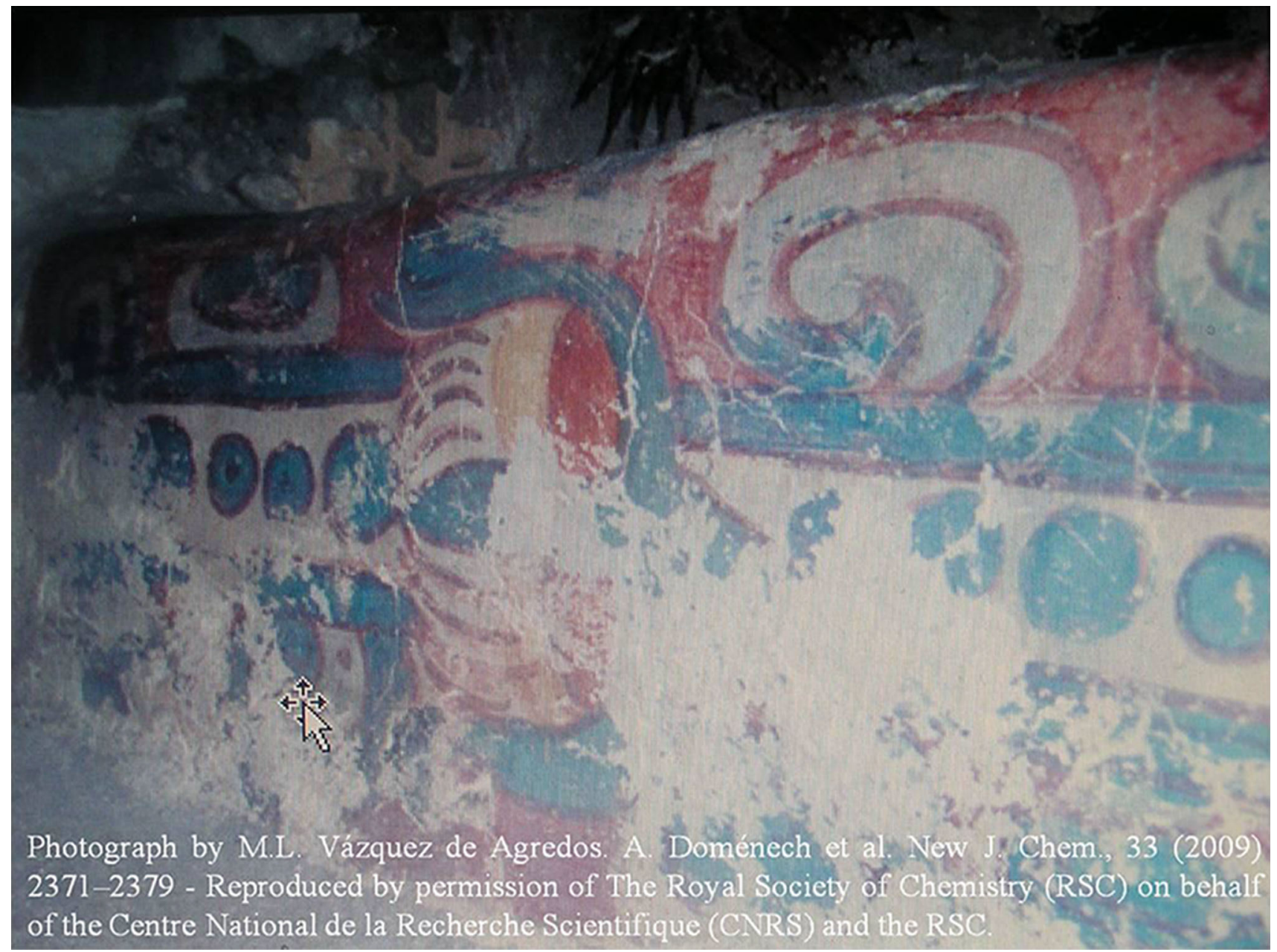

\section{Introduction}

Since the first reported technical examinations of cultural artefacts, such as artworks and archaeological remains, conducted in the late eighteenth century, the application of analytical techniques has been constantly widened in the heritage sector. Among the materials composing the art object, inorganic compounds used as coloring agents in paint layers or as grounds and supports have attracted the attention of archaeologists, art historians and the conservation professionals owing to the ability of such materials for undergoing morphological and chemical changes during aging. The importance of knowing the chemical composition of cultural goods has been understood by the personnel responsible for elaborating the syllabus of graduate and postgraduate studies in Conservation of Heritage and Archaeology, and consequently, Chemistry, in particular Analytical Chemistry, has been progressively included in courses or as subject of seminars and workshops. In parallel, this topic has been increasingly considered in the curriculum of Analytical Chemistry matter included in Chemistry graduate studies.
There are a small number of texts and reviews in the literature devoted to the principles of Chemistry and Physics of interest in the cultural heritage sector [1-7] and instrumental techniques applied to the analysis of cultural artefacts [8-19]. In this context, this study presents the contents that, in the opinion of the authors, should be included in a course of Analytical Chemistry applied to Archaeometry $^{1}$ and Conservation Science $^{2}$ as specific subject aimed to the analysis of inorganic pigments and

\footnotetext{
1 This term is associated with the name of the Journal Archaeometry, set up in 1958 by the Research Laboratory for Archaeology and the History of Art of the Oxford University. Several definitions for this branch of the archaeology have been made. Among them, "measurements made on archaeological material" [20] or "application and interpretation of natural science data in archaeological and art historical studies" [21].

2 The term "Conservation Science", which is now widely accepted within the cultural heritage sector, came into use in the 1980s. It encompasses Archaeometry. The term has also been used in advertising for positions which involve fieldwork in nature and environmental conservation [22].
} 
Fig. 1 Scheme of the historical development of the chemical analysis of cultural artefacts
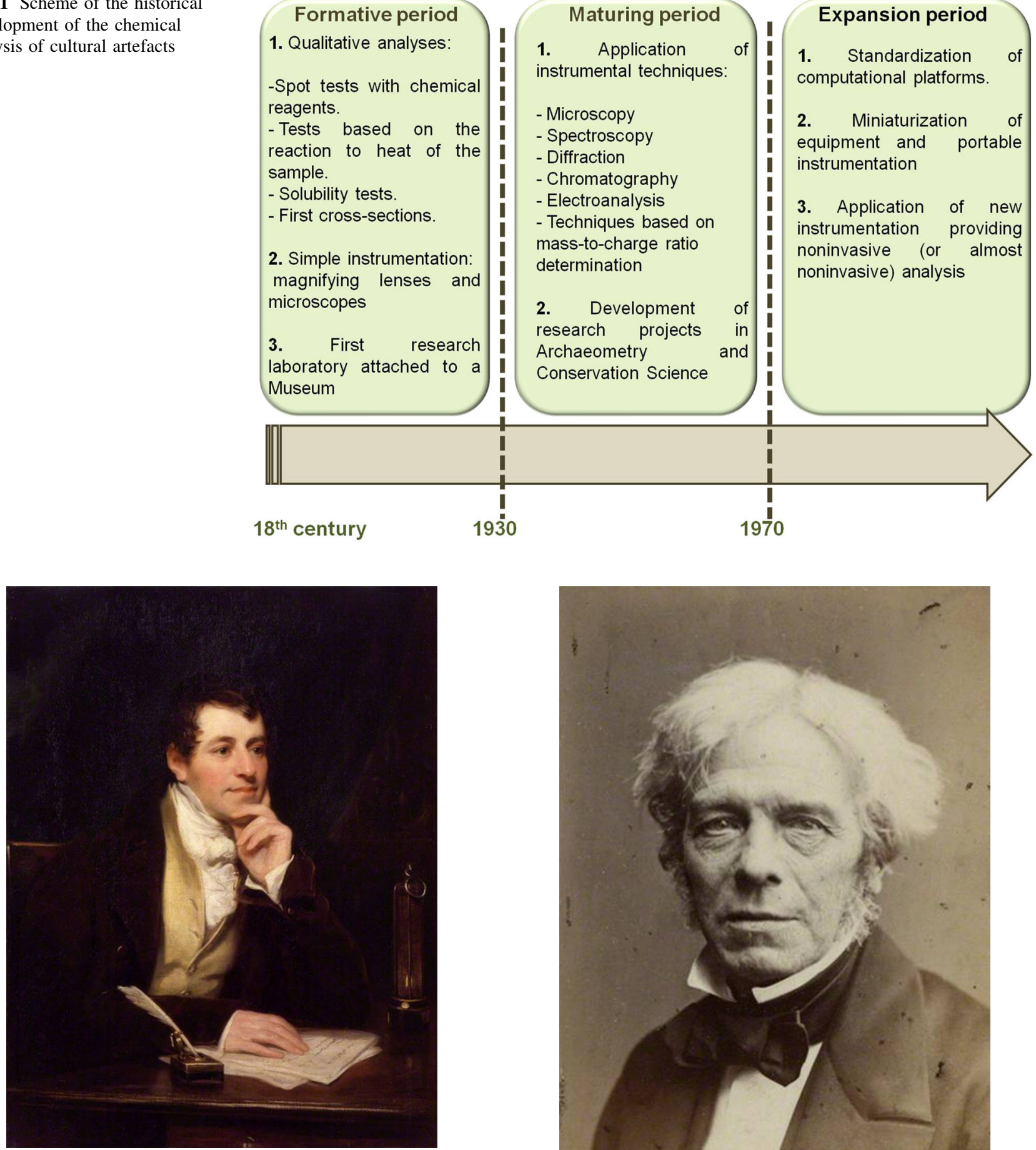

Fig. 2 Sir Humphry Davy (1778-1829) by Thomas Phillips. (C) National Portrait Gallery, London

related materials. After a summary of the historical development and a revision of the most common instrumentation currently used, relevant analytical data of interest and examples of application of these techniques are provided.

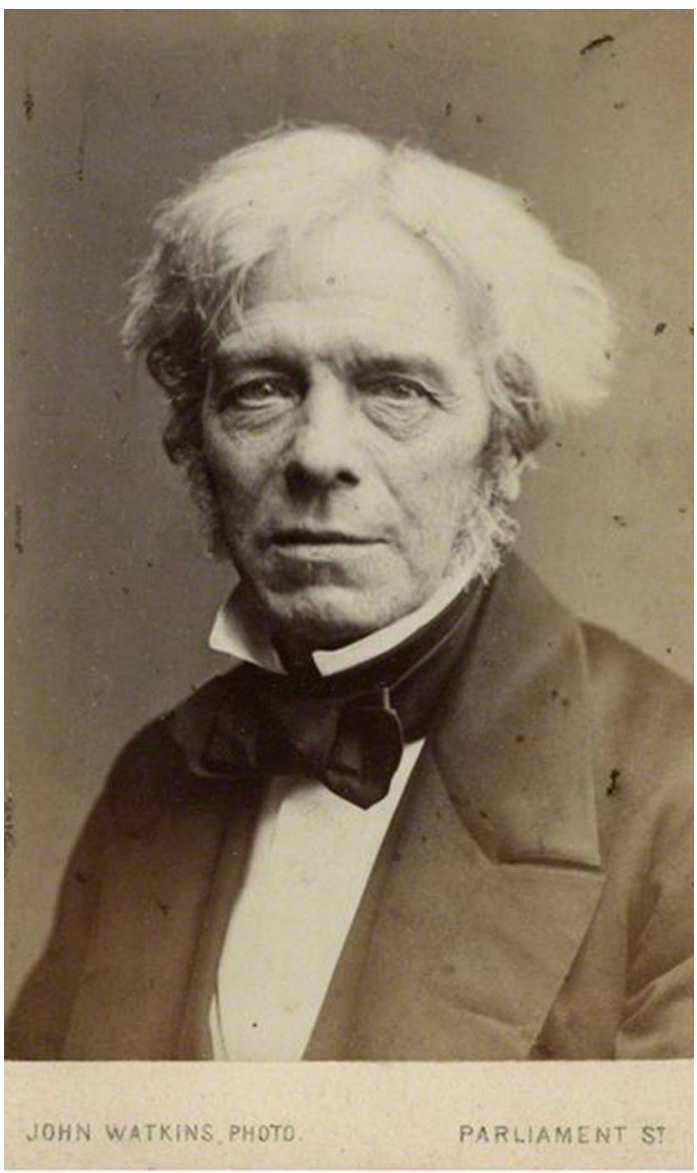

Fig. 3 Michael Faraday (1791-1867) by John Watkins. (C) National Portrait Gallery, London 


\section{Historical background}

The use of Chemistry and Physics for resolving questions related to Archaeology, Art History, and Conservation Science dates back to the eighteenth century as result of the dissemination of the new concepts and ideas of the German historian and archaeologist Johann Joachim Winckelmann (1717-1768) on the methodology applied in Art History and Archaeology studies. This new appraisal based the knowledge of the ancient civilizations not only on the study of old treatises and documents but also on the examination of the archaeological remains and artworks [23]. Since this early time until nowadays, chemical analysis has notably progressed becoming an essential tool in Archaeometry and Conservation Science studies. Three periods can be distinguished in the development of the chemical analysis of cultural artefacts, as shown in Fig. 1 [24, 25].

\section{Formation step}

The first dated studies of archaeological and art objects were restricted to geological examination of the objects as in the case of the characterization of the prehistorical stone of the Stonehenge carried out by the English astronomer and scientist Edmond Halley (1656-1742) in 1720. The analysis of the pigments and binding medium of an

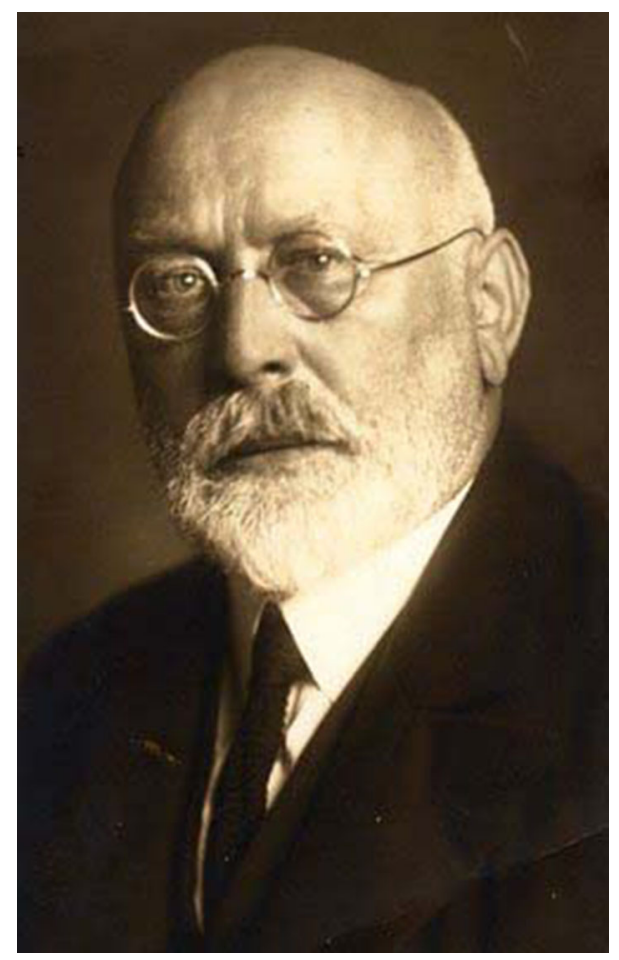

Fig. 4 Friedrich Rathgen (1862-1942). (C) bpk-Bildagentur für Kunst, Kultur und Geschichte/Rathgen Forschungslabor Staatliche Museen zu Berlin
Egyptian sarcophagus by the German physician and natural scientist Johann Friedrich Gmelin (1748-1804) in 1781 is the first account on an analytical study carried out by a physician/scientist [23]. Prior to that, a number of technical examinations of archaeological or art objects were carried out by art historians based on the application of wiping tests [23]. A quantitative analysis of a historical pigment was first published in 1826 by the French chemist LouisNicolas Vauquelin (1763-1829) [23]. In the nineteenth century, relevant chemists are involved in analytical studies of heritage. In 1815, the English chemist Sir Humphry Davy (1778-1829) (Fig. 2) analyzed the pigments of wall paintings from different sites (Pompeii and the Baths of Titus and Livia) [26], the English scientist Michael Faraday (1791-1867) (Fig. 3) analyzed materials from the Propylaeum of Athens in 1837, and in 1882, the Irish born US chemist John William Mallet (1832-1912), the seventh President of the American Chemical Society, carried out his Ph.D. project on analytical characterization of prehistoric Celtic objects (including precious stones, glass beads, pigments, bronzes, and gold ornaments) at the University of Göttingen (Germany) [27]. Most of those studies were based on microchemical test, ${ }^{3}$ tests based on the reaction to heat of a sample and wiping (solubility) tests. Although most of these analyses did not reach today's standards, the results were accurate enough to provide new insights into these artefacts.

First reference to the use of a magnifying lenses for observing the reaction of a paint sample after application of a reagent is the study of Christopher Barber (1736-1810), an English miniature painter, of sculptures and paintings in 1786 [23]. In 1783, this artist also describes a procedure for embedding a paint sample from the medieval Crouchback Tomb in Westminster Abbey in a block of wax. However, the preparation of a cross section in the modern sense of the term was pioneered by the Scottish chemist Arthur Pillans Laurie (1861-1949) in 1914 [28]. Reference to the use of a microscope for the examination of paint samples is found in the research of the German architect and art critic Gottfried Semper (1803-1879) on the ceiling of The Thesion of Athens in 1834 [23].

In 1888 , was set up the first research laboratory attached to a Museum, the Chemisches Labor der Königlichen Museen zu Berlin (Chemical Laboratory of the Royal Museums in Berlin). Its first director, Friedrich Rathgen (1862-1942) (Fig. 4), can be considered the first to adopt a scientific appraisal to the treatment of museum objects [29]. In the twentieth century, new scientific laboratories

\footnotetext{
3 The term microchemical analysis is not unambiguous, and it has been used historically with different meanings. Here, it is used in a rather relaxed way to designate the analysis of samples of $\mu \mathrm{g}$ or $\mu \mathrm{L}$ size. Often it also refers to much smaller samples.
} 


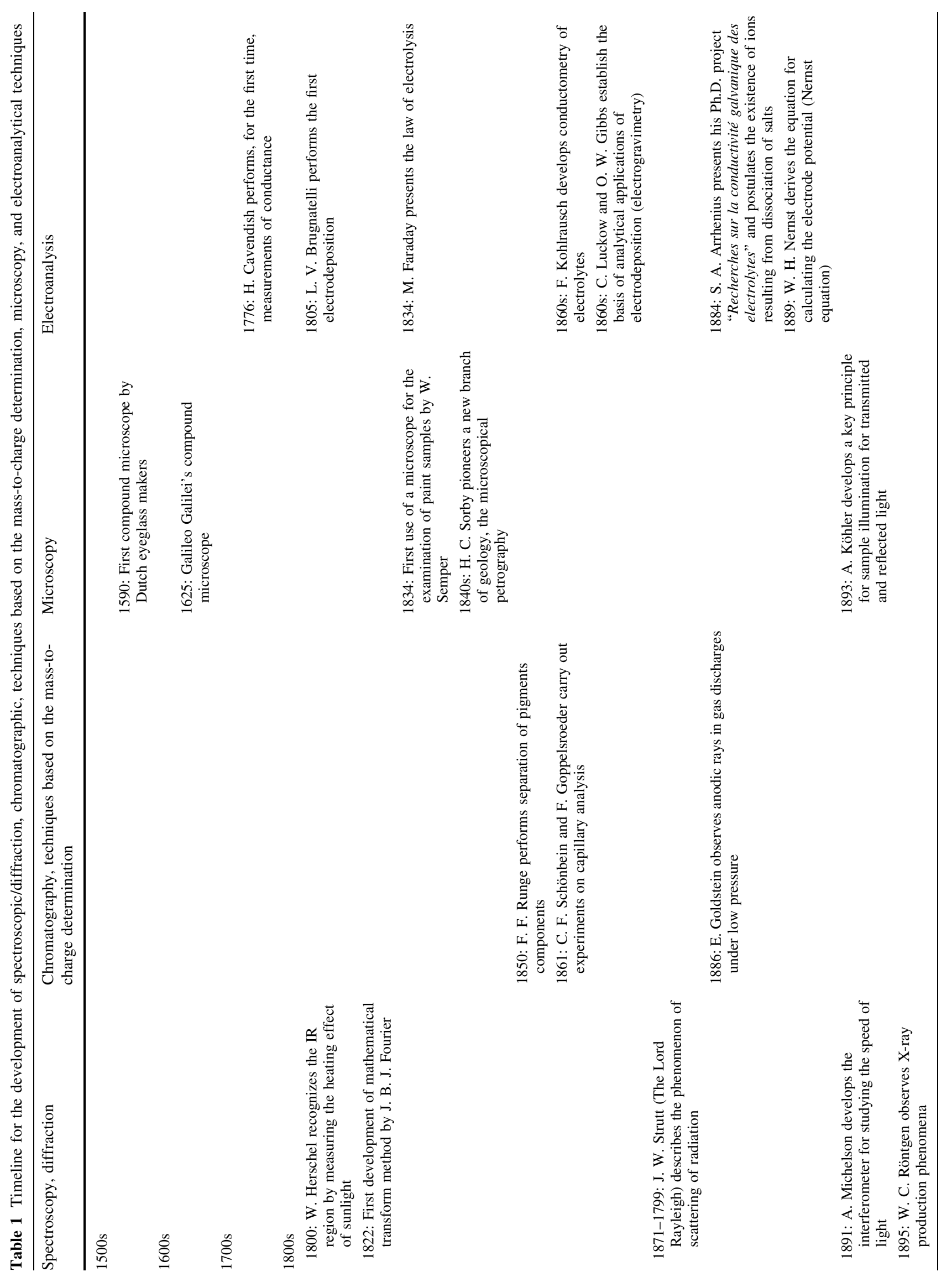




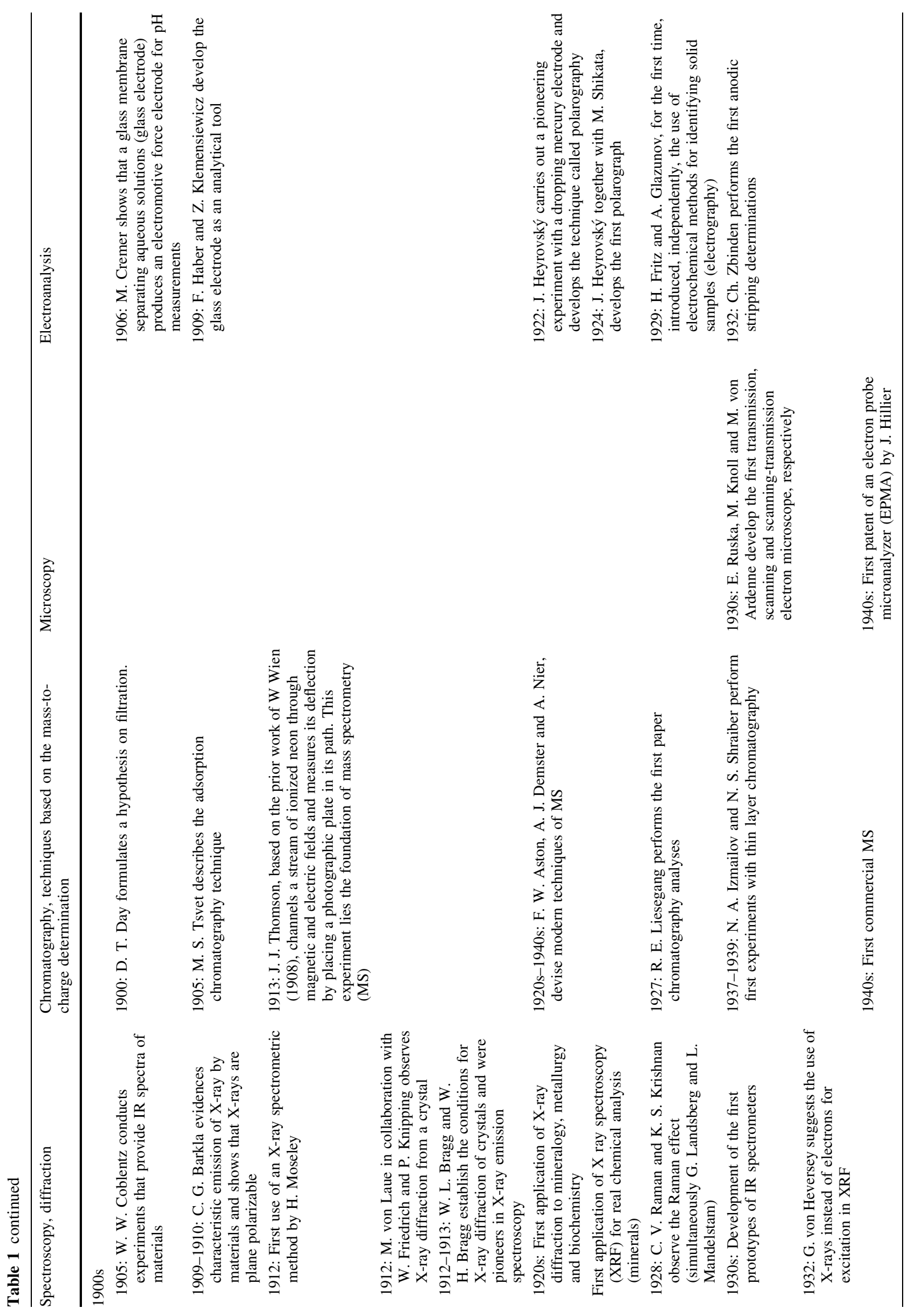




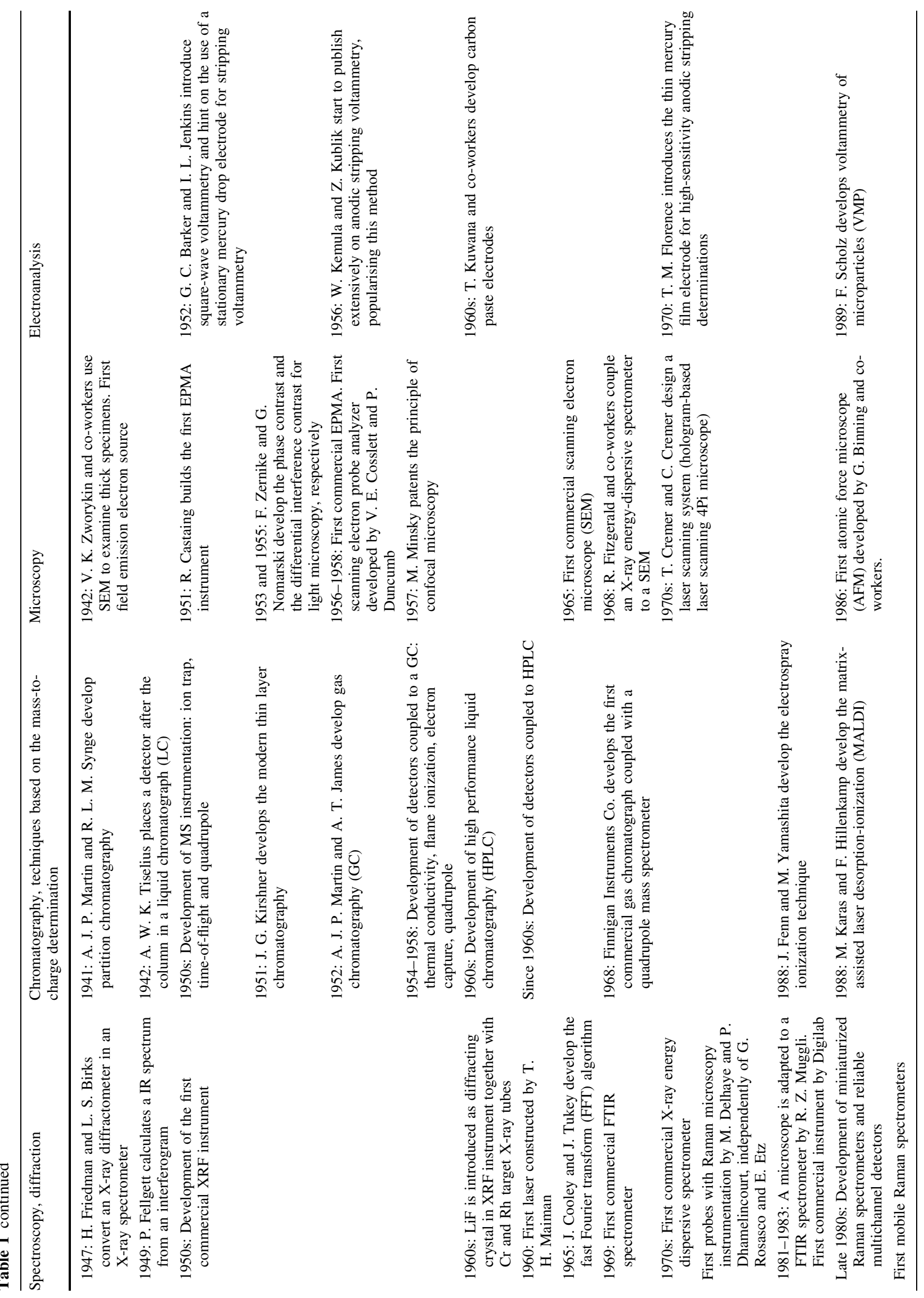


were set up. The Laboratory of the Fine Arts Museum of Boston was established in the 1920s. The Center de Recherche et de Restauration des Musées de France and the Laboratory of the British Museum started in 1931.

\section{Maturing step}

Advances in the analysis and physical examination of cultural goods run in parallel to the time the instruments were first introduced into this field (Table 1). During the late nineteenth century and the early twentieth century, dating techniques as well as microscopy, spectroscopy, diffraction, chromatographic, electroanalytical techniques, and techniques based on mass-to-charge ratio determination were introduced (see Fig. 1). The use of optical emission spectrography in the study of archaeological objects dates from 1931 [30]. This technique was first applied to the examination of metal objects. One of the first scientists to use IR spectroscopy for the characterisation of materials present in paintings was the chemist Robert L. Feller, director of the National Gallery of Art Research Project and the Research Center on the Materials of the Artist and Conservator at Carnegie Mellon Research Institute in Pittsburgh [31]. First electron probe microanalyzers (EPMA) and scanning electron microscopes coupled with energy dispersive X-ray microanalysis systems (SEM-EDX), which started to be used in the 1950s and 1960s, respectively, provided reliable qualitative and quantitative characterization of pigments with grain size in the range $2-5 \mu \mathrm{m}$ [32]. All these newly developed instrumental techniques notably contributed to the improvement of the analyses of artworks and archaeological remains, and consequently, the potential role of Analytical Chemistry in Archaeometry and Conservation Science studies increased. Greater sensitivity and selectivity in the analysis of atomic and molecular species helped scientists not only to recognize materials (pigments, binding media, supports, etc.) but also to differentiate between artefacts. Spot tests ${ }^{4}$ based on classical analytical procedures were also frequently used in this period in specialized laboratories in parallel to the instrumental techniques [28, 33-35]. They not only could serve for calibrating instrumental methods but also provided a quick method for identifying materials, and today, they are still in use.

\footnotetext{
${ }^{4}$ Spot tests (in German 'Tüpfelanalyse', in French 'analyse de tâche' or 'réaction à la touche', in Portuguese 'análise de toque', in Spanish 'ensayos a la gota') are analytical tests in which usually a droplet of a sample solution and of a reagent are placed on the same spot of a filter paper or a spot plate, where a characteristic color indicates the presence of a compound, ion, etc. Spot tests have been strongly developed and popularized by the Jewish Austrian-born chemist Fritz Feigl (1891-1971) who escaped from Nazi-occupied Austria and lived since 1940 in Brazil.
} 
Fig. 5 General classification of methods for scientific study of cultural artefacts

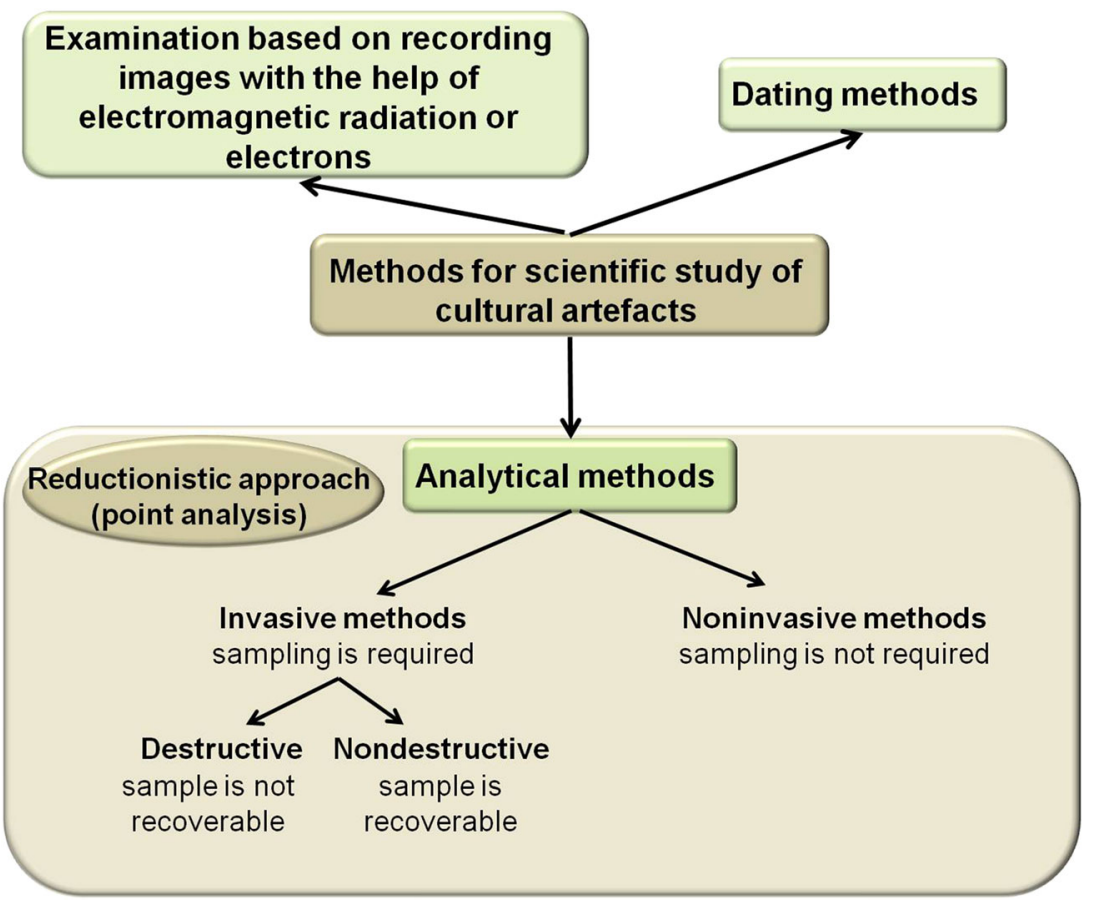

\section{Expansion step}

Since the 1970s, the application of instrumental techniques for the analysis of cultural artefacts has notably increased. Instrumentation has been progressively improved owing to the standardization of computational platforms that support the analytical equipments. Earliest applications of Raman spectroscopy to the identification of inorganic pigments date back to the end of the 1980s, for instance. In the middle of the 1990s, a few researchers were using Raman spectroscopy for the analysis of art and historical works [36]. By the 1990s, inductively coupled plasma spectroscopy (ICP-AES) replaced atomic absorption spectrometry (AAS) for multielement analysis [37]. On the other hand, the miniaturization of equipments enabled the development of portable instrumentation in techniques, such as X-ray fluorescence, X-ray diffraction or Raman spectroscopy, among others. Scope of microscopy was enlarged with the development of new instrumentation such as atomic force microscopes or confocal microscopes. Techniques based on mass-to-charge ratio determination were improved with the development of new instrumental devices such as electrospray ionization and soft laser desorption. Ultra-performance liquid chromatography (UPLC) contributed to enlarge the applications of chromatographic techniques in the analysis of organic and inorganic-organic hybrid pigments [38].

Activation techniques, such as neutron activation analysis (NAA) or proton activation analysis (PAA) [10, 11] and new electrochemical methods, such as voltammetry of microparticles [39], have widened the range of instrumental methodologies able to analyze pigments in the last decades. Microbeam analytical methods, also developed in late twentieth century, have minimal or no impact in the integrity of the object and afford high spatial resolution that ranges from $10^{2}$ to $10^{-2} \mu \mathrm{m}[15,40]$.

\section{Classification of analytical techniques}

According to Lahanier [16], methods currently available for scientific study of cultural artefacts are classified into three categories, as shown in Fig. 5:

1. Examination based on recording images with the help of electromagnetic radiations or electrons. This holistic approach includes images of the object as a whole visible to naked eye. The images can be acquired in the range of visible, ultraviolet and infrared light, X-rays, beta rays and gamma rays. They mainly provide qualitative and morphological information on the object that complement the analytical data supplied by dating and analytical methods [11].

2. Dating methods. They provide a chronological framework of a specific region or archaeological site. In general, dating methods follow a scheme based on a measurable time-dependent quantity or parameter with a well-known value associate with a determined event, which is used as "reference or starting point" in a time-scale relatable to the Archaeology of interest. It is interesting to note that dating techniques have limitations in applicability related to the type of materials, age range and state of preservation of the object $[9,10,41]$.

3. Analytical methods. They enable the identification and characterisation of materials and elucidation of their 
Fig. 6 Requirements of instrumental techniques applied to the analysis of cultural artefacts
Main requirements of instrumental techniques applied to the analysis of cultural artefacts

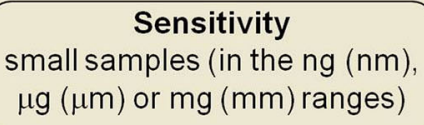
Specificity
unequivocally identifying and quantifying pigments

\section{Other considerations in choosing an analytical method for pigment studies}

a) nonintrusiveness (noninvasiveness): the physical integrity of the object is safeguarded.

b) nondestructiveness: the bulk of the sample is recoverable after analysis.

c) fastness: large assemblages of samples are analyzable.

d) universality: materials and objects of various shape, size and composition are analyzable with minimum sampling and pre-treatment.

e) versatility: average or bulk composition and specific composition of local areas can be provided;

f) multi-elemental: qualitative information on multiple elements or compounds present in the object is obtained by means of a single measurement.

g) availability and cost: instrumentation easily available worldwide. deterioration processes [10-12, 16]. In addition, information on provenance, chronology, and manufacture technique (most artefacts and artworks are the products of little-known, ill-documented technologies and past industries) is provided by such analytical techniques. The main characteristics and requirements of analytical methods are described thereafter.

Analytical methods, in general, are based in a reductionistic approach in which the material composition of a minute portion of the object is determined (point analysis). Analysis can be performed on the bulk or the object surface. Measurements are directly performed on the cultural artefact itself (noninvasive methods) or on a sample (invasive methods). In invasive methods, the analysis can be considered destructive or nondestructive depending on the destruction or recovery of the sample during the analysis (see Fig. 5).

Two basic requirements must be accomplished for the instrumental technique in the analysis of cultural artefacts (Fig. 6): sensitivity, for obtaining data from small samples on nano, micro or mili (-gram, -meter) scale, and specificity, for unequivocally identifying and quantifying pigments and inorganic compounds from complex mixtures. In addition, other requirements are desirable in an analytical method applied to cultural artefacts [16, 37], as shown in Fig. 6.

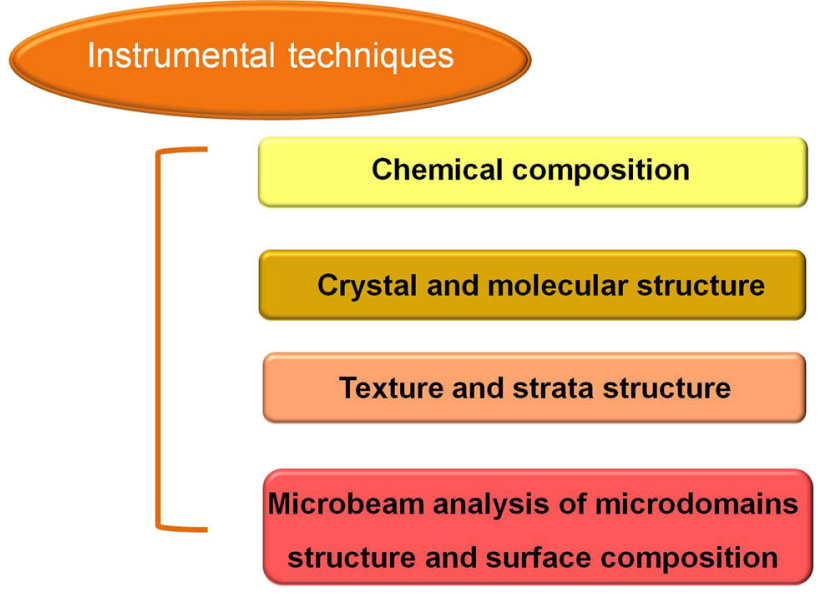

Fig. 7 Classification of instrumental techniques applied to the analysis of cultural artefacts

In a similar way to the proposal of Mairinger and Schreiner [42], analytical methods in Archaeometry and Conservation Science can be classified in four categories depending on the type of information provided, as shown in Fig. 7. Analysis of pigments can be carried out by techniques included in any of these groups. Often multi-technique strategies are applied to obtain more information. 
Fig. 8 Classification of instrumental techniques most frequently used in the analysis of cultural artefacts that provide data on chemical composition
Fig. 9 Classification of instrumental techniques most frequently used in the analysis of cultural artefacts that provide data on crystal and molecular structure

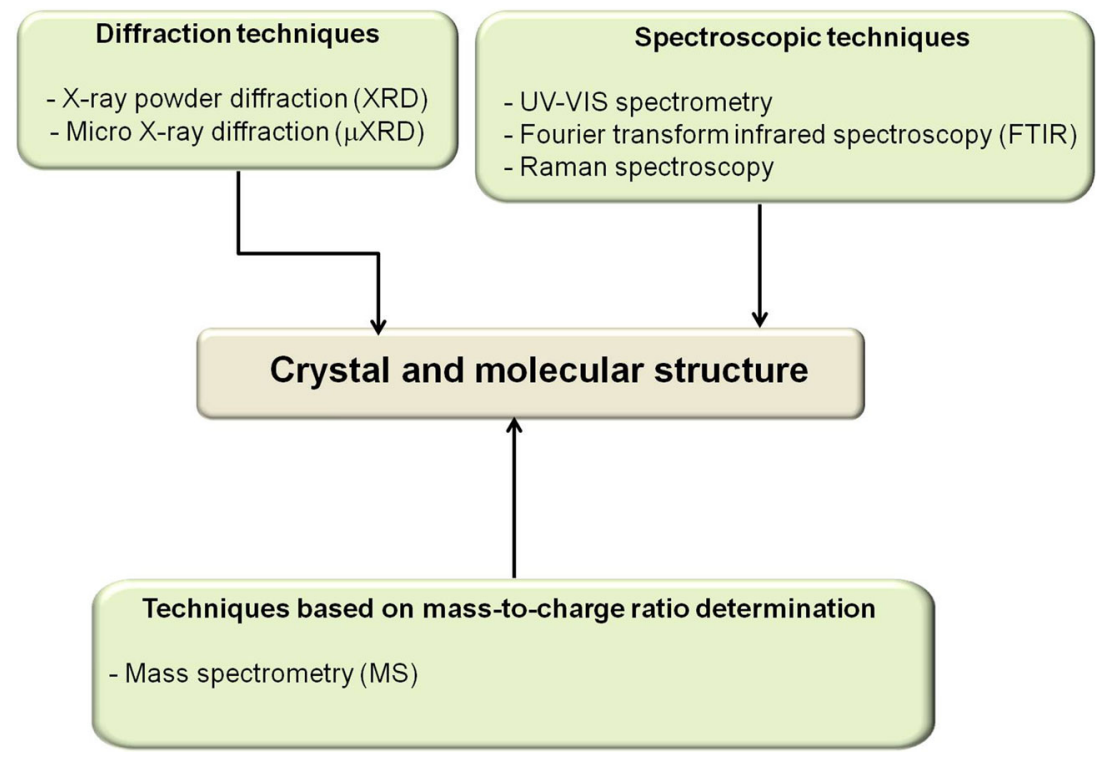

Activation methods

- Neutron activation analysis (NAA)

- Proton activation analysis (PAA)
- X-ray fluorescence (XRF)

- Atomic absorption spectroscopy (AAS)

- Optical emission spectroscopy (OES)

- Inductively coupled plasma-atomic

emission spectroscopy (ICP-AES)

- Mössbauer spectroscopy
- Thermogravimetry (TG)

- Differential thermal analysis (DT

- Differential scanning calorimetry (DSC)

- Thermogravimetry-mass spectrometry (TG-MS)
1. Chemical composition Analytical techniques included in this group provide elemental composition and/or identification of ionic species and groups present in the pigment. According to the physical or chemical principia in which the method is based, it can be classified into five main groups, as shown in Fig. 8: (a) classical chemical analysis $[11,12,28,33,43]$, (b) spectroscopic techniques $[10,11,17,44,45]$, (c) activation techniques $[10,11,19]$, (d) electrochemical methods $[14,46-50]$, and (e) thermoanalytical techniques $[11,18,51]$.
2. Crystal and molecular structure Techniques used for analyzing pigments that are included in this category can be grouped into three classes, as shown in Fig. 9: (a) spectroscopic techniques [11, 13, 15, 17], (b) diffraction techniques $[10,11]$, and (c) techniques based on mass-tocharge ratio determination [11].

3. Texture and strata structure Microscopy techniques included in this category can be grouped into three classes, as shown in Fig. 10: (a) light microscopy (LM) [11, 52], (b) electron microscopy [45, 53], and (c) atomic force microscopy (AFM) [54]. 
Fig. 10 Classification of instrumental techniques most frequently used in the analysis of cultural artefacts that provide data on texture and strata structure

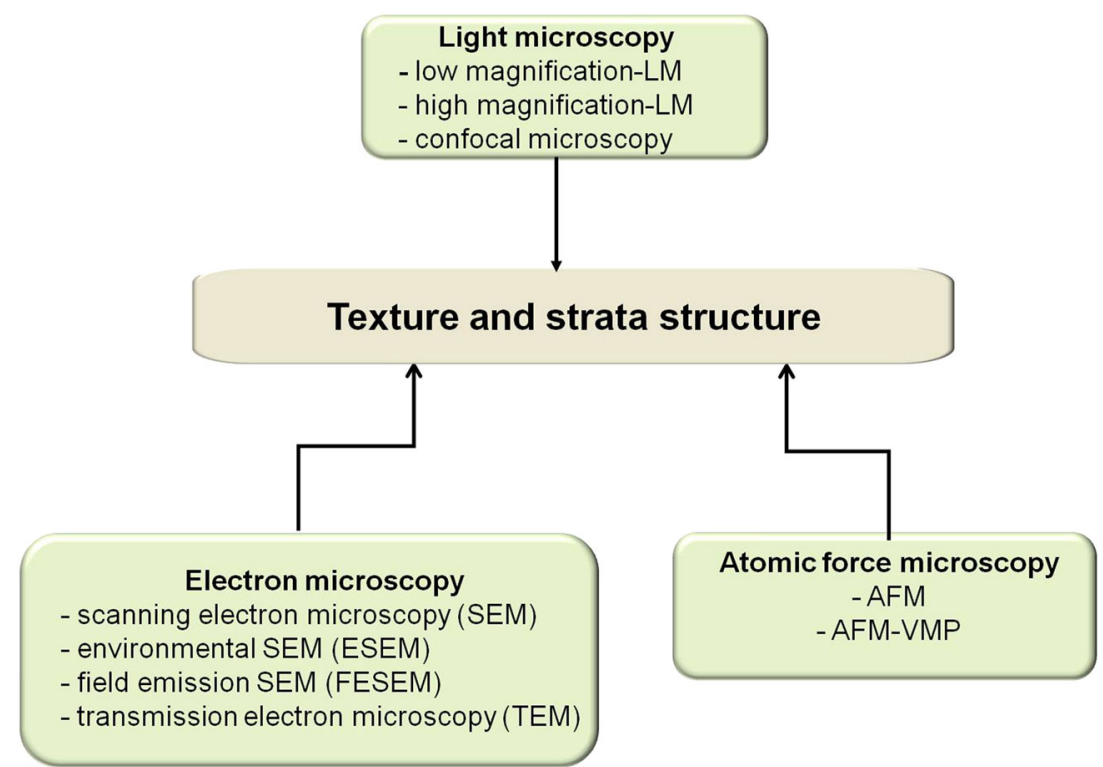

Table 2 Classification of microbeam techniques used in the analysis of pigments

\begin{tabular}{llll}
\hline Emission & Excitation & & Electron \\
\cline { 2 - 4 } & Photon & SEM-EDX EPMA & PIXE, PIGE \\
\hline Photon & $\begin{array}{l}\text { Vis light imaging microspectroscopy, microspectrofluorimetry, } \\
\text { LIBS, Raman and FTIR imaging microspectroscopy, } \mu \text { XRF, }\end{array}$ & & \\
& $\mu$ SRXRF, $\mu$ XANES, XAS, $\mu$ SRXRD & AES, EELS, TEM & RBS, SIMS, TOF-SIMS \\
Electron & XPS & & LDMS
\end{tabular}

LIBS laser-induced breakdown spectroscopy, $\mu X R F$ X-ray fluorescence microspectroscopy, $\mu S R X R F$ synchrotron X-ray fluorescence microspectroscopy, $\mu X A N E S \mathrm{X}$-ray absorption near-edge microspectroscopy, $X A S \mathrm{X}$-ray absorption spectroscopy, $\mu S R X R D$ synchrotron X-ray microdiffractometry, XPS X-ray-induced photoelectron spectroscopy, PIGE particle-induced $\gamma$-ray emission, PIXE particle-induced X-ray emission, $L D M S$ laser desorption mass spectrometry, $S E M-E D X$ scanning electron microscopy with energy-dispersive X-ray microanalysis, EPMA electron probe microanalysis, AES Auger electron spectrometry, EELS electron energy-loss spectroscopy, RBS Rutherford backscattering spectrometry, SIMS secondary ion mass spectrometry, TOF-SIMS time-of-flight-secondary ion mass spectrometry

4. Microbeam analysis of microdomains structure and surface structure and composition These methods are based on the interaction of the incident energy provided by a microbeam of photons, electrons or particles with the atoms or molecules located in the subjacent matter of the pigment achieving a depth in the range of a few micrometers [40]. Secondary particles, such as photons, electrons, ions or neutral particles, are released as result of the interaction with the primary corpuscles of the microbeam. These released particles may be the primary microbeam particles after interaction, or they may be secondary particles ejected from the atoms or molecules as a result of the interaction with the primary particles. These emitted corpuscles are carrying analytical information which is registered by a detection device. These techniques provide high spatial resolution and low dimensions for the analyzed area. Table 2 summarizes the microbeam techniques most commonly used in the analysis of pigments.

\section{Pigment analysis in practice}

\section{Sampling and sample pretreatment}

Analysis of pigments from cultural artefacts is made conditional to the premise that the object is unique and irreplaceable. Therefore, the object must be maintained as intact as possible, so that the complete process of analysis is subjected to this singular character inherent to heritage, in particular sampling. Not always it is possible to analyze pigments by means of a noninvasive technique, and thus, the sampling required in invasive techniques is subjected to severe restrictions as described thereafter. Even though the 
Table 3 Summary of requisites and criteria of sampling strategy for pigment analysis in cultural goods

\begin{tabular}{lll}
\hline Requisite & Criterion & Observations \\
\hline Number of samples & $\begin{array}{l}\text { Achieving a compromise between accuracy and minimal damage } \\
\text { to the object }\end{array}$ & - \\
Size of samples & $\begin{array}{l}\text { Achieving a compromise between minimal size over the } \\
\text { heterogeneity pattern of the analyzed material and minimal } \\
\text { damage to the object }\end{array}$ & - \\
Sampling points & $\begin{array}{l}\text { Analysis of the entire object } \\
\text { Homogenate the entire object and analyze a portion }\end{array}$ & Never applied \\
& $\begin{array}{l}\text { Take randomly located samples } \\
\text { Choose regularly patterned samples }\end{array}$ & Sever applied \\
& $\begin{array}{l}\text { Haphazardly or arbitrarily select points } \\
\text { Intentionally select or sample components not yet examined }\end{array}$ & Scarcely applied \\
Sampling method & Mechanical excision & Esually applied \\
& Abrasive transferring & Usually applied \\
& Dissolution with solvent impregnated in a cotton swab & Applied in several techniques \\
& & Applied prevalently for soluble salts and compounds \\
\hline
\end{tabular}

analytical technique is noninvasive, a sample may have to be taken, because the object is too large to fit into the sample chamber of the instrument.

Sampling is the first step in the analysis of pigments or inorganic materials present in the object. The strategy of sampling involves making decisions about number and size of samples, sampling points and sampling method, as summarized in Table 3.

The number of samples depends upon the painting or object that is analyzed, the type of information requested (identification of artist's palette, recognition of eventual alteration of a pigment) and the level of accuracy required for the estimate. In general, the larger the number of samples, the higher accuracy is reached in the analysis. Nevertheless, the number of samples to be taken is restricted by the constraints within the field of Cultural Heritage. Therefore, a compromise between these requisites must be achieved.

Similar to the number of samples, the sample size is severely restricted in the field of Cultural Heritage. Nevertheless, to guarantee an acceptable level of confidence in the analysis, the sample must have a minimum size that assures that all the components of the studied material are analyzed (vide infra). In other words, the analyst must be sure that the size of the sample taken is over the heterogeneity pattern of the material. Figure 11 shows, as an example, the cross section obtained from a fresco painting. Two possible volumes of sample can be excised. Volume of sample (a) contains all the pictorial strata but is under the heterogeneity pattern of the ground and, therefore, is not suitable for sampling. In contrast, volume of sample (b) is suitable for sampling, because it contains all the

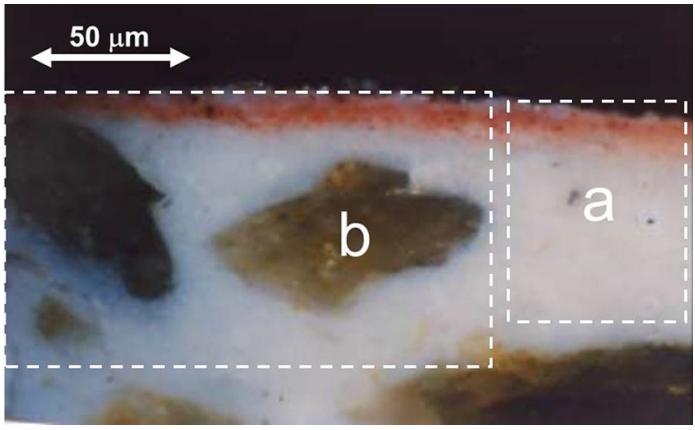

Fig. 11 Cross sections of a fresco painting. Image obtained by light microscope (XPL, $\times 100)$. The ground has a low homogeneity as this layer has been prepared with sand and slaked lime according to fresco painting technique

pictorial strata and is over the heterogeneity pattern of the ground.

According to Reedy and Reedy [55], six possible sampling strategies can be distinguished for the analysis of a single cultural artefact:

(a) Analysis of the entire object Despite it is the best method for obtaining an accurate result, this method is not applied in the analysis of cultural artefacts.

(b) Homogenate the entire object and analyze a portion Similar to the previous strategy, this method of sampling is not applied for archaeometric and conservation studies.

(c) Take randomly located samples This strategy is statistically equivalent to strategy (b), since it provides an estimate of the composition of the entire object from a portion of the object. Nevertheless, this sampling method can be applied to cultural artefacts. 
(d) Choose regularly patterned samples This strategy is based on taking samples to regular intervals across the object. Accuracy of the estimate is similar to strategy (c). Nevertheless, the risk of obtaining a biased result is comported in this strategy when a spatial pattern is present in the object at the same scale that the sampling interval.

(e) Haphazardly or arbitrarily select points This strategy imposes restrictions in sampling in particular positions for aesthetic or preservation reasons. Similar to strategy (d), there is the risk of obtaining a biased estimate.

(f) Intentionally select or sample components not yet examined This strategy is frequently applied to the characterisation of the artist's palette or the identification of a specific alteration of a pigment.

Sampling method is also made conditional to the ethical premises for object preservation. In some instances, such as illustrated manuscripts, samples are taken from smudges of pigment that had transferred onto the opposite page thus allowing for procurement of a relatively large amount of sample without disturbing the miniature. When samples are excised directly from the painting, the analyst has to avoid the lacunae to be discernible at naked eye, even at lowmagnification microscopy examination.

Method of sampling depends on the analytical technique chosen for performing the analysis. Mechanical excision of paint samples is frequently carried out for pigment analysis. Scalpels, lancets, and needles are usually used. Less frequently, instruments specially designed for this purpose are employed. Samples lesser than $1 \mathrm{~mm}^{3}$ are commonly used for preparing cross sections of canvas paintings for examination with light microscope. Nevertheless, panel and wall paintings with wider grounds can require larger samples to assure that the cross section includes the complete strata distribution. SEM-EDX analysis and/or microchemical tests usually are performed on the same cross section used for light microscopy examination. A few grains of pigment mechanically excised (ng or $\mu \mathrm{g}$ ) are typical amount of sample for analysis by microscopical petrography, electron and atomic microscopies, FTIR spectroscopy, micro-XRD, and MS. Other instrumental techniques, such as XRD, Raman microscopy, UV spectrophotometry, thermoanalytical techniques, emission, and absorption spectroscopies, require samples in the range mg- $\mu$ g. Sampling is, sometimes, performed by abrasive transferring a few grains (ng or $\mu \mathrm{g}$ ) of the solid material from the object. The pigment grains are directly transferred to the paraffin-impregnated graphite electrodes that consist of cylindrical rods of diameter ranging between 0.25 and $1 \mathrm{~mm}$ in "one touch" voltammetry of microparticles. Small SiC disks, which do not interfere during direct analysis of the sample, are used with techniques such as attenuated total reflectance Fourier transform infrared spectroscopy (ATR-FTIR). Samples of soluble materials such as soluble salts or organic compounds can be taken by dissolving them with an appropriate solvent. In such instances, a cotton swab is impregnated with solvent (1 drop $<40 \mu \mathrm{L}$ is the volume usually used), and then, it is rolled on the surface of the object until complete extraction of the soluble materials which are retained in the swab. The materials retained in the swab are redissolved (in the same volume of solvent at ca. $40 \mu \mathrm{L}$ ), and then, the solution obtained is analyzed. Less frequently, they are directly analyzed in the swab [i.e. by means of pyrolysis gas chromatography mass spectrometry (Py-GC-MS)].

Most of the analytical techniques require the preparation of the sample prior to the analysis step. Although the procedures of preparation of samples vary in a wide range, three procedures are commonly used for analyzing pigments and inorganic materials: grinding, melting, and embedding.

Samples are powdered or grinded in some techniques, such as XRD, DTA, TG or FTIR spectroscopy. The powdered sample is mixed with an inert binder (i.e. $\mathrm{KBr}$ in FTIR spectroscopy, cellulose or boric acid in XRF) and then pressed to form a disk which is exposed to the electromagnetic radiation. Control of the particle size during grinding enables more reliable results.

In XRF, the samples of ceramics and glass are melted with a flux such as lithium tetraborate. A solid solution of the sample compounds in the binder is formed after cooling of the melt.

Microscopic examination of samples can be performed directly on the sample but often it requires preparation of samples as cross sections and thin sections or mounting of sample on a glass slide by means a mounting medium. Cross sections of the samples (see Fig. 11) are obtained by placing the sample in a silicone mold and then embedding that in a polymer solution (i.e. polyester, acrylic or epoxy). After curing of the polymer, the cross or thin section is obtained by polishing the embedded sample with $\mathrm{SiC}$ abrasive disks. Alumina suspension or diamond paste is, occasionally, employed to rend completely planar and uniform the section obtained in the sample.

\section{Light microscopy}

\section{Description of instrumentation}

Depending on the type of sample preparation different models of microscope and optical configurations is used. Figure 12 shows the schemes of the more common optical systems used for observing paint samples under a light microscope. Direct examination of the sample is commonly 
Fig. 12 Scheme of three stereomicroscopy light illumination systems used for the examination of art and archaeological objects. a Specular reflected illumination. b Coaxial reflected illumination. c Transmitted illumination. Light from source pathway is shown in yellow, whereas the sample reflected/transmitted light pathway is shown by red arrows
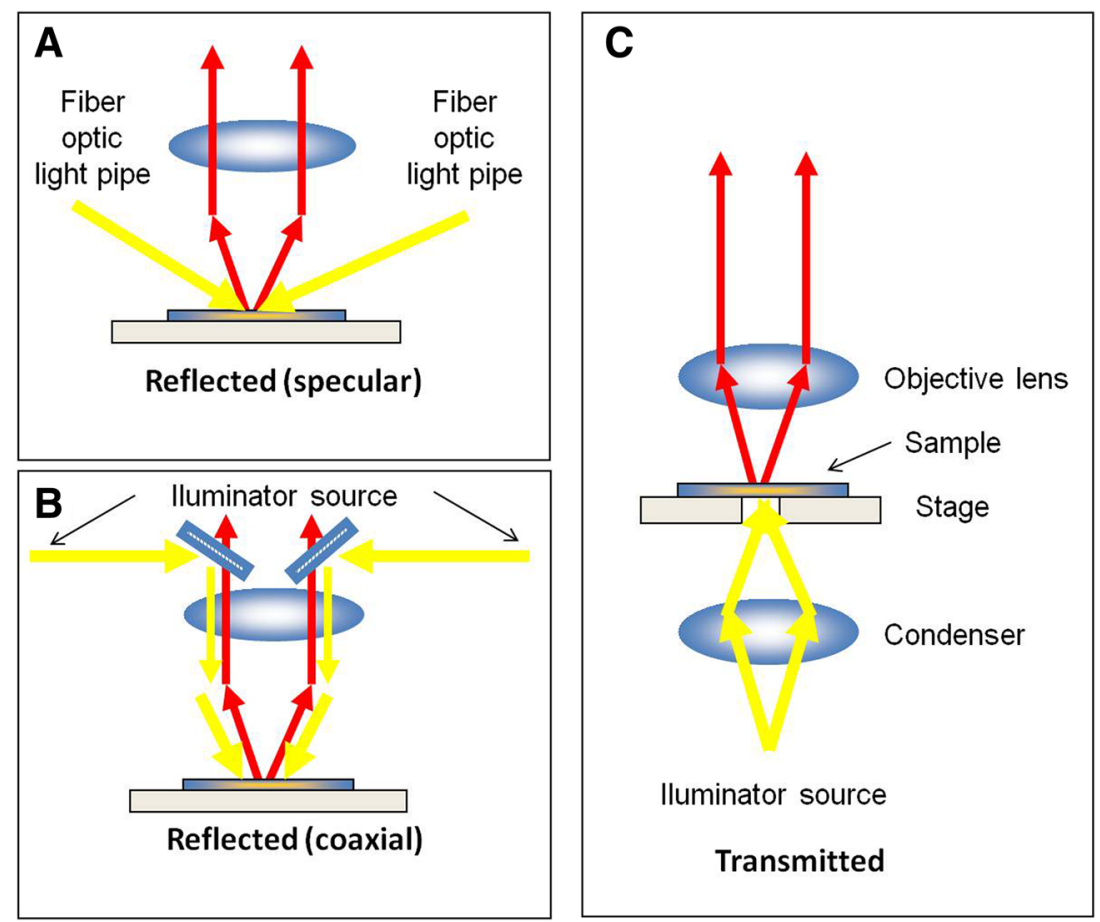

performed with low magnification-LM $(5 \times-80 \times)$ operating with reflected (episcopic) specular illumination (Fig. 12a) provided by external fiber optic light pipes. Cross sections are seen under high magnification-LM $(100 \times-400 \times)$ operating with coaxial reflected illumination (Fig. 12b). Crosspolarized light (XPL) is preferred for characterizing color and morphology of pigments, whereas surface topology and metal laminas are better recognized using plane polarized light (PPL). Pigments dispersed in a mounting medium and thin sections of paint layers are observed using transmitted (diascopic) light (Fig. 12c). By varying the optical configuration of the microscope, morphological and optical properties of pigments and minerals can be determined.

\section{Pigment properties}

Morphological, crystallographic, and mineralogical characteristics of pigments and inorganic materials can be recognized by examining them with a light microscope. As previously described, samples can be directly observed under the microscope, prepared as cross/thin sections or mounted the powdered samples with a mounting medium. Table 4 summarizes the diverse applications depending on the optical system and the illumination used in the microscope and the type of information provided. Detailed description of optical properties of minerals from thin sections can be found in general treatises on microscopic petrography [52]. More specific description of morphological and optical properties of pigments dispersed in mounting media is also provided by specific treatises on historical pigments [56, 57].

\section{Examination of paint samples}

Examples of pigment examination are provided in this section for illustrating the methodology of examination of paint samples.

Figure 13 shows the image of the cross section of a sample excised from an anonymous painting (Italy, seventeenth century). Average thickness of each stratum present in the sample can be easily determined from both photographs acquired at a 100-fold magnification. Crosspolarized light enables a better characterization of the different strata found in the sample (paint layer and ground) (Fig. 13a). White and red pigments present in the paint layer are clearly distinguishable providing an estimate of the color, shape, size, aggregation, and relative content of both pigments in such layer. Low homogeneity, characteristic of earth pigments used in the ground, is also recognized with this optical configuration. Large features like columnar particles and holes are observed in the ground. Photograph acquired with plane-polarized light (Fig. 13b) shows characteristic high reflectance of the red grains of vermilion in the paint layer. The features that appeared as holes with XPL illumination are clearly identified with PPL illumination as fragments of microfossils of the foraminiferida (or foraminera) phylum ascribed to the Globigerinidae family. 
Table 4 Applications of the microscopy examination of paint samples depending on the pre-treatment, optical system and type of illumination used in the microscope

\begin{tabular}{|c|c|c|c|}
\hline Illumination type & Optical system & Sample preparation & Applications \\
\hline Ordinary (unpolarized) & Reflected & Direct examination of sample & $\begin{array}{l}\text { Morphological properties } \\
\text { Strata distribution }\end{array}$ \\
\hline Cross-polarized & Reflected & Cross section & $\begin{array}{l}\text { Morphological and optical properties } \\
\text { Strata distribution }\end{array}$ \\
\hline Ordinary (unpolarized) & Transmitted & $\begin{array}{l}\text { Particles dispersed in a mounting medium } \\
\text { Thin-section }\end{array}$ & $\begin{array}{l}\text { Morphological properties: } \\
\text { Color }^{\mathrm{a}} \\
\text { Homogeneity } \\
\text { Particle size and size distribution } \\
\text { Particle shape } \\
\text { Particle surface } \\
\text { Aggregation } \\
\text { Inclusions } \\
\text { Fracture and cleavage } \\
\text { Diaphaneity }\end{array}$ \\
\hline Plane-polarized & Transmitted & $\begin{array}{l}\text { Particles dispersed in a mounting medium } \\
\text { Thin-section }\end{array}$ & $\begin{array}{l}\text { Optical properties: } \\
\text { Pleochroism } \\
\text { Refractive index and relief }\end{array}$ \\
\hline Cross-polarized & Transmitted & $\begin{array}{l}\text { Particles dispersed in a mounting medium } \\
\text { Thin-section }\end{array}$ & $\begin{array}{l}\text { Optical properties: } \\
\text { Birefringence } \\
\text { Extintion } \\
\text { Interference colors } \\
\text { Zoning and twinning } \\
\text { Elongation }\end{array}$ \\
\hline
\end{tabular}

a The use of dichroic filter is recommended
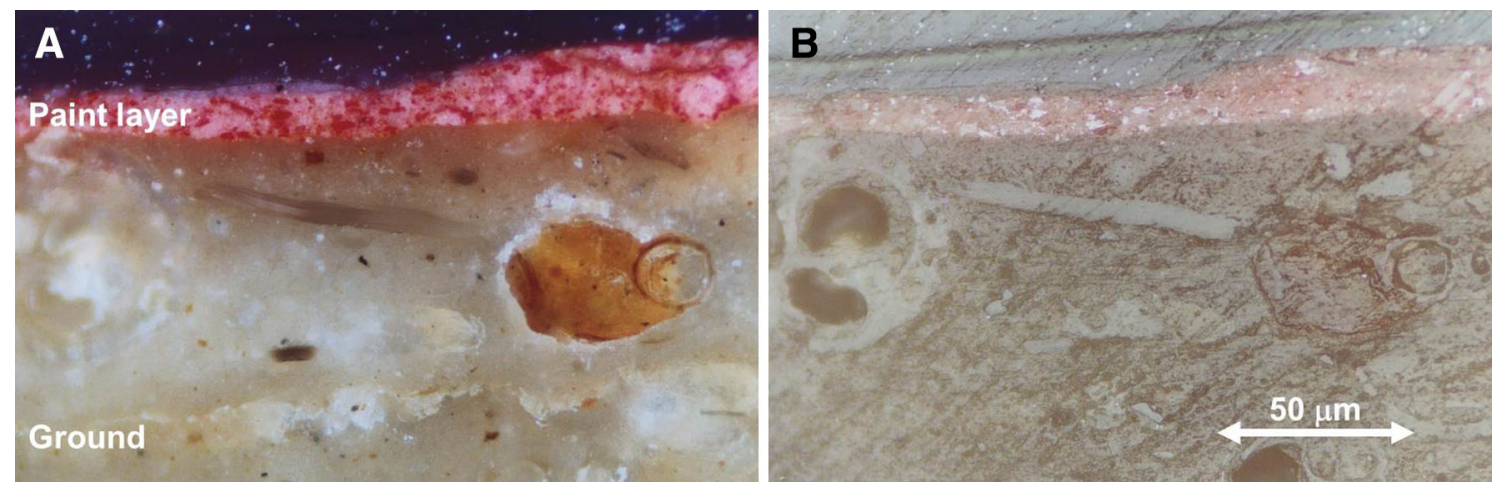

Fig. 13 Photograph of the cross section of a sample excised from an anonymous painting (Italy, seventeenth century). a Image acquired with XPL configuration $(\times 100)$. b Image acquired with PPL configuration $(\times 100)$. Coaxial reflected illumination

Figure 14 shows the image of particles of smalt dispersed in mounting medium. Figure $14 \mathrm{a}$ shows the image obtained under plane-polarized light. Size of smalt grains is ranging from medium to very coarse $(1-40 \mu \mathrm{m})$ [57]. This pigment has a glassy composition that determines the shape of the particles characterized by their angular habit with evident curved boundaries and concentric pressure ridges owing to the breaking with conchoidal fracture on manufacture crushing. This pigment is characterized by a moderate relief and a refractive index in the range 1.49-1.55 [56]. Inclusions due to the formation of bubbles of gas during the manufacture firing process are usually found in the grains of this pigment. They are clearly recognized in Fig. 14b (partially cross-polarized light configuration) as bright spots due to their strong birefringency. 


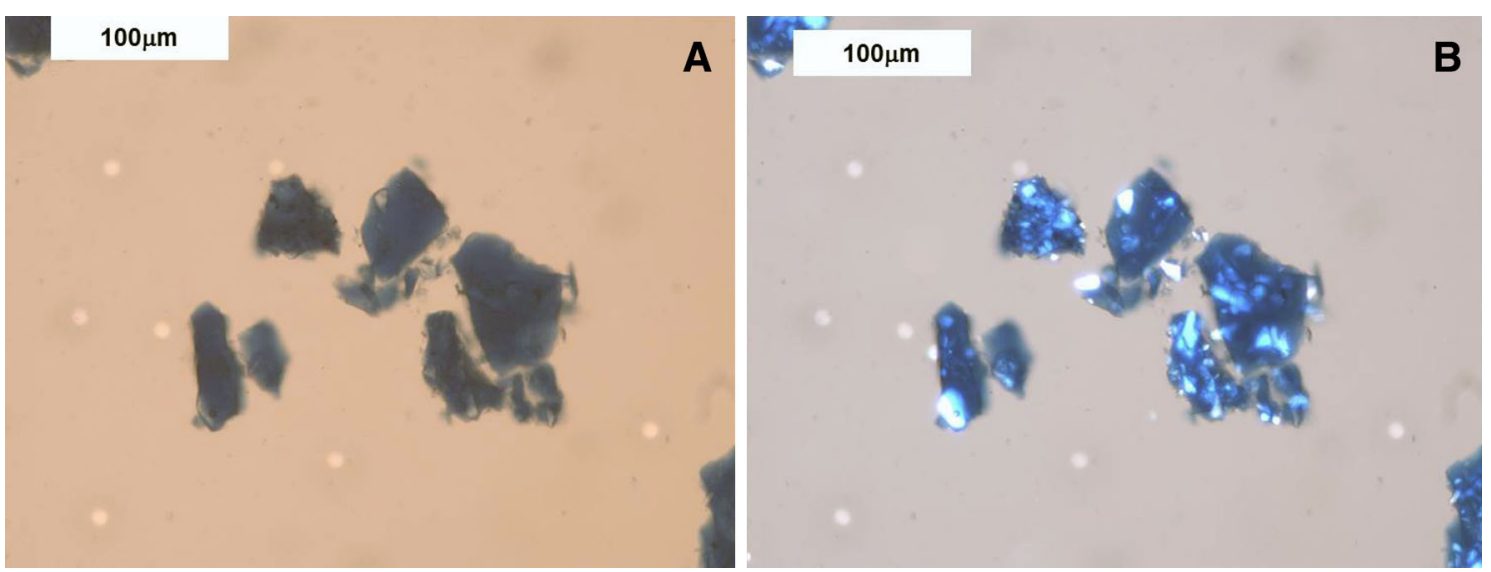

Fig. 14 Photograph of smalt pigment (Kremer Ref. K10000) mounted with acrylic mounting medium. a Image acquired with PPL configuration. b Image acquired with partially cross-polarized light configuration. Transmitted illumination

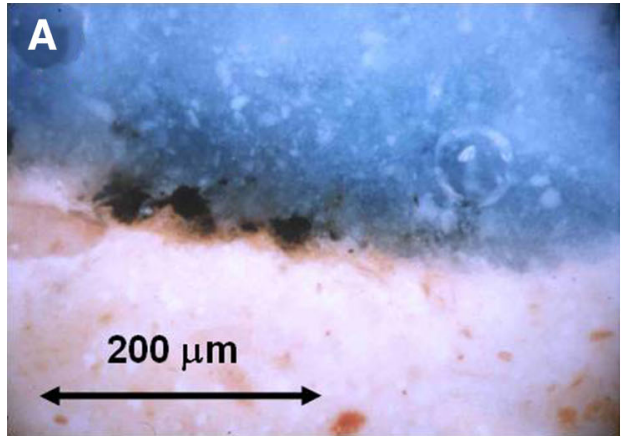

Fig. 15 a Cross section of a fifteenth blue-and-white ceramic ware produced in a workshop of Manises (Valencia, Spain). b Cross section of a ceramic fragment dated back from the eighteenth century

Examination of cross sections from paintings and glazed ceramics enables characterizing the artistic or manufacture technique used. Figure 15a shows the cross section of a blue-and-white ceramic ware produced in a workshop of Manises (Valencia, Spain). In the fifteenth century, this village became an important center of production of blue-and-white and lustreware ceramics, which were very appreciated in Europe. The "under glaze" technique used for applying the pigment is recognized by the rests of cobalt blue pigment that remain in the interphase between the ceramic body and the white glaze. In contrast, "over glaze" technique is recognized in Fig. 15b that shows the cross section of a ceramic fragment dated back from the eighteenth century and produced in a workshop of Alcora (Valenia, Spain). Application of two different green and white pigments over the glaze can be seen in the image. Since the fifteenth century, the older "under glaze" technique was progressively replaced in Valencian workshops by the "over glaze" technique which is still being used in modern Valencian workshops.

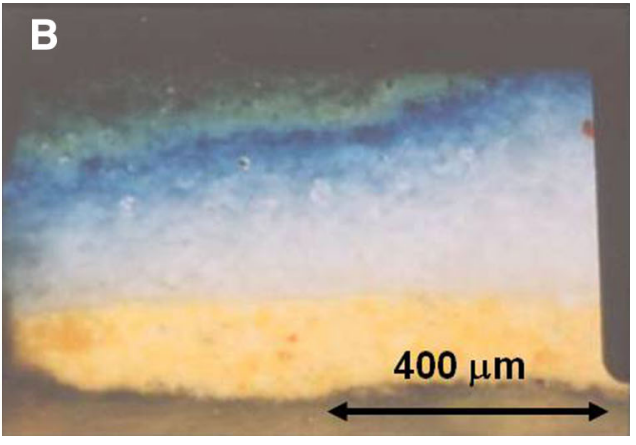

produced in a workshop of Alcora (Valenia, Spain). Images acquired with XPL configuration. Coaxial reflected illumination

\section{Microchemical tests}

Since the earliest times of scientific study of cultural artefacts, the chemical analysis was applied for identifying pigments and inorganic materials [23, 26, 28]. In parallel, solubility tests, histochemical tests or tests for determining some characteristic physical property of the medium such as the melting point were used for identifying organic components [23].

\section{Experimental procedure}

A few particles of pigment or a small sample of paint scrapped from the area of interest in the painting or artwork can be directly analyzed on spot plates (porcelain) or spot glass slides that can be placed on the stage of the microscope, so that the development of the reaction can be properly observed. Reagents in the order of a few microliters are added to the sample or cross section with the help of micropipettes. Strips of filter paper or thin cotton fibers impregnated with the reagent can also be used. In the latter, 


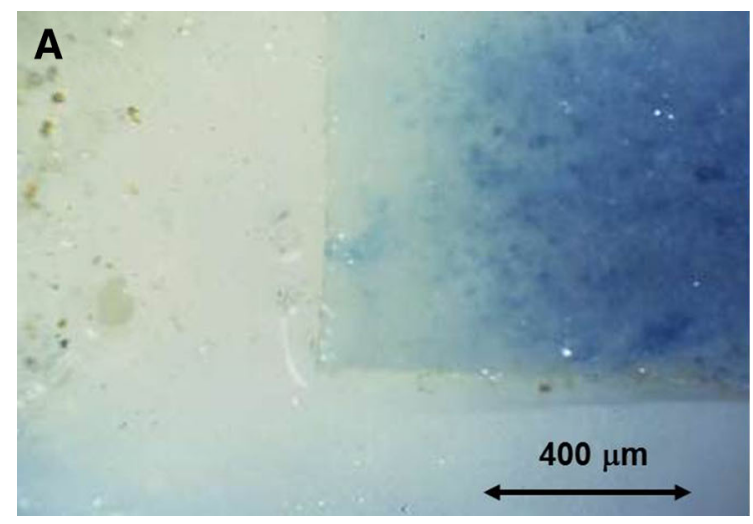

Fig. 16 a Spot test carried out on pigment particles of natural earth. Identification of $\mathrm{Fe}(\mathrm{III})$ with $\mathrm{K}_{4}\left[\mathrm{Fe}(\mathrm{CN})_{6}\right]$ using a paper strip. Photograph acquired with specular reflected illumination. b Spot test for identifying $\mathrm{Pb}$ (II) with $\mathrm{KI}$ carried out on a cross section containing

the change of color is observed directly on the strip or fiber (Fig. 16a). This method reduces the volume of reagent solution and the changes in the reactant system are better observed.

The main advantage of spot tests is the feasibility of identifying the pigment within the paint layer as these tests can be directly performed on the cross sections (Fig. 16b). The same procedure above described for pigment particles and paint samples can be used with cross sections. As the reaction volume is low, successive spot tests for different pigments can be carried out on the same cross section by washing off the excess of reagent. If necessary the cross section can be polished a few micrometers after each trial.

\section{Analysis of paint samples with microchemical methods}

Table 5 gives a survey of the most common chemical reactions used for identifying inorganic pigments from solid samples using a few milligrams. More information can be obtained in specific works [12, 26, 28, 34, 35, 58-61] and analytical chemistry treatises [33, 43]. In general, a preliminary treatment is required for solubilising the ionic species that are subjected to identification. Concentrated acidic solutions and, less frequently, alkaline solutions are used. Sometimes, the reaction of the pigment in acidic or alkaline medium results in developing gas bubbles or forming a colored precipitate, which enables the identification of the marker ion. Nevertheless, there are some pigments that can not be got into solution with acidic or alkaline solutions. This restricts the microchemical tests that can be carried out on cross sections. If the microchemical test is performed directly on pigment particles or paint samples excised from the painting, solubilisation of the pigment can be made by heating the sample in a platinum

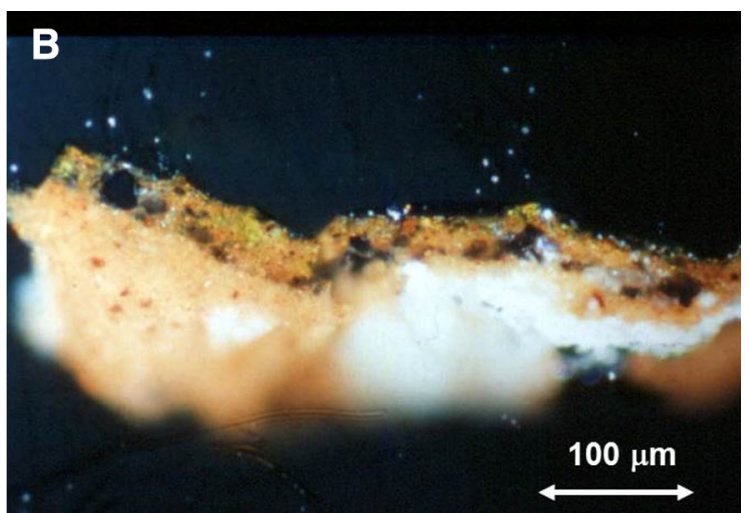

lead white pigment. $\mathrm{Pb}$ (II) is recognized by the yellow $\mathrm{PbI}_{2}$ formed in the paint layer. Photograph acquired with coaxial reflected illumination, XPL configuration

spoon with sodium persulphate, sodium fluoride/sulphuric acid, and sodium carbonate/sodium peroxide mixtures.

Different types of reactions can be used for identifying pigments: (a) formation of insoluble precipitates, (b) complexation reactions with formation of colored complexes, (c) redox reactions as in $\mathrm{Mn}(\mathrm{III})$-containing pigments such as manganese phosphate $\left(\mathrm{MnPO}_{4}\right)$ or permanent violet $\left(\left(\mathrm{NH}_{4}\right)_{2} \mathrm{Mn}_{2}\left(\mathrm{P}_{2} \mathrm{O}_{7}\right)_{2}\right)$ in which the oxidation of $\mathrm{Mn}^{3+}$ to $\mathrm{Mn}^{4+}$ and the subsequent formation of brown $\mathrm{MnO}_{2}$ enables the identification of the pigment, and (d) flame tests can also be used for identifying pigments containing elements, such as $\mathrm{Ca}, \mathrm{Ba}, \mathrm{Sr}$, etc.

Prior examination under a microscope of the sample/ cross section and consideration of the color and morphology of the pigment is essential for selecting the microchemical test to be carried out. Historical blue pigments, for instance, are composed of $\mathrm{Cu}^{2+}, \mathrm{Co}^{2+}, \mathrm{Fe}^{3+}$, and $\mathrm{S}$ marker species; therefore, the tests to be carried out should be restricted to those specific for these species. Alterations of pigments can cause false results. Thus, smalt bound with a drying oil is able to lixiviate $\mathrm{Co}^{2+}$ ions with fading of the pigment by loss of the coloring agent and formation of cobalt carboxylates from the free fatty acids released in the hydrolysis of the oil (vide infra). As consequence of these alteration processes, the test for $\mathrm{Co}^{2+}$ is disturbed.

In some cases, more than one test is necessary for unambiguously identify the pigment. The yellow pigments chrome yellow, barium yellow, and strontium yellow have a positive result in the $\mathrm{CrO}_{4}{ }^{2-}$ test. Therefore, a successive test for $\mathrm{Pb}^{2+}, \mathrm{Ba}^{2+}$ or $\mathrm{Sr}^{2+}$ should be performed for an accurate identification. A white pigment with positive test for $\mathrm{Ca}^{2+}$ can be assigned to both calcium carbonate white and gypsum. A second test for $\mathrm{CO}_{3}{ }^{2-}$ or $\mathrm{SO}_{4}{ }^{2-}$ should be performed for completing the identification. 
Table 5 List of microchemical procedures for analyzing inorganic pigments [12, 28, 35, 58-61]

\begin{tabular}{|c|c|c|c|}
\hline $\begin{array}{l}\text { Species } \\
\text { identified }\end{array}$ & Pigment & Reagent & Procedure \\
\hline \multicolumn{4}{|c|}{ Microchemical tests applicable on cross-sections, pigment particles and paint samples ${ }^{\mathrm{a}}$} \\
\hline $\mathrm{Ba}^{2+}$ & $\begin{array}{l}\text { Baryte }\left(\mathrm{BaSO}_{4}\right) \text {, barium yellow }\left(\mathrm{BaCrO}_{4}\right) \text {, lithopone } \\
\quad\left(\mathrm{ZnS}+\mathrm{BaSO}_{4}\right)\end{array}$ & Sodium rhodizonate & $\begin{array}{l}\text { Dissolution of the pigment with concentrated } \mathrm{HNO}_{3} \\
\text { Formation of a reddish-brown insoluble precipitate of } \\
\text { Ba-rhodizonate }\end{array}$ \\
\hline \multirow[t]{2}{*}{$\mathrm{Cd}^{2+}$} & \multirow[t]{2}{*}{$\begin{array}{l}\text { Cadmium red and deep orange }(\mathrm{Cd}(\mathrm{S}, \mathrm{Se})) \text {, cadmium } \\
\text { yellow and light orange }(\mathrm{CdS})\end{array}$} & $\begin{array}{l}\mathrm{H}_{2} \mathrm{SO}_{4}^{\mathrm{b}} \\
\text { Di-p- } \\
\text { nitrophenylcarbazide }\end{array}$ & $\begin{array}{l}\text { Formation of a white insoluble precipitate of } \mathrm{BaSO}_{4} \\
\text { Dissolution of the pigment with concentrated } \mathrm{HNO}_{3}\end{array}$ \\
\hline & & $\begin{array}{l}\mathrm{NaOH}, \mathrm{KCN} \\
\text { formaldehyde }\end{array}$ & Formation of a blue-green precipitate \\
\hline $\mathrm{Co}^{2+}$ & $\begin{array}{l}\text { Cobalt violet dark }\left(\mathrm{Co}_{3}\left(\mathrm{PO}_{4}\right)_{2}\right) \text {, cobalt yellow } \\
\left(\mathrm{K}_{3}\left[\mathrm{Co}\left(\mathrm{NO}_{2}\right)_{6}\right] \cdot n \mathrm{H}_{2} \mathrm{O}\right)(0<n<4)\end{array}$ & $\alpha$-Nitroso- $\beta$-naphtol & $\begin{array}{l}\text { Dissolution of the pigment with concentrated } \mathrm{HNO}_{3} \\
\text { Formation of an orange-brown complex }\end{array}$ \\
\hline $\mathrm{Cu}^{2+}$ & $\begin{array}{l}\text { Azurite }\left(2 \mathrm{CuCO}_{3} \cdot \mathrm{Cu}(\mathrm{OH})_{2}\right) \text {, bronze powder, emerald } \\
\text { green }\left(\mathrm{Cu}\left(\mathrm{CH}_{3} \mathrm{CO}_{2}\right) \cdot 3 \mathrm{Cu}\left(\mathrm{AsO}_{2}\right)_{2}\right) \text {, malachite } \\
\left(\mathrm{CuCO}_{3} \cdot \mathrm{Cu}(\mathrm{OH})_{2}\right), \mathrm{Scheele} \text { 's green }(\mathrm{CuHAsO}) \\
\text { basic verdigris }\left(\mathrm{xCu}\left(\mathrm{CH}_{3} \mathrm{CO}_{2}\right)_{2} \cdot \mathrm{y}\left(\mathrm{Cu}(\mathrm{OH})_{2}\right) \cdot \mathrm{nH}_{2} \mathrm{O}\right) \\
\text { neutral verdigris }\left(\mathrm{Cu}\left(\mathrm{CH}_{3} \mathrm{CO}_{2}\right)_{2} \cdot \mathrm{H}_{2} \mathrm{O}\right)\end{array}$ & $\mathrm{K}_{4}\left[\mathrm{Fe}(\mathrm{CN})_{6}\right]$ & $\begin{array}{l}\text { Dissolution of the pigment with } 3 \mathrm{M} \mathrm{HCl} \text { or } \\
\text { concentrated } \mathrm{HNO}_{3} \\
\text { Formation of a reddish brown complex of } \\
\mathrm{Cu}_{2}\left[\mathrm{Fe}(\mathrm{CN})_{6}\right]\end{array}$ \\
\hline \multirow[t]{4}{*}{$\mathrm{Fe}^{3+}$} & \multirow{4}{*}{$\begin{array}{l}\text { Green earth }(\mathrm{Fe}-\mathrm{Mg}-\mathrm{Al}-\mathrm{K} \text { hydrosilicate), red iron } \\
\text { oxide }\left(\mathrm{Fe}_{2} \mathrm{O}_{3}\right) \text {, jarosite }\left(\mathrm{KFe}_{3}\left(\mathrm{SO}_{4}\right)_{2}(\mathrm{OH})_{6}\right) \text { and all } \\
\text { type of natural and synthetic earth pigments that } \\
\text { contain } \mathrm{Fe}_{2} \mathrm{O}_{3}, \mathrm{Fe}_{2} \mathrm{O}_{3} \cdot \mathrm{nH}_{2} \mathrm{O} \text { or } \mathrm{FeOOH} \text { and clays } \\
\text { such as ochre yellow, ochre red, Sienna and umber } \\
\text { Prussian blue }\left(\mathrm{Fe}_{4}\left[\mathrm{Fe}(\mathrm{CN})_{6}\right]_{3} \text { and } \mathrm{KFe}\left[\mathrm{Fe}(\mathrm{CN})_{6}\right]\right)\end{array}$} & & $\begin{array}{l}\text { Dissolution of the pigment with } 3 \mathrm{M} \mathrm{HCl} \text { or } \\
\text { concentrated } \mathrm{HNO}_{3}\end{array}$ \\
\hline & & $\mathrm{KSCN}$ & Formation of a red complex of $\mathrm{Fe}(\mathrm{SCN})_{3}$ \\
\hline & & $\mathrm{K}_{4}\left[\mathrm{Fe}(\mathrm{CN})_{6}\right]$ & Formation of a blue complex of $\mathrm{Fe}_{4}\left[\mathrm{Fe}(\mathrm{CN})_{6}\right]_{3}$ \\
\hline & & $\mathrm{NaOH}^{\mathrm{c}}$ & $\begin{array}{l}\text { Formation of a brown-orange insoluble precipitate of } \\
\mathrm{Fe}(\mathrm{OH})_{3}\end{array}$ \\
\hline $\mathrm{Mn}^{3+}$ & $\begin{array}{l}\text { Manganese phosphate }\left(\mathrm{MnPO}_{4}\right) \text {, permanent violet } \\
\qquad\left(\left(\mathrm{NH}_{4}\right)_{2} \mathrm{Mn}_{2}\left(\mathrm{P}_{2} \mathrm{O}_{7}\right)_{2}\right)\end{array}$ & $\begin{array}{l}\text { Concentrated } \mathrm{NaOH} \\
\text { or } \mathrm{KOH}\end{array}$ & Formation of a black insoluble precipitate of $\mathrm{MnO}_{2}$ \\
\hline $\mathrm{Pb}^{2+}$ & $\begin{array}{l}\text { Chrome orange }\left(\mathrm{PbCrO}_{4} \cdot \mathrm{PbO}\right) \text {, chrome yellow } \\
\left(\mathrm{PbCrO}_{4} \text { and } \mathrm{PbCrO}_{4} \cdot \mathrm{PbSO}_{4}\right) \text {, lead white } \\
\left(2 \mathrm{PbCO}_{3} \cdot \mathrm{Pb}(\mathrm{OH})_{2}\right), \text { litharge }(\mathrm{PbO}), \text { minium }\left(\mathrm{Pb}_{3} \mathrm{O}_{4}\right) \text {, } \\
\text { molybdate orange }\left(\mathrm{PbCrO}_{4} \cdot \mathrm{PbMoO}_{4} \cdot \mathrm{PbSO}_{4}\right) \text {, Naples } \\
\text { yellow }\left(\mathrm{Pb}_{2} \mathrm{Sb}_{2} \mathrm{O}_{7}\right)\end{array}$ & KI & $\begin{array}{l}\text { Dissolution of the pigment with concentrated } \mathrm{HNO}_{3} \\
\text { Formation of a yellow insoluble precipitate of } \mathrm{PbI}_{2}\end{array}$ \\
\hline $\mathrm{Sr}^{2+}$ & Strontium yellow $\left(\mathrm{SrCrO}_{4}\right)$ & Sodium rhodizonate & $\begin{array}{l}\text { Dissolution of the pigment with concentrated } \mathrm{HNO}_{3} \\
\text { Formation of a reddish-brown insoluble precipitate of } \\
\text { Sr-rhodizonate }\end{array}$ \\
\hline $\mathrm{Zn}^{2+}$ & $\begin{array}{l}\text { Cobalt green }(\mathrm{CoO} \text { and } \mathrm{ZnO} \text { in solid solution), zinc } \\
\text { white }(\mathrm{ZnO}) \text {, zinc yellow }\left(\mathrm{K}_{2} \mathrm{O} \cdot 4 \mathrm{ZnCrO}_{4} \cdot 3 \mathrm{H}_{2} \mathrm{O}\right)\end{array}$ & Dithizone & $\begin{array}{l}\text { Dissolution of the pigment with concentrated } \mathrm{NaOH} \\
\text { Formation of a raspberry complex }\end{array}$ \\
\hline $\mathrm{AsO}_{4}^{3-}$ & Orpiment $\left(\mathrm{As}_{2} \mathrm{~S}_{3}\right)$, realgar $\left(\mathrm{As}_{4} \mathrm{~S}_{4}\right)$ & $\mathrm{SnCl}_{2}$ & $\begin{array}{l}\text { Dissolution of pigment with concentrated } \mathrm{HCl} \\
\text { Formation of a blackish brown insoluble precipitate of } \\
\text { stannous arsenate }\end{array}$ \\
\hline $\mathrm{CH}_{3} \mathrm{COO}^{-}$ & $\begin{array}{l}\text { Emerald green }\left(\mathrm{Cu}\left(\mathrm{C}_{2} \mathrm{H}_{3} \mathrm{O}_{2}\right) \cdot 3 \mathrm{Cu}\left(\mathrm{AsO}_{2}\right)_{2}\right) \text {, basic } \\
\quad \text { verdigris }\left(\mathrm{xCu}\left(\mathrm{CH}_{3} \mathrm{CO}_{2}\right)_{2} \cdot \mathrm{y}\left(\mathrm{Cu}(\mathrm{OH})_{2}\right) \cdot \mathrm{nH}_{2} \mathrm{O}\right), \\
\text { neutral verdigris }\left(\mathrm{Cu}\left(\mathrm{CH}_{3} \mathrm{CO}_{2}\right)_{2} \cdot \mathrm{H}_{2} \mathrm{O}\right)\end{array}$ & $\mathrm{AgNO}_{3}$ & $\begin{array}{l}\text { Dissolution of pigment with concentrated } \mathrm{HNO}_{3} \\
\text { Formation of a white insoluble precipitate of silver } \\
\text { acetate }\end{array}$ \\
\hline $\mathrm{CO}_{3}^{2-}$ & Calcium carbonate white $\left(\mathrm{CaCO}_{3}\right)$ & Concentrated $\mathrm{HCl}$ & Effervescence due to the formation of $\mathrm{CO}_{2}$ bubbles \\
\hline $\mathrm{CrO}_{4}^{2-}$ & $\begin{array}{l}\text { Chrome orange }\left(\mathrm{PbCrO}_{4} \cdot \mathrm{PbO}\right) \text {, chrome yellow } \\
\left(\mathrm{PbCrO}_{4} \text { and } \mathrm{PbCrO}_{4} \cdot \mathrm{PbSO}_{4}\right) \text {, molybdate orange } \\
\left(\mathrm{PbCrO}_{4} \cdot \mathrm{PbMoO}_{4} \cdot \mathrm{PbSO}_{4}\right) \text {, strontium yellow } \\
\left(\mathrm{SrCrO}_{4}\right)\end{array}$ & $\begin{array}{l}\text { Diphenylcarbazide } \\
\mathrm{AgNO}_{3}\end{array}$ & $\begin{array}{l}\text { Dissolution of pigment with concentrated } \mathrm{HNO}_{3} \\
\text { Formation of a violet complex } \\
\text { Formation of a red-violet insoluble precipitate of } \\
\mathrm{Ag}_{2} \mathrm{CrO}_{4}\end{array}$ \\
\hline & & Lead acetate & Formation of a yellow insoluble precipitate of $\mathrm{PbCrO}_{4}$ \\
\hline $\mathrm{S}^{2-}$ & $\begin{array}{l}\text { Artificial ultramarine blue }\left(\mathrm{Na}_{6-10} \mathrm{Al}_{6} \mathrm{Si}_{6} \mathrm{O}_{24} \mathrm{~S}_{2-4}\right) \text {, } \\
\text { natural ultramarine blue } \\
\left((\mathrm{Na}, \mathrm{Ca})_{8}\left(\mathrm{AlSiO}_{4}\right)_{6}\left(\mathrm{SO}_{4}, \mathrm{~S}, \mathrm{Cl}\right)_{2}\right) \text {, cadmium yellow } \\
(\mathrm{CdS}) \text {, vermilion }(\mathrm{HgS})\end{array}$ & $\begin{array}{l}\text { Sodium azide/iodine/ } \\
\text { KI }\end{array}$ & $\begin{array}{l}\text { Dissolution of pigment with } 3 \mathrm{M} \mathrm{HCl} \\
\text { Effervescence due to the formation of } \mathrm{N}_{2} \text { bubbles }\end{array}$ \\
\hline $\mathrm{SO}_{4}^{2-}$ & Gypsum $\left(\mathrm{CaSO}_{4} \cdot 2 \mathrm{H}_{2} \mathrm{O}\right)$ & Diluted $\mathrm{HCl}$ & $\begin{array}{l}\text { The drop of reagent is transferred to a glass slide with a } \\
\text { micropipette. Characteristic stellate agglomerates of } \\
\text { acicular glomerocrysts radiating from a single } \\
\text { nucleation point are formed by recrystallization of } \\
\text { the dissolved } \mathrm{Ca}^{2+} \text { and } \mathrm{SO}_{4}{ }^{2-} \text { ions }\end{array}$ \\
\hline $\mathrm{Ag}$ & Silver laminas and powder & Concentrated $\mathrm{HNO}_{3}$ & Formation of a white insoluble precipitate of $\mathrm{AgNO}_{3}$ \\
\hline $\mathrm{Au}$ & Gold laminas and powder & $\begin{array}{l}\text { Aqua regia }(3 \\
\left.\mathrm{HCl}: 1 \mathrm{H}_{2} \mathrm{SO}_{4}\right)\end{array}$ & Soluble \\
\hline
\end{tabular}


Table 5 continued

\begin{tabular}{|c|c|c|c|}
\hline $\begin{array}{l}\text { Species } \\
\text { identified }\end{array}$ & Pigment & Reagent & Procedure \\
\hline $\mathrm{S}$ & $\begin{array}{l}\text { Artificial ultramarine blue }\left(\mathrm{Na}_{6-10} \mathrm{Al}_{6} \mathrm{Si}_{6} \mathrm{O}_{24} \mathrm{~S}_{2-4}\right) \\
\text { natural ultramarine blue } \\
\left((\mathrm{Na}, \mathrm{Ca})_{8}\left(\mathrm{AlSiO}_{4}\right)_{6}\left(\mathrm{SO}_{4}, \mathrm{~S}, \mathrm{Cl}\right)_{2}\right)\end{array}$ & $\begin{array}{l}3 \mathrm{M} \mathrm{HCl} \text { or } \\
\text { concentrated } \mathrm{HNO}_{3}\end{array}$ & $\begin{array}{l}\text { Effervescence due to the formation of } \mathrm{H}_{2} \mathrm{~S} \text { bubbles, } \\
\text { pigment becomes white }\end{array}$ \\
\hline $\mathrm{Sn}$ & Powder & $\begin{array}{l}\text { Phosphomolybdic } \\
\text { acid/NH }\end{array}$ & $\begin{array}{l}\text { Dissolution of pigment with concentrated } \mathrm{HCl} \\
\text { Formation of a blue complex }\end{array}$ \\
\hline \multicolumn{4}{|c|}{ Microchemical tests applicable on pigment particles and paint samples ${ }^{\mathrm{d}}$} \\
\hline $\mathrm{Al}^{3+}$ & Thénard's blue $\left(\mathrm{CoO} \cdot \mathrm{Al}_{2} \mathrm{O}_{3}\right.$ or $\left.\mathrm{CoAl}_{2} \mathrm{O}_{4}\right)$ & Concentrated $\mathrm{NaOH}$ & Formation of a white precipitate of $\mathrm{Al}(\mathrm{OH})_{3}$ \\
\hline $\mathrm{Ba}^{2+}$ & $\begin{array}{l}\text { Barium yellow }\left(\mathrm{BaCrO}_{4}\right) \text {, baryte }\left(\mathrm{BaSO}_{4}\right) \text {, lithopone } \\
\quad\left(\mathrm{ZnS}+\mathrm{BaSO}_{4}\right)\end{array}$ & Flame test & Yellow green color of flame \\
\hline $\mathrm{Ca}^{2+}$ & $\begin{array}{l}\text { Bone black }\left(\mathrm{C}+\mathrm{Ca}_{3}\left(\mathrm{PO}_{4}\right)_{2}\right) \text {, calcium carbonate white } \\
\quad\left(\mathrm{CaCO}_{3}\right) \text {, gypsum }\left(\mathrm{CaSO}_{4} \cdot 2 \mathrm{H}_{2} \mathrm{O}\right)\end{array}$ & Flame test & Bright red color of flame \\
\hline $\mathrm{Co}^{2+}$ & $\begin{array}{l}\text { Cerulean blue }\left(\mathrm{CoO} \cdot n \mathrm{SnO}_{2} \text { or } \mathrm{Co}_{2} \mathrm{SnO}_{4}\right) \text {, cobalt green } \\
\left(\mathrm{CoO} \cdot \mathrm{nZnO} \text { or } \mathrm{CoZnO} \mathrm{Zn}_{2}\right) \text {, cobalt violet light } \\
\left(\mathrm{Co}_{3}(\mathrm{AsO})_{4}\right), \text { smalt }(\mathrm{K}-\mathrm{Co}-\mathrm{Al} \text { silicate glass }) \\
\text { Thénard's blue }\left(\mathrm{CoO} \cdot \mathrm{Al}_{2} \mathrm{O}_{3} \text { or } \mathrm{CoAl}_{2} \mathrm{O}_{4}\right)\end{array}$ & $\alpha$-Nitroso- $\beta$-naphtol & Formation of an orange-brown complex \\
\hline $\mathrm{Hg}^{2+}$ & Vermilion (HgS) & Diphenyl carbazone & Formation of a violet-blue fleck \\
\hline $\mathrm{Na}^{+}$ & $\begin{array}{l}\text { Artificial ultramarine blue }\left(\mathrm{Na}_{6-10} \mathrm{Al}_{6} \mathrm{Si}_{6} \mathrm{O}_{24} \mathrm{~S}_{2-4}\right) \text {, } \\
\text { natural ultramarine blue } \\
\left((\mathrm{Na}, \mathrm{Ca})_{8}\left(\mathrm{AlSiO}_{4}\right)_{6}\left(\mathrm{SO}_{4}, \mathrm{~S}, \mathrm{Cl}\right)_{2}\right)\end{array}$ & Flame test & Golden yellow color of flame \\
\hline $\mathrm{Sr}^{2+}$ & Strontium yellow $\left(\mathrm{SrCrO}_{4}\right)$ & Flame test & Crimson color of flame \\
\hline \multirow[t]{3}{*}{$\mathrm{CrO}_{4}^{2-}$} & \multirow[t]{3}{*}{ Chromium oxide green $\left(\mathrm{Cr}_{2} \mathrm{O}_{3}\right)$, viridian $\left(\mathrm{Cr}_{2} \mathrm{O}_{3} \cdot 2 \mathrm{H}_{2} \mathrm{O}\right)$} & Diphenylcarbazide & Formation of a violet complex \\
\hline & & $\mathrm{AgNO}_{3}$ & $\begin{array}{l}\text { Formation of a red-violet insoluble precipitate of } \\
\mathrm{Ag}_{2} \mathrm{CrO}_{4}\end{array}$ \\
\hline & & Lead acetate & Formation of a yellow insoluble precipitate of $\mathrm{PbCrO}_{4}$ \\
\hline$S^{2-}$ & Cadmium yellow $(\mathrm{CdS})$, vermilion $(\mathrm{HgS})$ & $\begin{array}{l}\text { Sodium azide/iodine/ } \\
\text { KI }\end{array}$ & Effervescence due to the formation of $\mathrm{N}_{2}$ bubbles \\
\hline
\end{tabular}

${ }^{a}$ Prior to the addition of the reagent the pigment must be solubilized by adding a drop of concentrated acid (usually hydrochloric or nitric acid) or alkali (usually, $\mathrm{NaOH}$ or $\mathrm{KOH}$ )

b Spot test for barium yellow

c Applied on Prussian blue. Pigment is got into solution directly with $\mathrm{NaOH}$

${ }^{\mathrm{d}}$ Prior to the addition of the reagent the pigment must be solubilized by heating the sample in a platinum spoon with $\mathrm{HCl}$, sodium persulphate $\mathrm{o}$ mixtures of sodium fluoride/sulphuric acid or sodium carbonate/sodium peroxide

\section{X-ray fluorescence}

\section{Fundamentals of the technique}

Atomic properties of the matter are the basis for this instrumental technique. Each element has a characteristic distribution of electrons in shells and orbitals around the nucleus, so that each electron has a specific energy. As shown in Fig. 17, when the atom is irradiated with high-energy electromagnetic radiation (X-ray) or accelerated particles (electrons, light ions), an electron located in the inner shells $(K, L)$ is ejected resulting in a vacancy in this shell. Furthermore, a second electron located in an orbital placed in outer shells $(N, M, L)$ falls into the vacancy and releases the absorbed energy as a photon (fluorescent X-ray) with a frequency $(v)$ proportional to the energy $(E)$ released according to Planck's equation:

$E=h v$,

where Plank's constant $h=6.626 \times 10^{-34}$ Js.
$\mathrm{X}$-ray spectroscopy is based on the measurement of high-energy transitions between electrons located in deeper orbitals of an atom $(K, L, M, N)$. Due to the characteristic distribution of electrons around the nucleus, each element has a specific pattern of emission lines whose intensities are proportional to the number of atoms emitting. That enables the identification and quantification of each element. Thus, the characteristic elements of an inorganic pigment may be identified by X-ray fluorescence analysis on the surface of an object. The pattern of emission lines obtained from a pigment is the combination of the characteristic emission line patterns of each element that composes the pigment, which are like fingerprints that enable their identification.

\section{Instrumentation}

Several methods can be used to excite the atoms of the pigment analyzed, including photons from X-ray tubes 
Fig. 17 Scheme of characteristic X-ray production

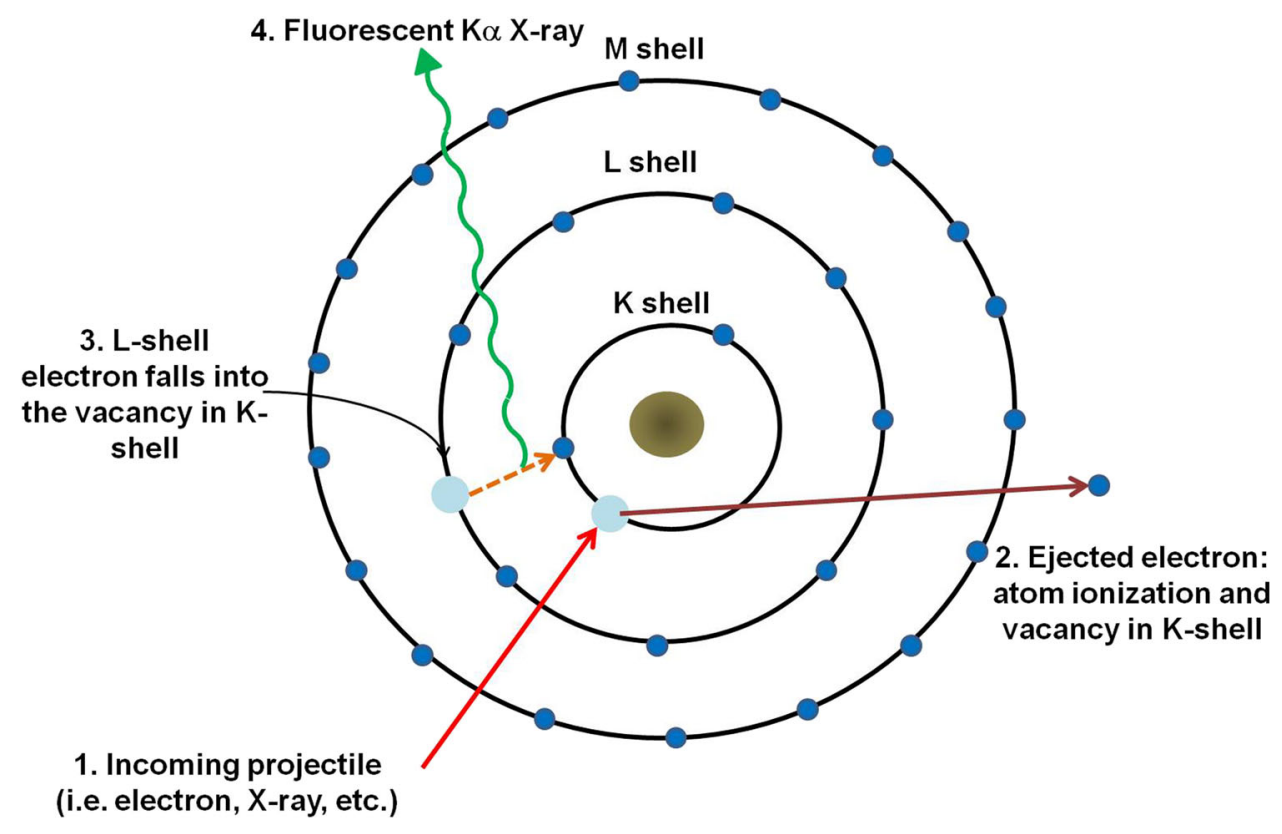

(XRF) (Fig. 18a) and synchrotrons ( $\mu$ SRXRF), electrons (EPMA, SEM-EDX) (Fig. 18b), and protons (PIXE, PIGE) (Fig. 18c). These excitation beams interact with the atoms at different depths within $200 \mu \mathrm{m}$ of the surface of the sample. The exciting beam can be scanned across the sample surface to produce elemental concentration maps. Energy-dispersive systems (EDX) are the most common methods of detection of the X-ray emission. Here, the energy $(E)$ is measured using a known crystal angle. EDX system enables fast identification and quantitative determination of most of the elements that compose pigments. This method is, in principle, applicable to all elements of the periodic system except the first two $(\mathrm{H}$ and $\mathrm{He})$. Elements of relatively low atomic number can be better recognized using wavelength-dispersive system (WDS). Wavelength $(\lambda)$ is measured in WDS at different angles from the sample. Pigments that exhibit emission lines at the same energy value, i.e. $\mathrm{K}_{\alpha}(\mathrm{S})$ and $\mathrm{M}_{\alpha}(\mathrm{Hg})$ in vermilion, can be better discriminated by this detection system. Quantification of elements is carried out by applying a number of mathematical methods for correcting interelemental/matrix effects in the samples [44].

Conventional XRF equipments are not the most suitable method for the identification of pigments. The use of vacuum chambers in older instruments barely enabled the detection of elements below $z=12(\mathrm{Mg})$. Even though newer instrumentation is provided of special filters that allow analysis for almost all elements, this methodology would only be used when there is disposal of detached samples that are entirely ruled out and preferably where the pigment is suspected to have been used unmixed with any other in a single layer applied on an organic support that does not interfere the analysis (i.e. illustrated manuscripts).

Modern portable X-ray spectrometers are capable of in situ detecting pigments from paintings due to the great sensitivity and separation of peaks achieved. The main disadvantage is that they are limited in the elements than can be analyzed in air. Shielding effect due to the presence of coatings (varnishes), roughness and particles deposited on the surface due to pollution may also affect the result of analyses [45]. In addition, the elements detected can arise from any component of the paint where a layered structure is present, so that penetration of X-ray beam and excitation of constituents of the underlayers may serve to confuse the results of identification. For this reason, this instrumentation has been applied predominantly for the analysis of works of art where a single paint layer covers a support such as frescoes and ceramics; therefore, the observed $\mathrm{X}$-ray features can straightforwardly be ascribed to constituents of the external paint layer.

Synchrotrons allow for microbeam analysis with high sensitivity due to their extremely intense X-ray sources. In PIXE, a particle accelerator generates an intense proton beam that causes the initial electron vacancies in the sample atoms. The main advantage of this technique is its capability for analyzing pigments directly in air without sample removal.

The composition of pigments in a sample and, specially, in the cross section of a paint can be accurately established using energy-dispersive X-ray microanalysis in the scanning electron microscope (SEM-EDX). These equipments have great sensitivity and spatial resolution (typically focused on spots $1-40 \mu \mathrm{m})$. For this reason, they became 
Fig. 18 Scheme of X-ray spectroscopy instruments: a Xray spectrometer (XRF),

b scanning electron microscopeenergy dispersive X-ray microanalysis (SEM-EDX), and c particle-induced X-ray emission (PIXE)
A

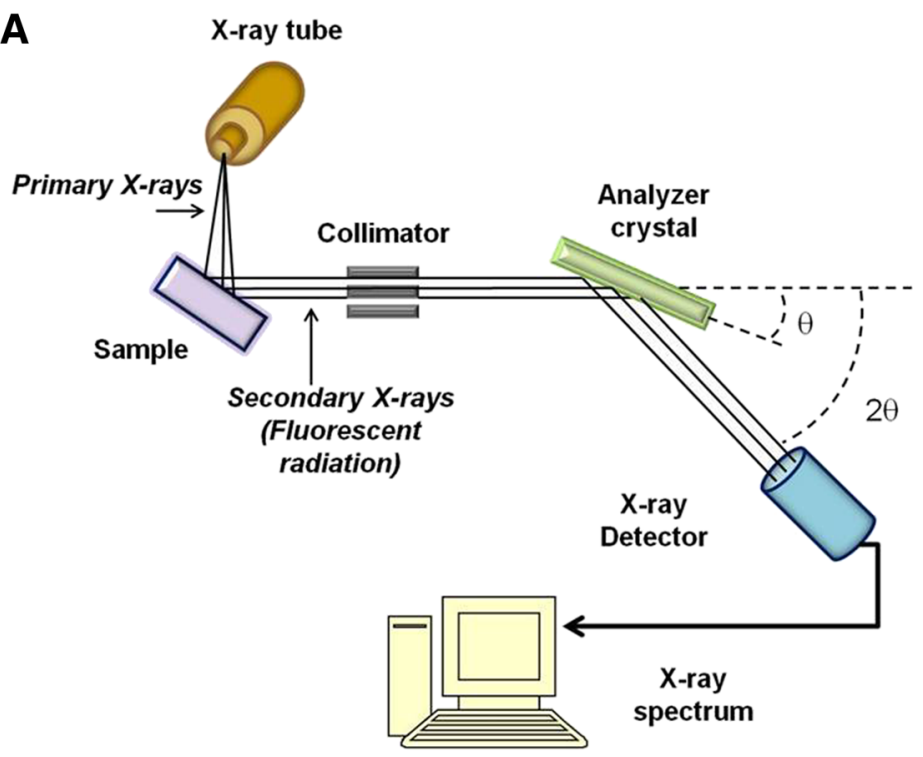

B

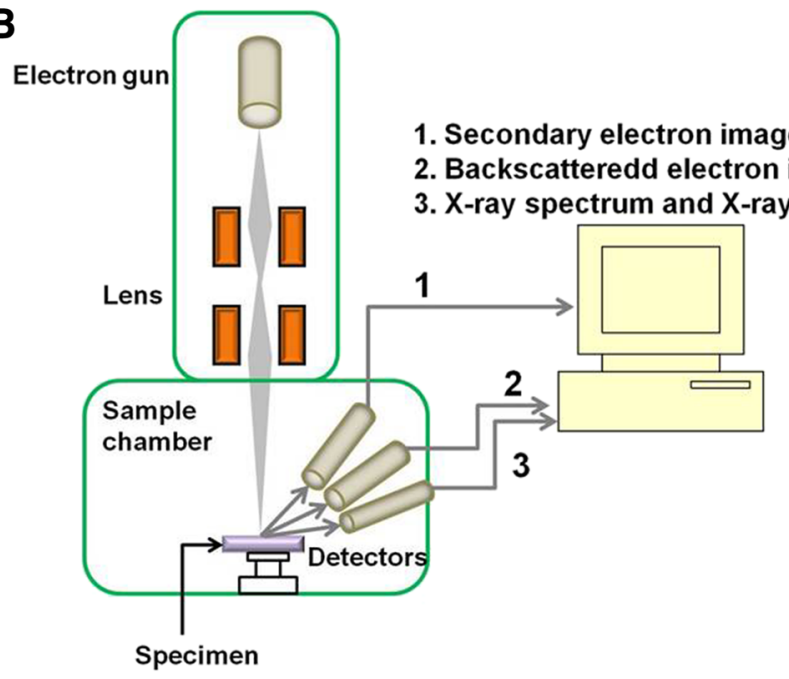

C

Particle accelerator

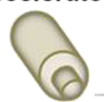

Scan generator Focusing lens Sample

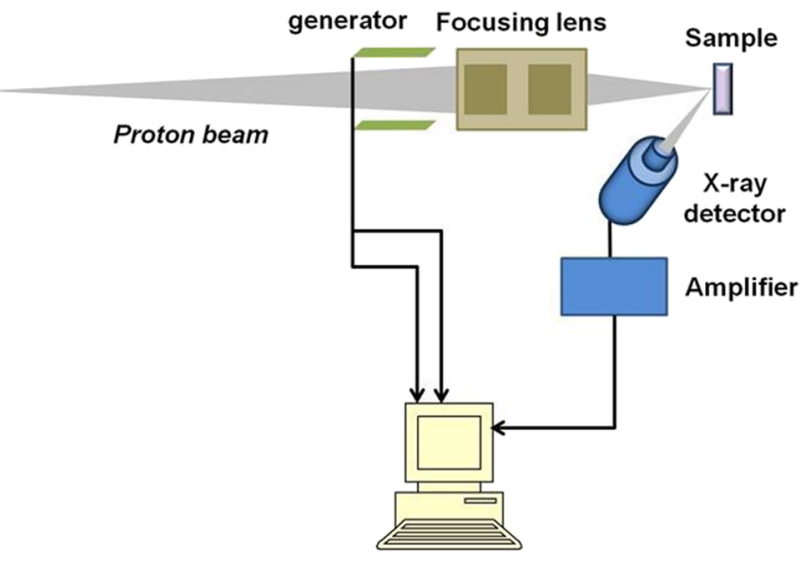

X-ray spectrum maps 


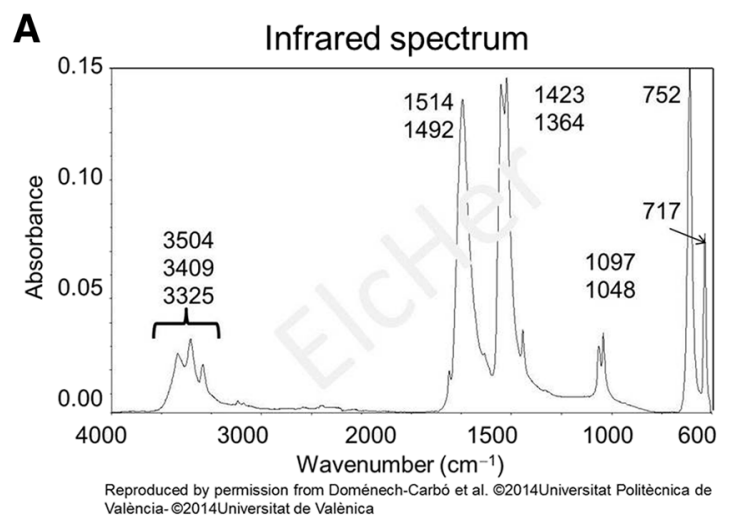

C

\begin{tabular}{|c|c|c|}
\hline \multirow{2}{*}{ Raman and IR band position } \\
\hline \multirow{2}{*}{$\begin{array}{c}\text { Vibration } \\
\text { mode }\end{array}$} & \multicolumn{2}{|c|}{ Band position $\left(\mathbf{c m}^{-1}\right)$} \\
\cline { 2 - 3 } & Raman & Infrared \\
\hline$v(\mathrm{OH})$ & & 3504 \\
& - & 3409 \\
& & 3325 \\
\hline$v_{1}\left(\mathrm{CO}_{3}\right)$ & 1085 & 1097 \\
& & 1048 \\
\hline$v_{2 s y m m e t r i c a l}$ & 816 & - \\
\hline$v_{3} \mathrm{~B}_{2}\left(\mathrm{CO}_{3}\right)$ & 1492 & 1514 \\
& & 1492 \\
\hline$v_{3} \mathrm{~A}_{1}\left(\mathrm{CO}_{3}\right)$ & & 1423 \\
\hline$v_{4} \mathrm{~B}_{2}\left(\mathrm{CO}_{3}\right)$ & 752 & 752 \\
\hline$v_{4} \mathrm{~A}_{1}\left(\mathrm{CO}_{3}\right)$ & - & 717 \\
\hline
\end{tabular}

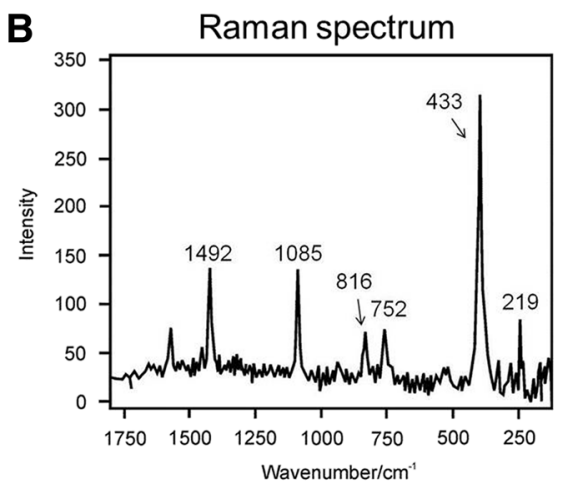

Reproduced by permission from Domenech-Carbo et al. Copyright (2012) John Wiley \& Sons.

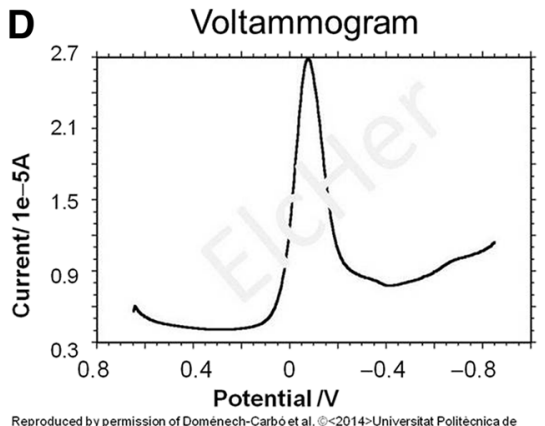

Reproduced by permission of Domenech-Cat
Valencia. $\Theta<2014>$ Universitat de Valencia.

Cathodic peak: $-0.1 \mathrm{~V}$

Anodic peak: $-0.025 \mathrm{~V}$ (copper stripping).

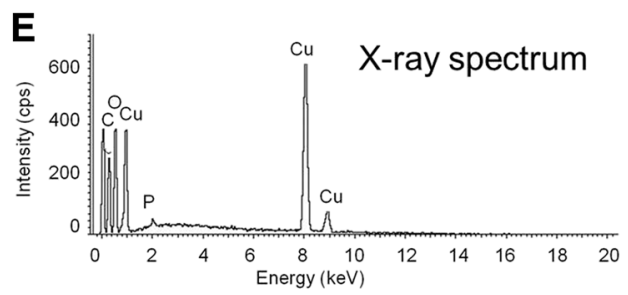

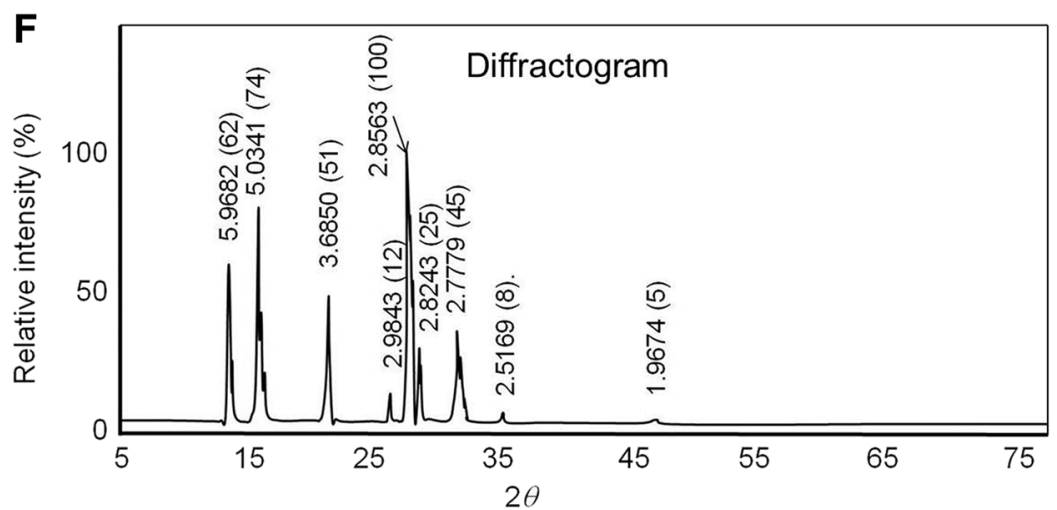

Fig. 19 Experimental characterization of the historical pigment malachite $\left(\mathrm{CuCO}_{3} \cdot \mathrm{Cu}(\mathrm{OH})_{2}\right)$. a IR spectrum (resolution $4 \mathrm{~cm}^{-1}$ ). b Raman spectrum $\left(\lambda_{\mathrm{e}}: 785 \mathrm{~nm}\right.$ excitation, $\times 20$ objective, $2 \mathrm{~cm}^{-1}$ spectral resolution, wavenumber range $150-1800 \mathrm{~cm}^{-1}$ ). c Assignation of IR and Raman bands of analytical interest. d Square wave voltammogram at pigment-modified graphite bars (Alpino, Masats
SL, Spain) immersed into $0.25 \mathrm{M} \mathrm{HAc/NaAc}$ aqueous solution at $\mathrm{pH}$ 4.75. Negative-going scan. Potential step increment $4 \mathrm{mV}$; square wave amplitude $25 \mathrm{mV}$; frequency $5 \mathrm{~Hz}$. e X-ray spectrum (X-ray tube voltage $20 \mathrm{kV}$ ). f diffractogram (X-ray wavelength: $1.541838 \mathrm{~nm})$ 
Fig. 20 X-ray spectrum of lead tin yellow type II (Kremer K10110) obtained using SEMEDX. Spectrum acquired at $20 \mathrm{kV}$
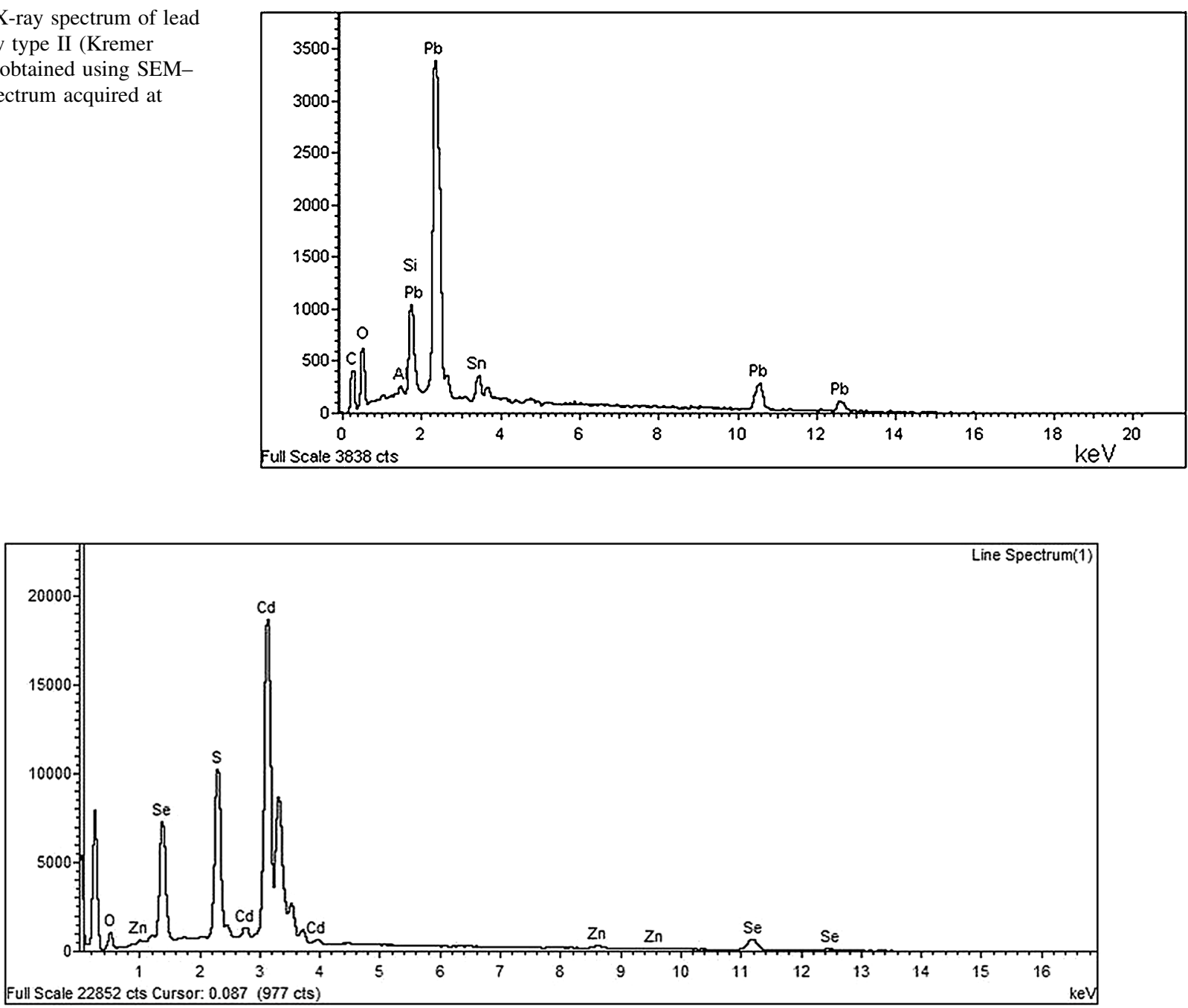

Fig. 21 X-ray spectrum of cadmium orange from a painting from the twentieth century obtained using SEM-EDX. Spectrum acquired at $20 \mathrm{kV}$

preferred instrumentation for routine analysis of pigments. Secondary electrons released from atoms in the sample surface enable topographical maps of the sample, whereas backscattered electrons from interactions of primary electrons with the atomic nucleus reflect atomic number/mass. Elemental composition of individual grains of pigment can be obtained with a high level of confidence with this technique. Quantification is usually carried out by applying the ZAF method based on the atomic number ( $Z$ ), absorption (A), and fluorescence (F) correction of the $\mathrm{X}$-ray intensity value observed for an element present in a sample with an unknown matrix. In addition, lineal variation of chemical composition and 2D distribution of pigments in a sample or cross section can be accurately mapped [53].
Table 6 Chemical composition of the pigment raw umber (Kremer K40610) obtained using SEM-EDX and applying the ZAF method

\begin{tabular}{lcccl}
\hline Element & Weight & Atomic\% & Compd\% & Formula \\
\hline Mg K & 0.26 & 0.15 & 0.34 & $\mathrm{MgO}$ \\
$\mathrm{Al} \mathrm{K}$ & 0.47 & 0.24 & 0.72 & $\mathrm{Al}_{2} \mathrm{O}_{3}$ \\
Si K & 2.19 & 1.09 & 3.78 & $\mathrm{SiO}_{2}$ \\
P K & 0.19 & 0.08 & 0.34 & $\mathrm{P}_{2} \mathrm{O}_{5}$ \\
S K & 0.31 & 0.14 & 0.63 & $\mathrm{SO}_{3}$ \\
K K & 0.17 & 0.06 & 0.17 & $\mathrm{~K}_{2} \mathrm{O}$ \\
Ca K & 1.32 & 0.46 & 1.5 & $\mathrm{CaO}$ \\
Mn K & 3.17 & 0.81 & 3.3 & $\mathrm{MnO}$ \\
Fe K & 18.32 & 4.61 & 19.05 & $\mathrm{FeO}$ \\
O & 73.61 & 64.65 & & \\
Totals & 100 & & & \\
\hline
\end{tabular}




\section{Spectral features and identification of pigments}

Qualitative analysis Identification of a pigment is carried out by recognizing the emission lines of the elements that compose it (see Fig. 19e). Energy values for the emission lines of elements of analytical interest used in EDX instruments are provided in the software of the X-ray microanalysis systems and are also available in the CRC Handbook for Physics and Chemistry [62]. $\mathrm{K}_{\alpha}$ and $\mathrm{K}_{\beta}$ lines are used for most elements present in pigments $(\mathrm{C}, \mathrm{O}, \mathrm{N}, \mathrm{F}$, $\mathrm{Cl}, \mathrm{S}, \mathrm{Na}, \mathrm{Mg}, \mathrm{Al}, \mathrm{Si}, \mathrm{K}, \mathrm{Ca}, \mathrm{Ti}, \mathrm{Mn}, \mathrm{Fe}, \mathrm{Co}, \mathrm{Ni}, \mathrm{Cu}$, etc.). $\mathrm{A}$ number of pigments such as $\mathrm{Sb}$ or $\mathrm{Sn}$ are identified by their intense emission lines in the $\mathrm{L}$ series $\left(\mathrm{L}_{\alpha}, \mathrm{L}_{\beta}\right)$. Heavy elements present in some pigments such as $\mathrm{Pb}, \mathrm{Hg}$ and some metals $(\mathrm{Au})$ exhibit intense $\mathrm{M}_{\alpha}$ emission lines accompanied by the $\mathrm{L}$ series $\left(\mathrm{L}_{\alpha}, \mathrm{L}_{\beta}, \mathrm{L}_{\gamma}\right)$.

In practice, identification of a pigment is mainly carried out by recognizing the heaviest element as it has
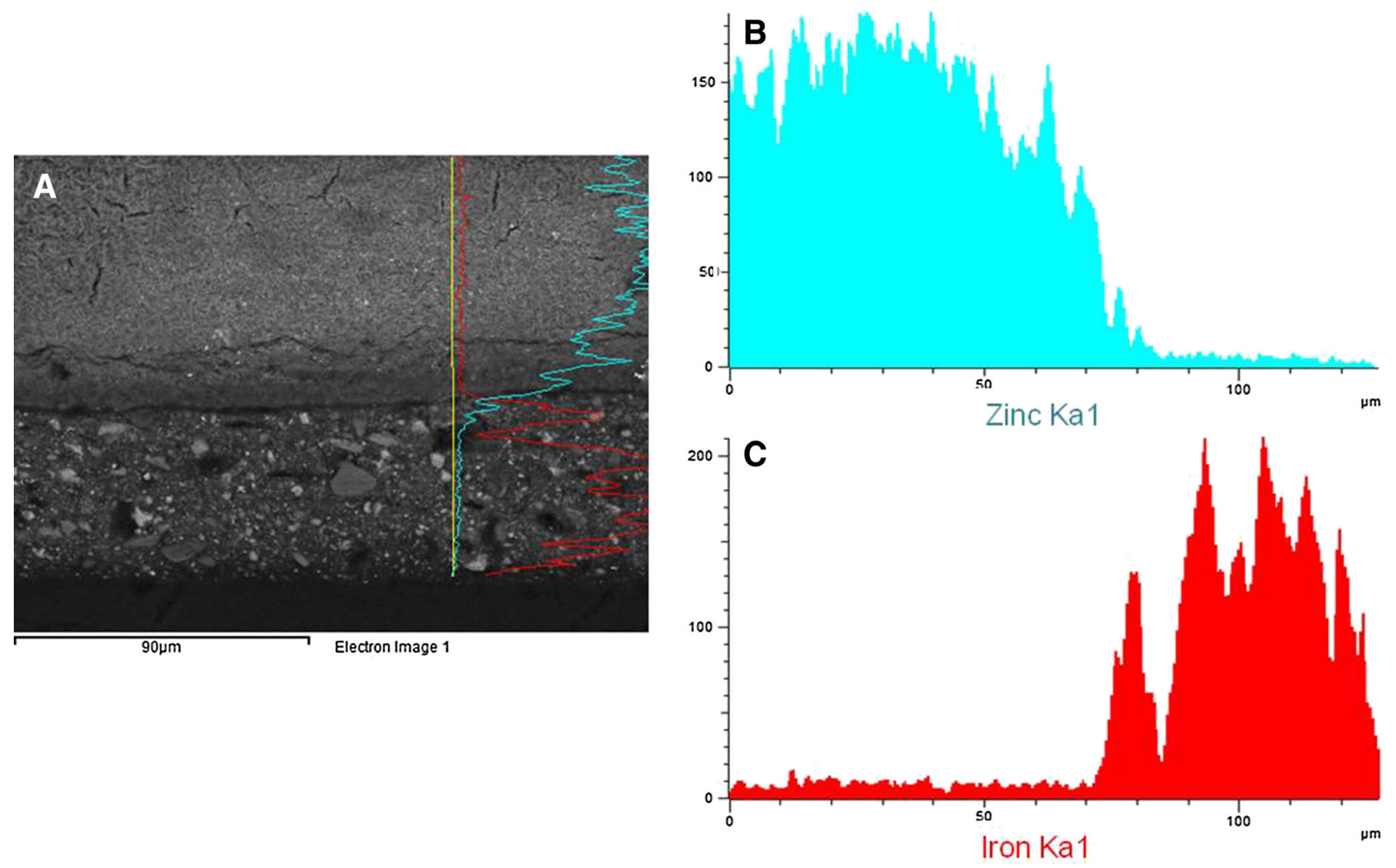

Fig. 22 a Backscattered electron image of the cross section of an oil paint sample composed of a zinc white paint layer (up) applied on a burnt umber ground (down). Graphs of X-ray intensity vs. position for: $\mathbf{b} \mathrm{K}_{\alpha}(\mathrm{Zn})$ emission line and $\mathbf{c} \mathrm{K}_{\alpha}(\mathrm{Fe})$ emission line

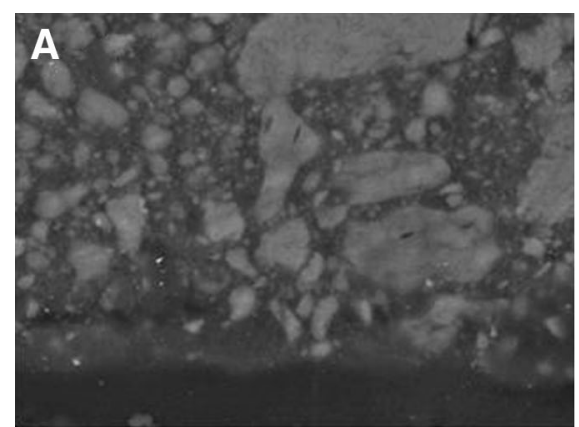

Electron Image 1

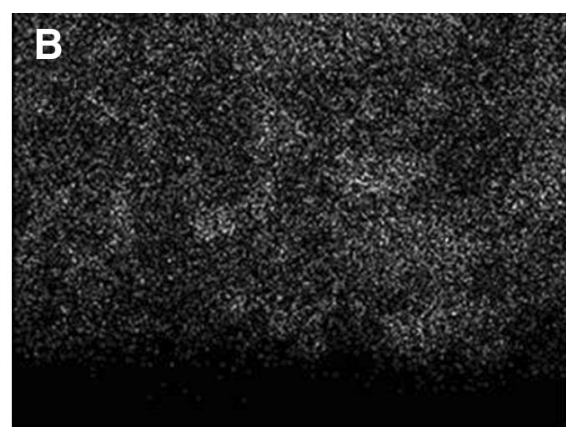

PKa1

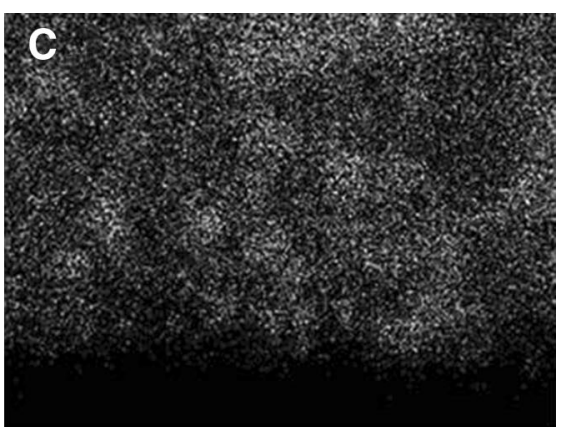

CaKa1

Fig. 23 a Backscattered electron image carried out on the cross section of a paint layer of bone black bound with linseed oil. 2D X-ray mapping performed with $\mathbf{b} \mathrm{K}_{\alpha}(\mathrm{P})$ emission line and $\mathbf{c} \mathrm{K}_{\alpha}(\mathrm{Ca})$ emission line 
the highest concentration in the pigment; nevertheless, selection or recognition of two elements is required for discriminating among pigments that contain the same element [45]. For example, yellow pigments litharge and Naples yellow can be easily discriminated by the presence of $\mathrm{Sb}$ together with $\mathrm{Pb}$ in the latter.

Figure 20 shows the X-ray spectrum of lead tin yellow type II pigment. This pigment is a variety of lead-tin oxide with an approximate formula $\mathrm{Pb}\left(\mathrm{Si}_{x} \mathrm{Sn}_{1-x}\right) \mathrm{O}_{3}$ that may contain free tin oxide and additional silicon. The X-ray spectrum is dominated by the $\mathrm{M}_{\alpha}(\mathrm{Pb})$ line that appears at $2.34 \mathrm{keV}$. Weak $\mathrm{L}_{\alpha}(\mathrm{Pb}), \mathrm{L}_{\beta}(\mathrm{Pb})$, and $\mathrm{L}_{\gamma}(\mathrm{Pb})$ emission lines are also seen at $10.45,12.30$, and $14.76 \mathrm{keV}$, respectively. Weak peaks in the range $3-4 \mathrm{keV}$ that correspond to the $\mathrm{L}(\mathrm{Sn})$ series are also recognized. Intense $\mathrm{K}_{\alpha}(\mathrm{Si})$ line and weak $\mathrm{K}_{\beta}(\mathrm{Si})$ line at 1.74 and $1.83 \mathrm{keV}$, respectively, appear overlapped together with the weak $\mathrm{M}_{\mathrm{z} 2}(\mathrm{~Pb})$ line at $1.84 \mathrm{keV} . \mathrm{K}_{\alpha}(\mathrm{Al})$ line at $1.49 \mathrm{keV}$ is also identified. This last element probably is associated with raw materials of aluminosilicate type used in the preparation of this pigment. Emission line of $\mathrm{C}$ is due to the support used for placing the sample in the vacuum chamber of the electron microscope.

Figure 21 shows the $\mathrm{X}$-ray spectrum of cadmium orange pigment. This pigment is a cadmium sulphide-selenide. This compound results from the replacement of part of the sulfur atoms by selenium in the CdS lattice. Characteristic emission lines of this pigment, namely, $\mathrm{K}_{\alpha}(\mathrm{S})$ at $2.31 \mathrm{keV}$, $\mathrm{L}_{\alpha}(\mathrm{Se})$ at $1.38 \mathrm{keV}$, and $\mathrm{L}_{\alpha}(\mathrm{Cd}), \mathrm{L}_{\beta}(\mathrm{Cd})$, and $\mathrm{L}_{\gamma}(\mathrm{Cd})$ emission lines at $3.13,3.32$, and $3.72 \mathrm{keV}$, respectively, are easily recognized. Interestingly, $K_{\alpha}$ and $K_{\beta}$ emission lines of $\mathrm{Zn}$ are also identified at 8.64 and $9.57 \mathrm{keV}$. It has been reported that many cadmium sulphide pigments consist of zinc sulphide in solid solution with the cadmium [63]. The $\mathrm{X}$-ray spectrum of this commercial cadmium sulphide-selenide suggests that, similar to the pure cadmium sulphide pigments, zinc sulphide can be present in the sulphideselenide type. Nevertheless, the presence of zinc could be due to some adulteration of this pigment with zinc oxide or zinc carbonate, similar to that reported for cadmium pigments [63].

Quantitative analysis Table 6 shows the chemical composition of the pigment raw umber (Kremer K40610) obtained using SEM-EDX and applying the ZAF method for correcting interelemental effects. Chemical composition is presented as element weight percentage and as atomic percentage. The latter allows calculating the stoichiometry of the compound in the case of pigments composed of pure chemical compounds (vide infra). Composition of earth pigments is commonly expressed as oxide percentage, which is provided in the last column of Table 6.
Line scan and mapping of elements Combination of scanning electron microscopy and X-ray microanalysis enables determining the distribution of pigments in the
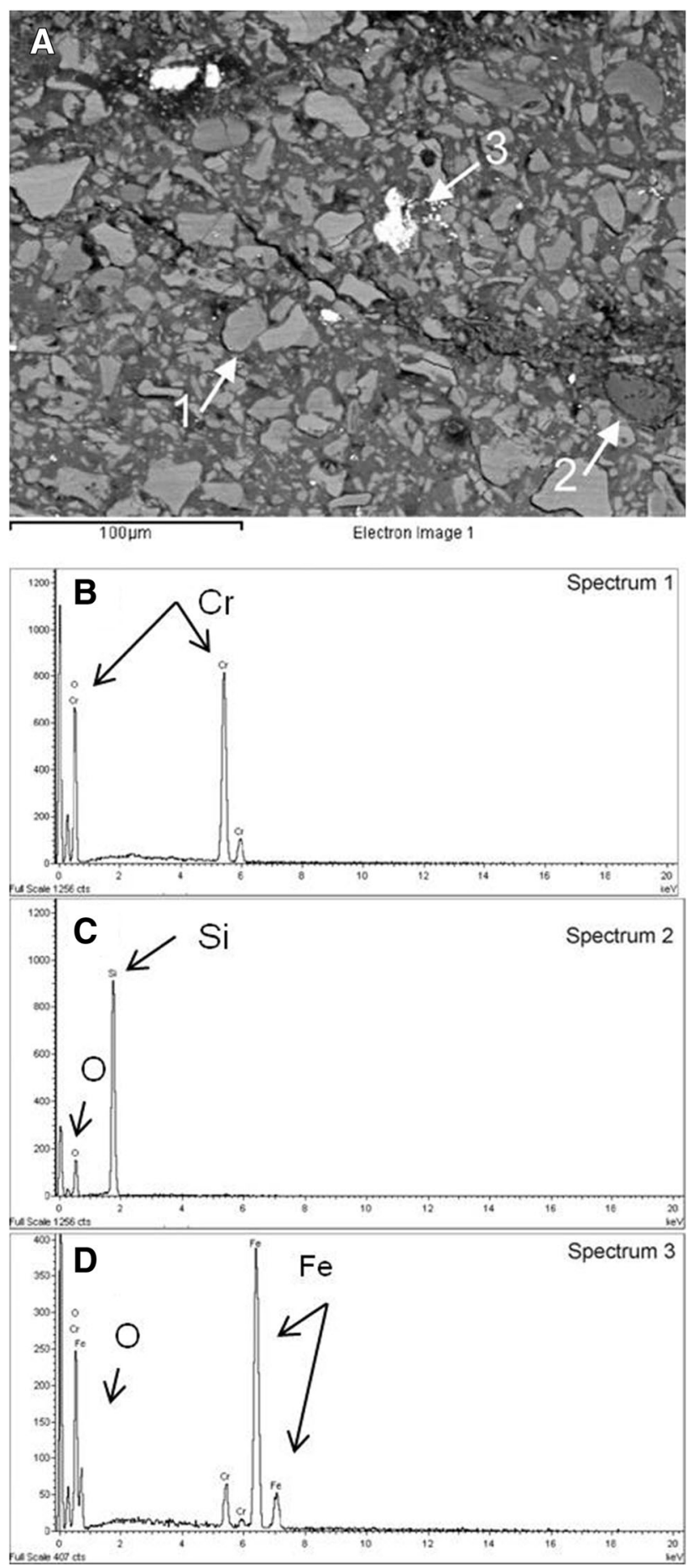

Fig. 24 a Backscattered electron image of the cross section of a sample of a commercial green oil paint excised from the colors' palette of the Spanish painter José Benlliure (1855-1937). b X-ray spectrum acquired in a grain of chrome oxide (point 1 in a). $\mathbf{c} X$-ray spectrum acquired in a grain of silicon (point 2 in a). d X-ray spectrum acquired in a grain of iron oxide (point 3 in a) 
surface of a sample or in a cross section by scanning the $\mathrm{X}$-ray signal in a line or by mapping the $\mathrm{X}$-ray signal in a restricted area. In the line scan mode, a graph $\mathrm{X}$-ray intensity vs. position is obtained by scanning of the X-ray detector throughout a line. This method is used for studying the composition of the paint sample over the interface of the paint layers and thus detecting possible migration of ions. Although the X-ray detector simultaneously acquires $\mathrm{X}$-ray photons emitted by all the elements present in the sample, practically, the analyst selects the elements of interest. The result is a graph that shows the variation of the $\mathrm{X}$-ray emission on distance. Figure 22 shows the backscattered electron image (Fig. 22a) and the graphs obtained by X-ray scanning the signals of $K_{\alpha}(\mathrm{Zn})$ (Fig. 22b) and $\mathrm{K}_{\alpha}$ (Fe) (Fig. 22c) throughout a line 130- $\mu \mathrm{m}$ long perpendicular to the cross section of a pictorial sample in the interface between a zinc white paint layer and a burnt umber ground. X-ray intensity of $\mathrm{Zn}$ abruptly decreases up to $75 \mu \mathrm{m}$, thus providing a measure of the thickness of the paint layer and confirming that migration of $\mathrm{Zn}^{2+}$ ions has not taken place in the ground. Similar information can be obtained from the ground. Noticeable fluctuations in the $\mathrm{X}$-ray intensity of $\mathrm{K}_{\alpha}(\mathrm{Fe})$ emission line are observed in Fig. 22c that are associated with the aggregates of iron oxide-rich grains. Burnt umber is an earth pigment composed of abundant grains of iron oxide together with clayey minerals, and other accessory minerals. Line scan method provides a picture of the spatial distribution and size of these iron oxide grains, which are the main minerals responsible for the color of this pigment.

Mapping of X-ray lines of different elements present in the sample can also be made in selected areas of the sample surface or cross section as that shown in Fig. 23 that corresponds to an oil paint layer of bone black. This pigment, obtained from the calcination of bones, contains appreciable amount of the materials resulting from the partial combustion of calcium hydroxylapatite $\left(\mathrm{Ca}_{10}\left(\mathrm{PO}_{4}\right)_{6}\right.$ $\left.(\mathrm{OH})_{2}\right)$, the main component of the inorganic matrix of animal bones and teeth. Backscattered electron image of Fig. 23a and X-ray maps for $\mathrm{P}$ and $\mathrm{Ca}$ in Fig. 23b, c, respectively, perfectly fit, thus showing the shape and size of the $\mathrm{Ca}$ and P-rich grains conforming this black pigment.

\section{Examination of paint samples}

Identification of pigments Study of colors' palette of painters is frequently carried out by multi-technique approaches that include SEM-EDX among other advanced instrumental techniques. Elemental analysis provided by the X-ray microanalysis system is combined with characterization of morphological properties, such as homogeneity, particle size, shape, and aggregation that makes available the SEM. Figure 24 shows the cross section of a sample of a commercial green oil paint excised of the colors' palette of the Spanish painter José Benlliure (1855-1937). The backscattered electron image shown in Fig. 24a enables morphological characterization of this pigment with heterometrical particle size distribution ranging from coarse to fine according to the Feller's and Bayard classification [57] and shape ranging from subangular to rounded plates. X-ray microanalysis performed in the majority of grains (Fig. 24b) shows $\mathrm{K}_{\alpha}(\mathrm{Cr})$ and $\mathrm{K}_{\beta}(\mathrm{Cr})$ characteristic emission lines that are associated to a chrome oxide pigment, namely, chromium oxide green $\left(\mathrm{Cr}_{2} \mathrm{O}_{3}\right)$ or viridian $\left(\mathrm{Cr}_{2} \mathrm{O}_{3} \cdot 2 \mathrm{H}_{2} \mathrm{O}\right)$. Further analysis by FTIR spectroscopy confirmed that the sample analyzed corresponded to viridian. In addition to the chromium oxide hydrate particles, some grain of silicon (Fig. 24c) and iron oxide (Fig. 24d) are identified that are associated with impurities, adulteration or sophistication of the manufacturer.

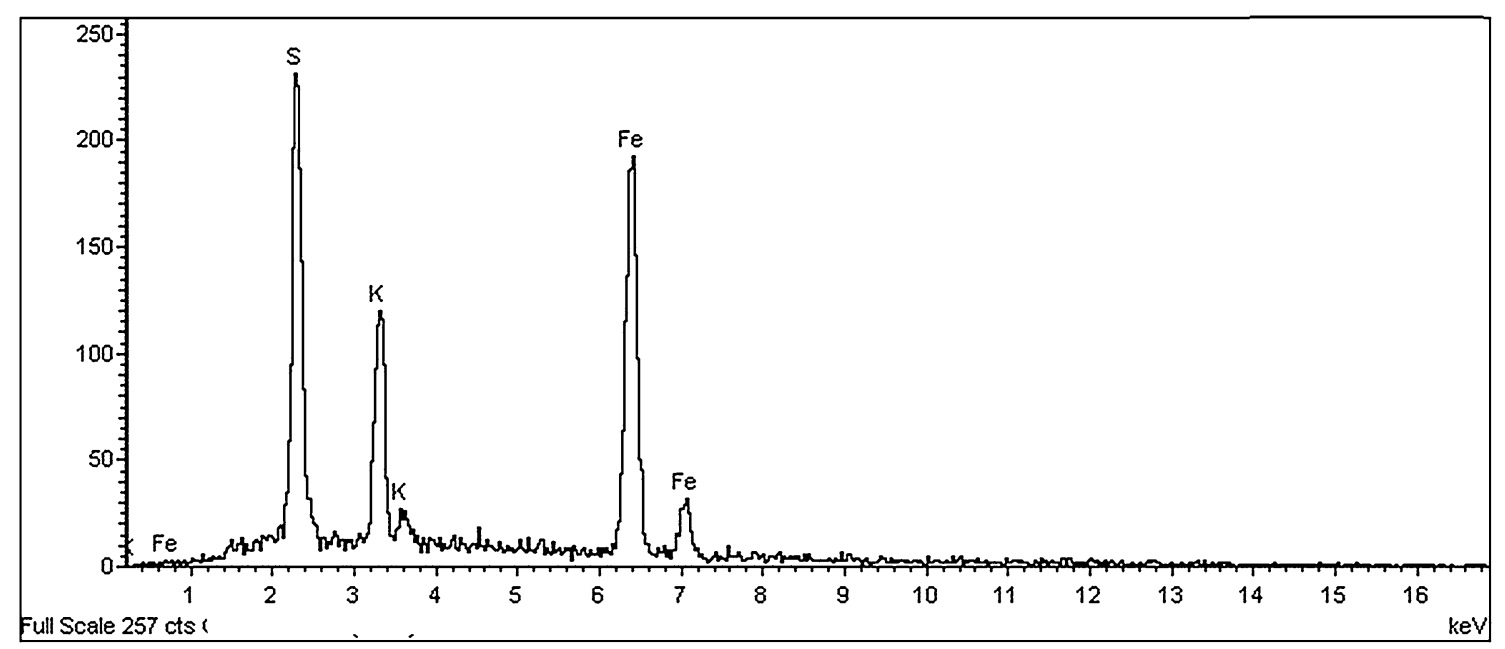

Fig. 25 X-ray spectrum of jarosite obtained using SEM-EDX. Spectrum acquired at $20 \mathrm{kV}$ 


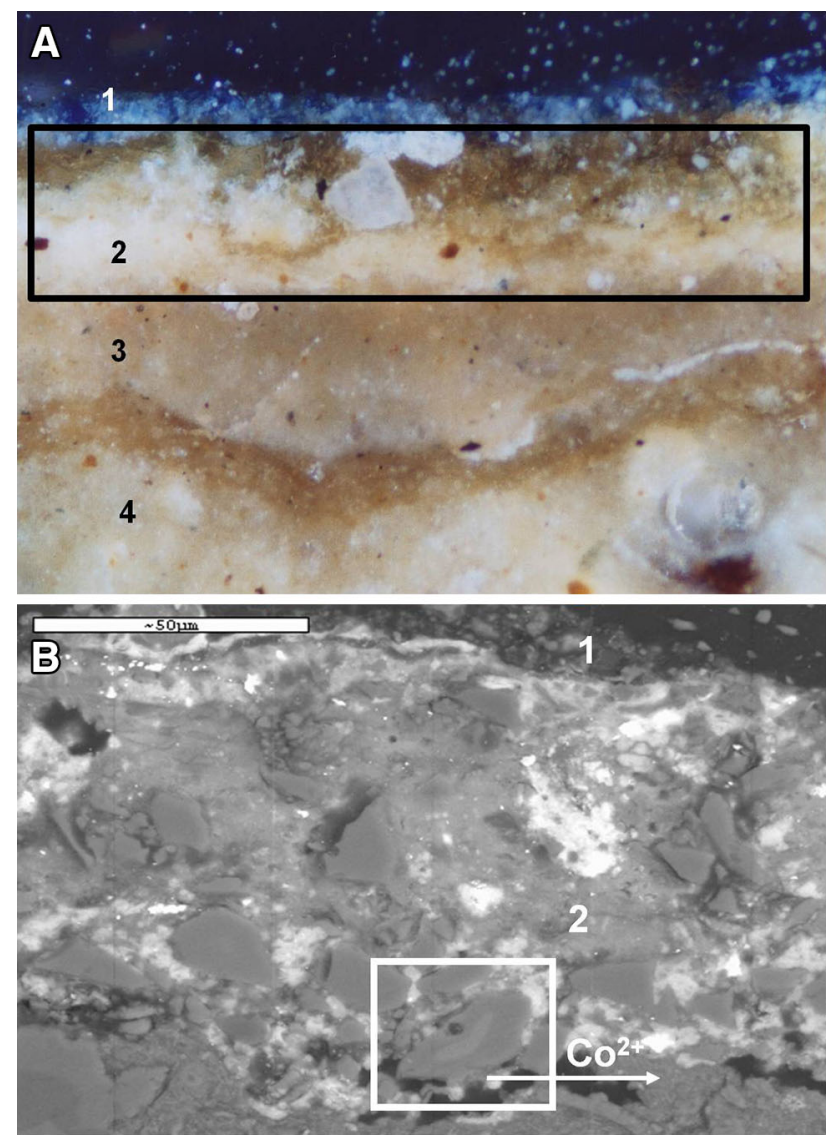

Fig. 26 a Photograph (coaxial reflected illumination, XPL, $\times 100)$ of the cross section of a blue paint sample from an anonymous Italian oil painting from the seventeenth century. Strata distribution: 1 repainted blue paint layer, 2 original smalt layer. The grains of pigment are notably faded, 3 upper ground layer, 4 lower ground layer. b Backscattered electron image obtained by SEM in the paint layers 1 and 2. The inner zone of the framed smalt grain exhibits more intense X-ray fluorescence, whereas the external zone in the periphery of the grain exhibits less X-ray fluorescence as result of the lixiviation of metal ions, in particular, $\mathrm{Co}^{2+}$

Figure 25 shows the X-ray spectrum corresponding to the analysis of a yellow pre-Columbian pigment. The intense emission lines $\mathrm{K}_{\alpha}(\mathrm{S}), \mathrm{K}_{\alpha}(\mathrm{K})$, and $\mathrm{K}_{\alpha}(\mathrm{Fe})$, accompanied of weak $K_{\beta}(\mathrm{K})$ and $\mathrm{K}_{\beta}(\mathrm{Fe})$ lines, suggest that this pigment has a chemical composition mainly involved with these elements. Atomic percentage values provided by the point analysis performed in several individual crystals enable the estimate of the chemistry of this mineral used as pigment. The atomic percentage values obtained, $\mathrm{S}$ (12.5-12.6 \%), K (6.3\%), and Fe (19.8-20.2\%) provide a measured chemistry in the range $\left(\mathrm{K}_{1.00}\right)\left(\mathrm{Fe}_{0.99-1.05}\right)_{3}$ $\left(\mathrm{S}_{1.07-1.10} \mathrm{O}_{4}\right)_{2}(\mathrm{OH})_{6}$, which satisfactorily approaches to the ideal chemistry of the mineral jarosite given by $\mathrm{KFe}_{3}$ $\left(\mathrm{SO}_{4}\right)_{2}(\mathrm{OH})_{6}$ [64].

Alterations of pigments can also be identified by SEMEDX. Figure 26a shows the photograph of the cross

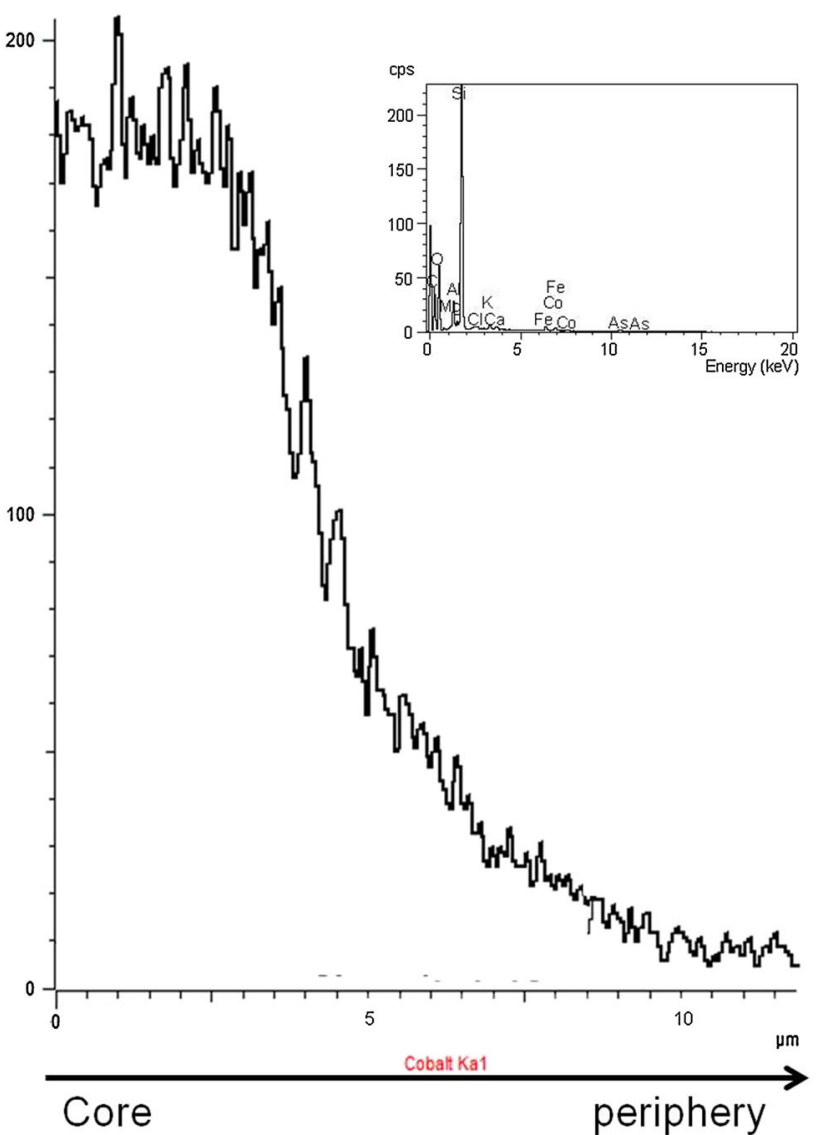

Fig. 27 Linescan of the X-ray emission line $\mathrm{K}_{\alpha}(\mathrm{Co})$ carried out in the altered grain of smalt. The center of the grain is the starting point of the line scan that finishes in the surface of the grain

section of a blue paint sample from an anonymous Italian oil painting from the seventeenth century. This painting exhibited a repaint in a blue area (layer 1) that was applied in a prior restoration due to the notable discoloration exhibited by the smalt pigment originally used (layer 2). The backscattered electron image in Fig. 26b shows the original blue layer (2) in which the smalt grains are well recognized by their characteristic large size and subangular shape. Interestingly, the core of the smalt grain (bright gray color) in the frame exhibits more intense X-ray fluorescence for Co if it is compared with the external zone of the grain (dark gray color) that exhibits less X-ray fluorescence for Co. This variation is put in evidence by performing a line scan of the X-ray emission of Co. As it can be seen in Fig. 27, a significant reduction in the intensity of the $\mathrm{K}_{\alpha}(\mathrm{Co})$ emission line takes place in the periphery of the grain. Smalt bound with oil medium is often observed to have discolored. A number of combined factors have been pointed out as the cause of the discoloration of this pigment in oil painting. Among them, loss of cobalt ion by migration from the 


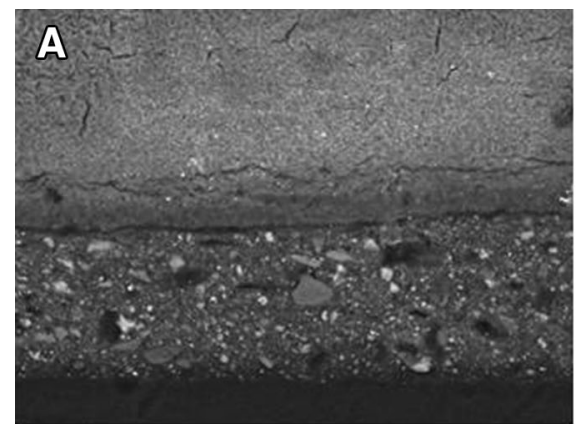

Electron Image 1

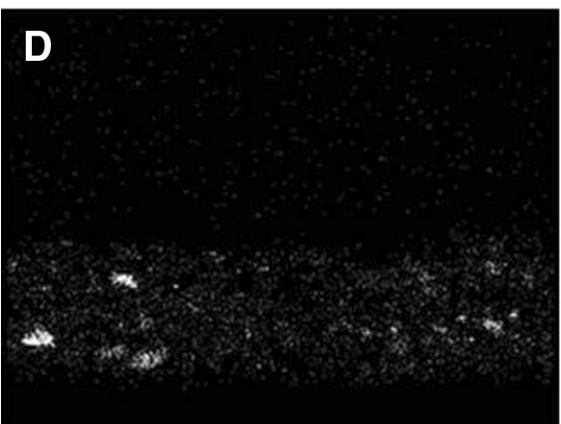

SiKa1

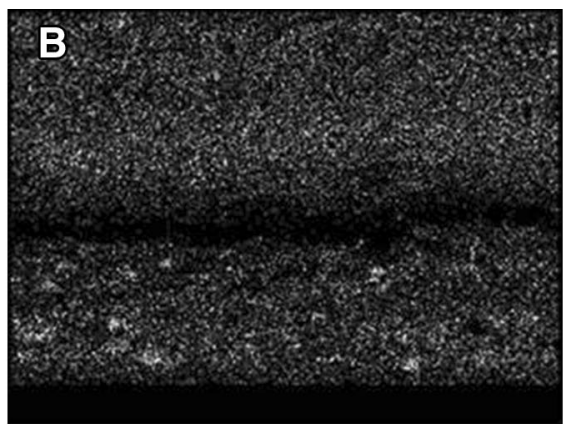

OKa1

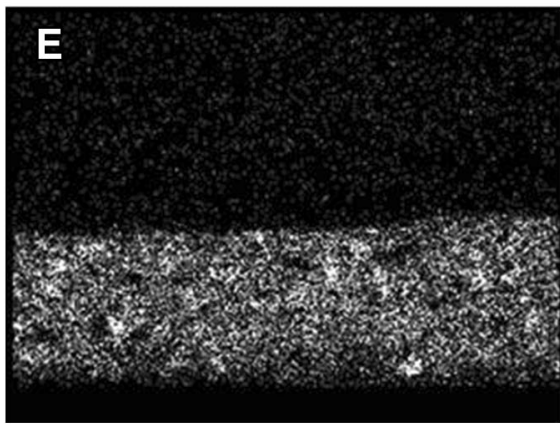

Fe Ka1

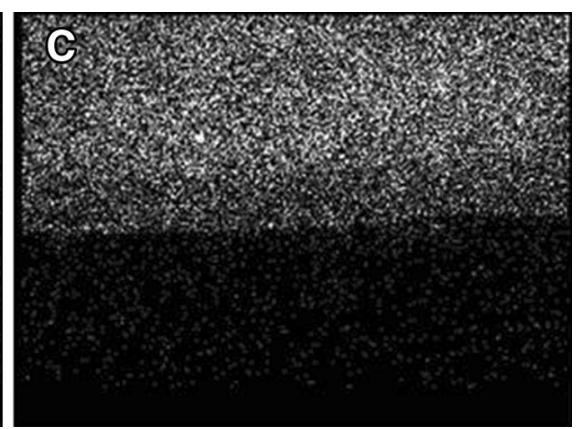

Zn Ka1

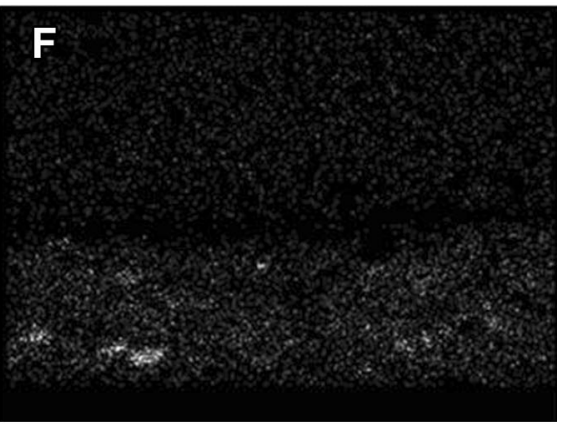

Al Ka1

Fig. 28 a Backscattered electron image of the cross section and 2D X-ray mapping carried out in the cross section of Fig. 22. 2D X-ray mapping for: $\mathbf{b} \mathrm{K}_{\alpha}(\mathrm{O}), \mathbf{c} \mathrm{K}_{\alpha}(\mathrm{Zn}), \mathbf{d} \mathrm{K}_{\alpha}(\mathrm{Si}), \mathbf{e} \mathrm{K}_{\alpha}(\mathrm{Fe})$, and $\mathbf{f} \mathrm{K}_{\alpha}(\mathrm{Al})$

Table 7 Composition of samples A-J of natural red earth pigments used as bole in gildings obtained by FESEMEDX

\begin{tabular}{|c|c|c|c|c|c|c|c|c|c|}
\hline \multirow[t]{2}{*}{ Compound (wt\%) } & \multicolumn{9}{|c|}{ Bole sample } \\
\hline & $\mathrm{A}$ & B & $\mathrm{C}$ & $\mathrm{D}$ & $\mathrm{E}$ & $\mathrm{F}$ & $\mathrm{G}$ & $\mathrm{H}$ & $\mathrm{J}$ \\
\hline $\mathrm{Na}_{2} \mathrm{O}$ & - & - & - & 0.8 & - & - & - & - & - \\
\hline $\mathrm{MgO}$ & 13.8 & 11.1 & 15.7 & - & 0.9 & 1.3 & 1.6 & 6.9 & 6.5 \\
\hline $\mathrm{Al}_{2} \mathrm{O}_{3}$ & 21.1 & 20.9 & 24.4 & 40.4 & 37.8 & 34.9 & 28.9 & 29.4 & 13.2 \\
\hline $\mathrm{SiO}_{2}$ & 37.5 & 41.9 & 41.0 & 48.7 & 51.3 & 55.5 & 46.9 & 47.4 & 52.8 \\
\hline $\mathrm{SO}_{3}$ & - & 2.8 & - & - & 2.5 & 1.0 & - & - & 2.6 \\
\hline $\mathrm{K}_{2} \mathrm{O}$ & 4.1 & 5.6 & 4.4 & 3.6 & 1.0 & 2.2 & 4.1 & 5.4 & 3.4 \\
\hline $\mathrm{CaO}$ & 2.2 & 5.6 & 1.2 & 0.8 & - & 2.4 & 4.4 & - & 4.3 \\
\hline $\mathrm{FeO}$ & 16.1 & 12.1 & 13.3 & 5.6 & 5.6 & 2.7 & 14.0 & 8.8 & 17.2 \\
\hline $\mathrm{TiO}_{2}$ & 5.3 & - & - & - & 0.9 & - & - & 2.2 & - \\
\hline
\end{tabular}

grain and subsequent interaction with the oil medium with the consequent diminution of the color of the pigment has been proposed as cause of this alteration [65].

Figure 28 shows a second example of $2 \mathrm{D}$ mapping obtained in a pictorial sample from a painting dated back to the twentieth century, composed of a zinc white paint layer and a burnt umber ground. Whereas X-ray emission of $\mathrm{Zn}$ is only present in the upper paint layer (Fig. 28c), Fe X-ray emission is restricted to the ground (Fig. 28e). X-ray graphs of $\mathrm{Si}$ (Fig. 28d) and $\mathrm{Al}$ (Fig. 28f) enable the recognition of some silicon and feldspar grains that accompany to the iron oxide and clays that mainly compose this earth pigment.
Quantification of pigments Quantitative X-ray microanalysis can be used for discriminating earth pigments from their chemical composition. This type of studies can provide interesting information relative to the provenance and/or dating of the painting. Table 7 summarizes the chemical composition of several Spanish earth pigments traditionally used as bole in gilding techniques. Discrimination among pigments can be better obtained by applying chemometrics. Among the statistical methods applicable, principal component analysis (PCA) has became one of the most used tools for resolving a number of problems in Conservation Science, such as painted plasters acid soluble components, aggregate granulometric distributions, and 
Fig. 29 a PCA score plot of samples A-J of natural red earth pigments used as bole in gildings. b Contribution of the different components to the principal components (PC1 and PC2)
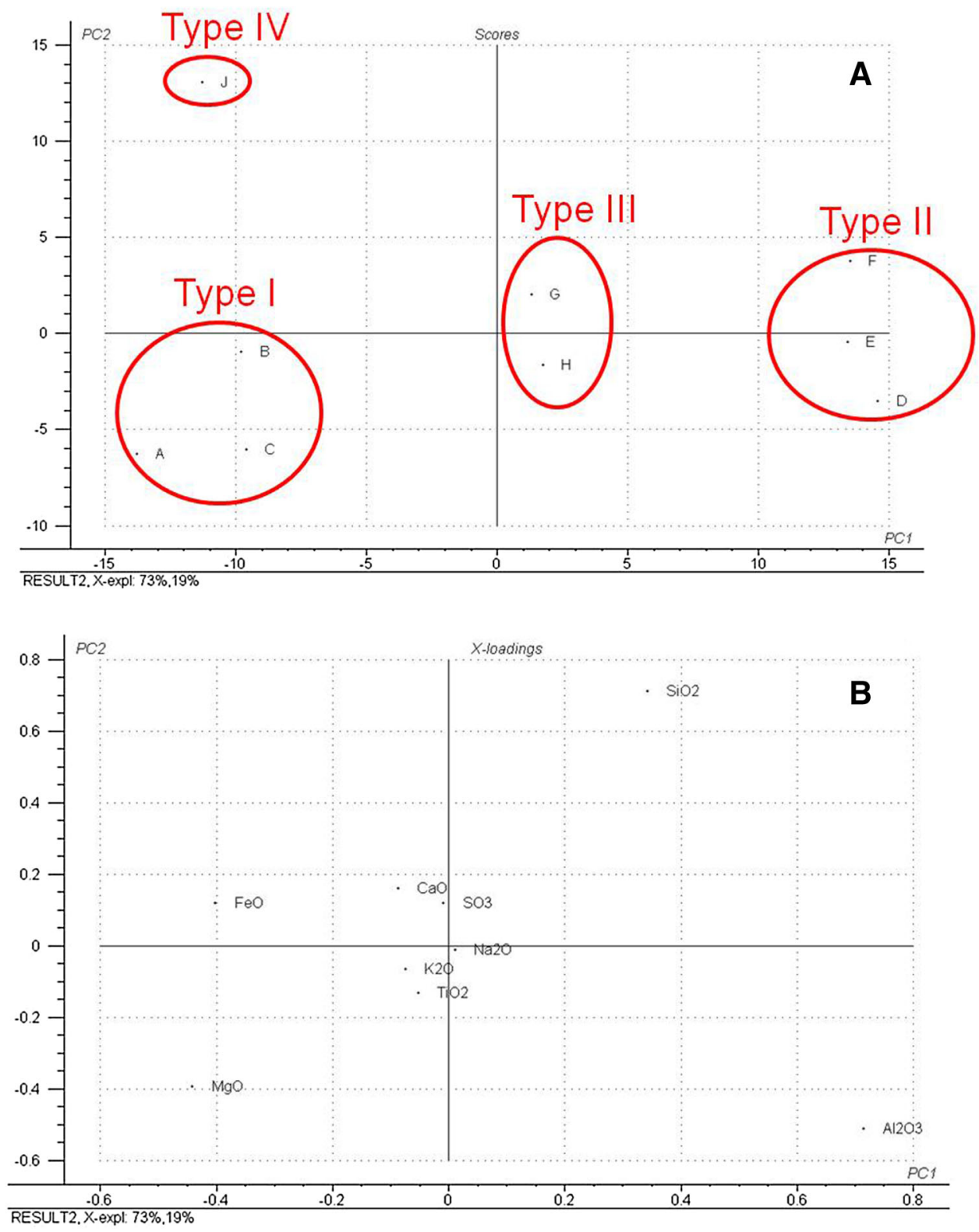

multivariate characterization of the mass spectral and amino acid 'fingerprints' of proteinaceous binding media [66]. PCA shown in Fig. 29a enables the discrimination among earth pigments used as bole in gildings. All oxide weight percentages have been considered as variables. Thus, two principal components that account for the $92 \%$ of the variance have been considered. It can be seen that the samples analyzed can be grouped in four different types of earth pigments according to their composition. A first group that includes boles $\mathrm{A}, \mathrm{B}$, and $\mathrm{C}$ is characterized by a high content in $\mathrm{FeO}$ and $\mathrm{MgO}$ over 12 and $11 \%$, respectively. A second group integrated by pigments $\mathrm{D}, \mathrm{E}$, and $\mathrm{F}$ is characterized by high content in $\mathrm{Al}_{2} \mathrm{O}_{3}$ over $34 \%$ that suggests that notable amounts of bauxite or iron aluminum silicate could compose this natural earth. The third group, which includes pigments $\mathrm{G}$ and $\mathrm{H}$, is characterized by moderate content in iron oxide, aluminum oxide, and silicon, and finally, pigment $\mathrm{J}$ exhibits the highest content in $\mathrm{SiO}_{2}$ and $\mathrm{FeO}$. Figure $29 \mathrm{~b}$ shows that iron oxide, magnesium oxide, aluminum oxide, and silicon are main contributors to the principal component (PC1), whereas magnesium oxide, aluminum oxide, and silicon are main contributors to the principal component (PC2).

\section{X-ray diffraction}

\section{Fundamentals of the technique}

$\mathrm{X}$-ray diffraction is an analytical technique widely used since the 1920s for determining the crystallographic 
A

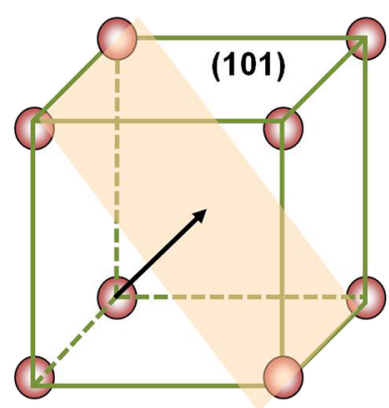

B

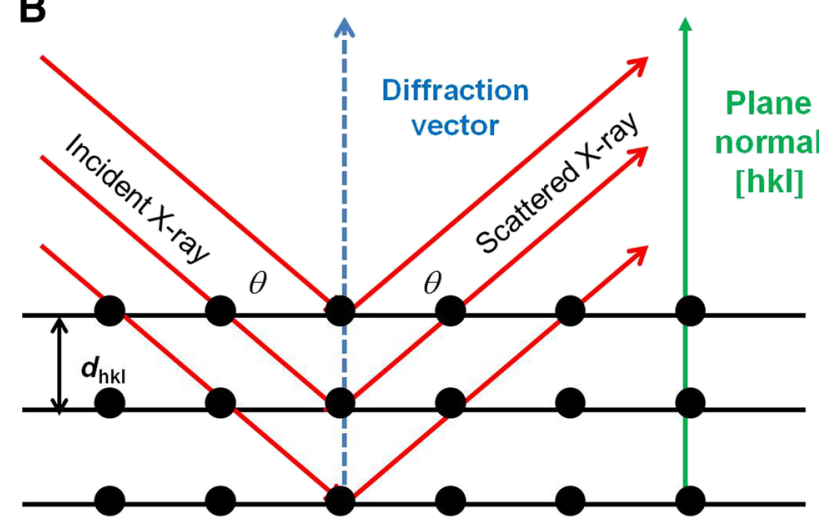

Fig. 30 a Unit cell of a crystalline material showing the crystallographic plane (101) and b scheme of Bragg's law

structure of materials in chemistry, geology, and biology fields, among others. X-ray diffraction occurs when a beam of primary $\mathrm{X}$-rays is scattered, without change in wavelength (elastic scattering), by the electrons of the atoms in a crystal in which such atoms are arranged in a periodic array with long-range order. As result of such scattering, a diffracted beam is produced only when certain geometrical conditions are satisfied (vide infra). Diffraction takes place as the wavelength of X-rays is similar to the distance between atoms. Moreover, the strength with which the electrons of the atoms scatter the radiation is proportional to the atomic number.

Parallel planes occupied with atoms that intersect the unit cell define directions and distances in the crystal (Fig. 30a), so that a single crystal is characterized by the values exhibited by the $d_{h k l}$ spacing of its pattern of planes of atoms. The $d_{h k l}$ is a parameter defined as the vector drawn from the origin of the unit cell to intersect a crystallographic plane $(h k l)$ at a $90^{\circ}$ angle, where the Miller indices $h, k$, and $l$ are three parameters defined as the reciprocals of the parameters of each crystal face. The magnitude of the vector $d_{h k l}$ is the distance between parallel planes of atoms in the family $(h k l) . d_{h k l}$ can be considered a geometric function of the size and shape of the unit cell that conforms the macroscopic crystal.

The British Australian-born physicist William Lawrence Bragg (1890-1971) explained the X-ray diffraction effects

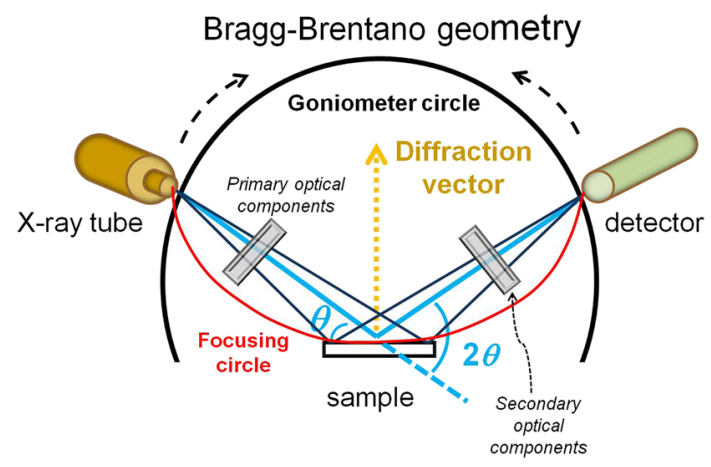

Fig. 31 Scheme of a X-ray powder diffraction instrument with Bragg-Brentano geometry

in terms of "reflection" from a stack of parallel atomic planes. Bragg's law calculates the angle $\theta$ where constructive interference from X-rays scattered by parallel planes of atoms takes place resulting in a diffraction peak. According to Bragg's law, wavelength is directly related to the angle $\theta$ and the $d_{h k l}$ spacing of the crystal (see Fig. 30b):

$\lambda=2 d_{h k l} \sin \theta$.

Usually, X-ray wavelength $\lambda$ is a fix parameter determined by the X-ray source of the diffractometer. Consequently, the angle $\theta$ formed by the scattered $\mathrm{X}$-rays and each specific family of planes in the crystal, which is characterized by its $d_{h k l}$ spacing, are univocally related and produce a diffraction peak. Thus, the scattering of X-rays from atoms in a crystalline material produces a diffraction pattern, which contains information about the atomic arrangement within the crystal. The position and intensity of peaks in a diffraction pattern are determined by the crystal structure: the position is determined by the lattice of the crystal structure (geometry of diffraction), whereas the intensity of diffraction is determined by the arrangement of all atoms in the unit cell (where the atoms are on the lattice planes and what atoms are on the lattice planes) (vide infra).

\section{Instrumentation}

$\mathrm{X}$-ray powder diffraction (XRPD) equipment is one of the most common types of instrumentation based on elastic $\mathrm{X}$-ray scattering that is applied for the analysis of crystalline materials. In a powder diffractometer, the X-rays produced by the tube pass through primary optical components, irradiate the sample, are diffracted by the sample phases, pass secondary optical components, and enter the detector (Fig. 31). By varying the diffraction angle (20, the angle between the incident and the diffracted beam) by movements of tube or sample and detector, the intensities are 
Fig. 32 a X-ray diffraction pattern of a iron oxide red preColumbian pigment, b list of $d$ spacing and intensities of the chrysocolla pigment

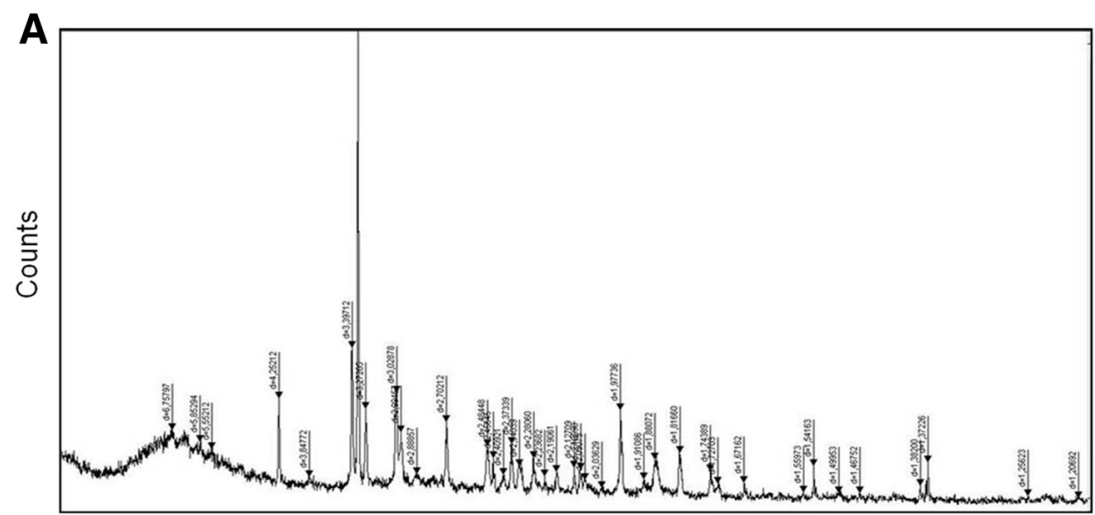

\begin{tabular}{|c|c|c|c|c|c|c|}
\hline Pattern: & \multicolumn{2}{|c|}{ Radiation $=1.540560$} & \multicolumn{3}{|c|}{ Quality: } & \\
\hline \multicolumn{2}{|c|}{$\begin{array}{l}\left((\mathrm{Cu}, \mathrm{Ca})_{2} \mathrm{H}_{2} \mathrm{Si}_{2} \mathrm{O}_{5}(\mathrm{OH})_{4} \cdot \mathrm{nH}_{2} \mathrm{O}\right) \\
\text { Chrysokoll }\end{array}$} & $\begin{array}{l}c l(\hat{A}) \\
10.058232 \\
4.26217 \\
3.34669\end{array}$ & $\begin{array}{l} \\
7.5 \\
33.6 \\
100.0\end{array}$ & $h$ & $k$ & 1 \\
\hline Lattice: & Mol.Weight $=$ & $\begin{array}{l}3.15533 \\
2.46003 \\
2.28325\end{array}$ & $\begin{array}{l}10.3 \\
6.6 \\
10.1\end{array}$ & & & \\
\hline \multicolumn{2}{|c|}{$\begin{array}{l}\text { Purchased by: Kremer Pigmente, ref: } \\
10350\end{array}$} & $\begin{array}{l}2.12895 \\
1.98055 \\
1.81852 \\
1.54243\end{array}$ & $\begin{array}{l}8.5 \\
6.0 \\
9.4 \\
13.9 \\
\end{array}$ & & & \\
\hline
\end{tabular}

recorded as a function of diffraction angle, i.e., as a diffractogram (see Fig. 32). The majority of commercial XRPD instruments use parafocusing geometry such as the Bragg-Brentano geometry (Fig. 31), since it gives a suitable compromise between mechanical simplicity and performance. This focusing arrangement is not really focusing because of the finite width of the source and the specimen and, for this reason, is called parafocusing. In the BraggBrentano geometry, the focal spot of the tube, the sample surface, and the detector slit are positioned on the so-called focusing circle (see Fig. 31), so that the diffraction vector is always normal to the surface of the sample, which is normally flat. As mentioned above, a diffracted beam is produced by scattering only when certain geometrical conditions are satisfied. These conditions are fulfilled when the diffraction vector is perpendicular on reflective lattice planes. Therefore, only a small part of the randomly oriented crystallites forming the powdered sample with lattice planes $d(h k l)$ parallel to the sample surface fulfills the Bragg equation and contributes to the constructive interference. This is one of the disadvantages of the parafocusing geometry in which a comparatively large sample area is irradiated, which means the sample volume itself.

Different X-ray sources are used in current diffractometers. Conventional XRPD instruments use an X-ray tube in which wavelength of X-rays produced is determined by the anode material, usually copper. Synchrotron radiation is used in synchrotron radiation $\mathrm{X}$-ray diffraction
(SR-XRD). The use of SR improves the experimental conditions of the analysis due to the availability of very intense microbeams.

It is difficult to carry out noninvasive XRD, because it requires a large and flat painted area. Quasi-noninvasive analysis of microsamples typically excised from cultural artefacts has became possible with the development of micro-XRD devices as an alternative to conventional XRPD instruments. Microdiffraction experiments require a small irradiated area. Special optics like mono-capillaries is used, together with, e.g. a linear or 2D detector. This technique allows the investigation of sample areas less than $1 \mathrm{~mm}^{2}$. However, the analysis of low quantities usually leads to problems with limits of detection (LOD) or limits of quantification (LOQ). In these equipments, the sample is scanned beneath the incident X-ray microbeam within the focal plane. At each step in the scan, diffraction data can be collected via a CCD detector. In most cases, the microdiffraction measurements have been performed using synchrotron radiation (SR) [67]. Micro-XRD can be used for quantification of phases in mixtures. Other disadvantage of this technique is that instrumentation is not commonly available for the routine analyses [68].

New portable X-ray diffraction equipments have been designed and constructed recently, some of them combining two different techniques in the same system such as XRD/XRF [69]. These instruments have been tested for paintings analysis. 

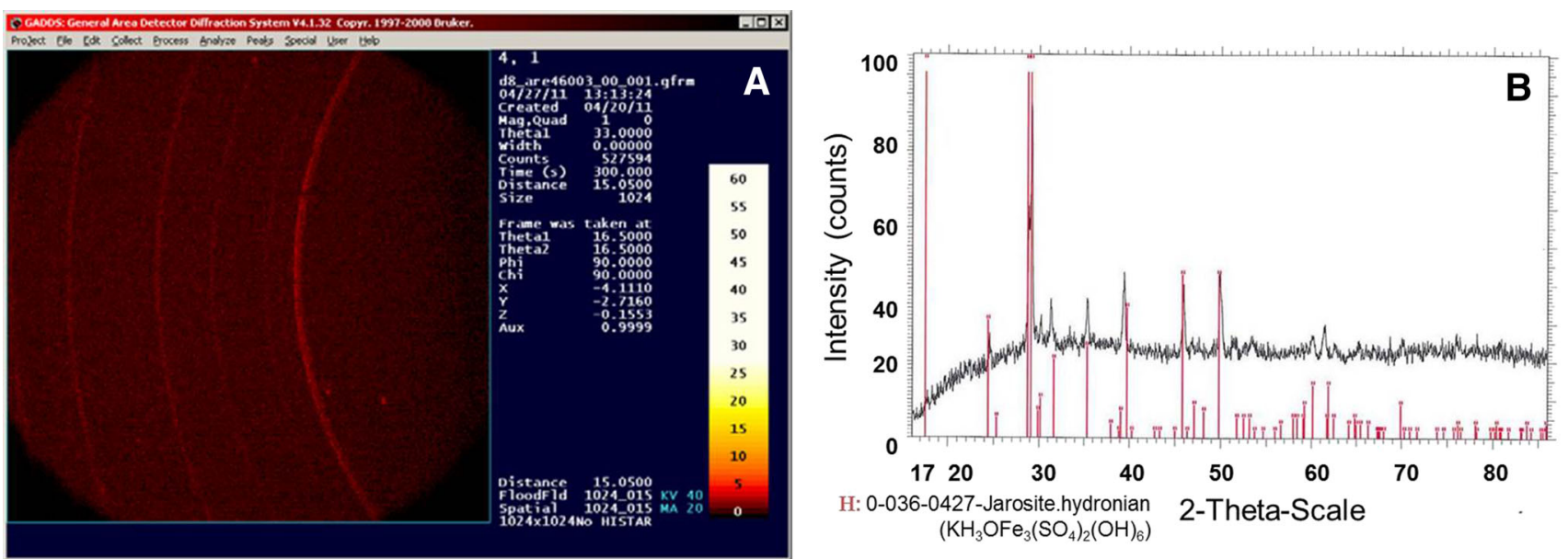

Fig. 33 a Diffraction rings obtained from a pre-Columbian pigment in a $\mu$ XRD spectrometer. b X-ray diffraction pattern of the pigment

\section{Pigment characterization}

In XRPD, X-rays from the source are scattered in a sphere around the sample. The randomly oriented crystallites in a sample produce Debye diffraction cones along the sphere that correspond to single Bragg angles 2 $\theta$. The linear diffraction pattern, commonly presented as a diagram including a number of discrete diffraction peaks, is obtained, because the detector scans through an arc that intersects each Debye cone at a single point. Diffraction patterns are commonly collected as diagrams in which the integral intensity is depicted vs. detector angle $2 \theta$ (Figs. 19f, 32a). Nevertheless, $2 \theta$ angle depends on instrumental characteristics such as the wavelength $\lambda$ of the source; therefore, correlation between $d$-spacing vs. relative peak intensity is more suitable. In any case, diffraction data can be reduced to a list of peak positions and intensities (Fig. 32b).

The diffraction pattern of a crystal comprising the positions, intensities and line profiles of the diffraction effects, is a fundamental physical property of the substance, and thus, it can provide useful information on lattice parameters and Bravais lattice symmetry, residual strain, crystal structure, epitaxy/texture/orientation, and crystallite size and microstrain.

From an analytical point of view, qualitative analysis based on the identification of the phase composition of a paint sample and quantitative phase analysis that determines the relative amounts of phases in a mixture, by referencing the relative peak intensities, are the two main applications of this technique to the analysis of pictorial artworks.

The position of the set of peaks that compose the diffractogram of a paint sample together with their relative intensities enables the identification of the different phases (crystalline structures) present in the paint sample. Phase identification is based on the assumption that:

(A) The diffraction pattern for every phase is unique (can be considered as its fingerprint). Here, it is of worth to mention that phases with the same chemical composition (i.e. the polymorphs anatase and rutile $\left(\mathrm{TiO}_{2}\right)$ ) can have drastically different diffraction patterns.

(B) The diffraction pattern of a mixture is the sum of the scattering from each component phase.

Thus, identification is carried out by matching the experimental data of position and relative intensity of peaks appearing in the diffractogram to the reference patterns contained in a database. In the last decades, huge databases including more than 300,000 compounds are available with the instrumentation. Some tentative of building artists' pigments database has also been carried out [70].

\section{Examination of paint samples}

Pure pigment Figure 33a shows the diffraction rings obtained from a pre-Columbian yellow pigment from microdiffraction scan with a monochromatic beam. The diagram intensity vs. $2 \theta$ angle is the result of the processing of the former (Fig. 33b). Comparison of diffraction pattern obtained from the sample with those stored in X-ray diffraction databases enables the unambiguous identification of jarosite in this sample. More intense peaks that appear in the diagram at $2 \theta$ values of $28.73,29.01$, and 39.32 correspond to intense and moderate peaks in the diffractogram of the mineral jarosite stored in databases, whose $d$-spacing values are $3.109(71), 3.080(100)$, and $2.292(31)$. 


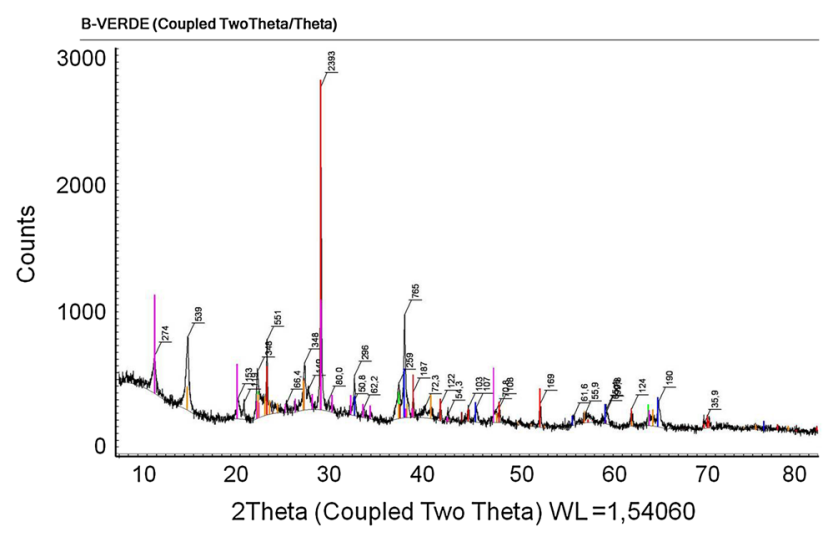

Fig. 34 X-ray diffraction pattern of a green pigment. The identification of components present in the sample has been made by matching with Bruker software diffract plus. Powder diffractogram pattern database PDF-2/Release $2010 \mathrm{RDB}$. The diffraction pattern of the reference compounds identified are shown as lines in different color: quartz (red), chromium oxide (blue), mica (green), illite (pink), strontium sulphate (brown), kaolinite (ochre)

Mixtures of pigments or minerals Figure 34 shows the diffractogram obtained by the conventional XRPD from a rare greenish pigment found in a pre-Columbian archaeological site. Consecutive matching of $d$-spacing values of the sample with those of minerals stored in databases enables the identification of the main components of this pigment: quartz, illite, kaolinite and, at lesser extent, chrome oxide, mica, and strontium sulphate.

\section{FTIR and Raman spectroscopy}

\section{Fundamentals of FTIR spectroscopy}

The infrared (IR) spectral region of the electromagnetic spectrum extends from the red end of the visible spectrum to the microwave region (wavenumbers from 14,000.0 to
$20 \mathrm{~cm}^{-1}$ or wavelengths in the range $\left.0.7-500 \mu \mathrm{m}\right)$. Most analytical applications of this technique use the middle region that extends from 4000 to $500 \mathrm{~cm}^{-1}(2.5-20 \mu \mathrm{m})$.

In infrared spectroscopy techniques, transitions between different energy states of vibration and rotation of molecules are measured (cf. Fig. 35a). Rotations can be observed only for small gas molecules, i.e. they play no role for the analysis of condensed phases. A fundamental transition occurs when the absorbed photon increases the energy level from the ground state to the first excited state. An overtone occurs when the transition covers other two vibrational energy states.

As the molecule's vibrations are unique to its structure, the measurement of these vibrational bands makes IR radiation able for compound characterization. The most common modes of vibration are stretching, torsional, and bending (Fig. 35a). Stretching vibrations modify (increase or decrease) the length of the bonds between the atoms, whereas twisting of the backbone of the molecule takes place in torsional (skeletal) vibrations. In bending vibrations (scissoring, rocking, wagging, and twisting), the bond angles of the atoms, relative to one another, change. On the other hand, vibrations can be classed according to their symmetry in symmetric or asymmetric.

Functional groups, which consist of combinations of atoms such as a carbonate group or a carbonyl group, are responsible for IR absorptions or bands appearing in the IR spectrum at specific frequencies, regardless of the rest of the molecule. These characteristic IR bands can be used for the identification of materials and for the characterization of structure in an unknown pure compound. The position of the IR band of a functional group, the so-called group frequency, depends on the mass of the atoms as well as on the strength and angles of the connecting bonds.
Fig. 35 a Scheme of energy levels for vibrational and rotational transitions. It should be noted that rotational transitions are only observable for gas molecules. b Scheme of energy levels for Raman and Rayleigh scattering transitions

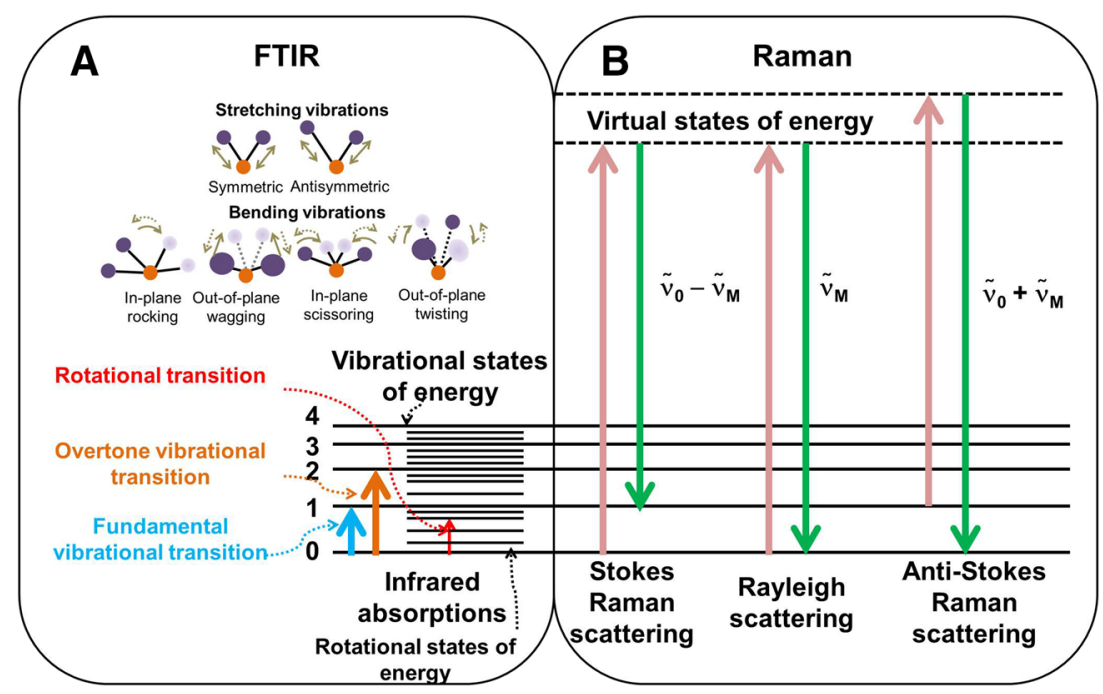


Fig. 36 a Scheme of a FTIR spectrometer and $\mathbf{b}$ detail of the ATR cell

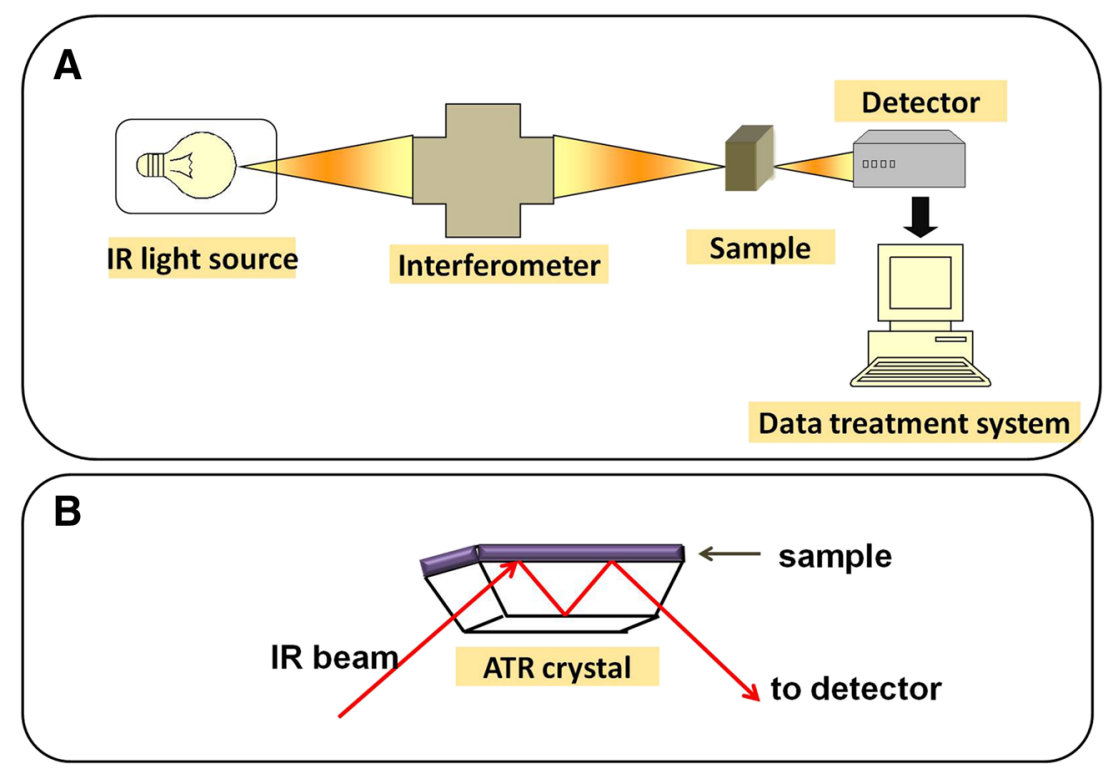

Nevertheless, the energy of a vibration and, therefore, the group frequency can be sometimes influenced by the atoms surrounding the functional group.

Although any vibrational transition produces energy absorptions, only those that are active in the IR region will be seen as an absorption band in the IR spectrum. Selection rules, which are based on the symmetry of the molecule, determine whether a given vibration will be seen in the spectrum. The primary selection rule is that only vibrations are IR-active when the dipole moment of the molecule changes.

IR absorption bands are displayed in the IR spectrum as the percentage of transmitted IR radiation $(T)$ or the related magnitude absorbance $(A)$ :

$A=\log \frac{1}{T}$

vs. the reciprocal wavelength (spatial frequency), called wavenumber $\left(\mathrm{cm}^{-1}\right)$.

\section{FTIR spectroscopy instrumentation}

Infrared and Raman spectroscopy are instrumental techniques widely used in the fields of Archaeology, Archaeometry, and Conservation Science due to their versatility and ability for providing structural information of both inorganic and organic materials together with the minimum requirement of sample preparation. Since the 1980s of the last century, a number of FTIR techniques have been used in Archaeometry and Conservation Science fields in addition to the conventional FTIR instrumentation (Fig. 36a): diffuse reflection Fourier-transform Infrared spectroscopy (DRIFT), attenuated total reflection (ATR) (Fig. 36b), FTIR photoacoustic spectroscopy (FTIR-PAS), and FTIR microspectroscopy in either the transmission or reflected mode [13]. In this instrumentation, the IR signal is detected as an interferogram, so that the IR spectrum is obtained from the interferogram by the mathematical process of Fourier transformation (FTIR).

\section{Fundamentals of Raman spectroscopy}

Scattering of monochromatic radiation incident to a material (Rayleigh scattering) was described by the English physicist John William Strutt (3rd Baron Rayleigh) (1842-1919) in 1871. After several decades, in 1928, the Indian physicist Chandrasekhara Venkata Raman (1888-1970) described a new type of scattering of radiation with change in the wavenumber, which was termed Raman scattering. As shown in Fig. 35b, Rayleigh scattering is an elastic scattering that involves a net change of energy between the radiation and the molecule, which is smaller than the wavelength of the incident radiation, without a change of wavenumber. In contrast, Raman scattering takes place as result of the inelastic interaction between radiation (in current instrumentation invariably monochromatic) and molecule. Nevertheless, the energy of the incident photon does not correspond to any transition of energy of the scattering molecule as this photon is not absorbed in the strict sense owing to the inelastic character of the interaction between incident photon and molecule. Instead, the incident radiation perturbs the molecule opening the possibility of spectroscopic transitions other than pure absorptions as shown in the energy level diagram of Fig. 35b, where broken horizontal lines represent virtual energy states of the molecule, whereas unbroken lines represent vibrational energy states of the molecule; the arrows pointing upwards represent photon annihilation, 
whereas the arrow pointing downwards represent photon creation. Absorption without energy conservation is termed virtual absorption and the resulting state is considered a virtual state.

The radiation scattered by a specific molecule includes radiation with the same wavenumber $\tilde{v}_{0}$ than the incident radiation together with pairs of new wavenumbers of type $\tilde{v}_{0} \pm \tilde{v}_{M}$. The wavenumber $\tilde{v}_{M}$ is in the ranges associated with transitions between rotational, vibrational and electronic energy levels specific of the molecule involved in the scattering. Stokes Raman bands have wavenumber less than $\tilde{v}_{0}$ given by $\tilde{v}_{0}-\tilde{v}_{M}$ whereas anti-Stokes Raman bands have wavenumbers greater than $\tilde{v}_{0}$ given by $\tilde{v}_{0}+\tilde{v}_{\mathrm{M}}$. The intensity of Raman scattered radiation follows from the Rayleigh fourth power law, so that the Stokes Raman scattering is proportional to $\left(\tilde{v}_{0}-\tilde{v}_{M}\right)^{4}$ and the intensity of the anti-Stokes Raman scattering to $\left(\tilde{v}_{0}+\tilde{v}_{\mathrm{M}}\right)^{4}$. Therefore, a Raman spectrum consists of a pattern of bands that are characteristic of the molecule involved in the scattering as a fingerprint that can be used for identification purposes.

In Raman spectroscopy, only those transitions in which the polarizability of the molecule changes are active. Thus, this technique is complementary to FTIR spectroscopy.

\section{Raman spectroscopy instrumentation}

Advances in the identification and determination of the constituents of materials of cultural artefacts by means of Raman spectroscopy can be mainly attributed to improvements in instrument technology. The selection of wavelength of excitation is of fundamental importance in Raman spectroscopy of cultural goods, in particular, of biomaterials for which longer wavelengths into the nearinfrared $\left(\mathrm{Nd}^{3+}\right.$ :YAG laser, $\left.1064 \mathrm{~nm}\right)$ provide advantages such as the suppression of their intense fluorescence emission. Nowadays, most of the commercial instruments are provided of this laser source (Fig. 37a). For inorganic pigments, several lines can cover a wide range of case studies: $\mathrm{Ar}^{+}$laser, $488 \mathrm{~nm}$ or $514 \mathrm{~nm}, \mathrm{Kr}^{+}$laser, $647 \mathrm{~nm}$, $\mathrm{He} / \mathrm{Ne} 632.8 \mathrm{~nm}$, diode laser, 780-800 nm [71]. Further improvements in Raman spectroscopes are related to the use of alternative irradiating sources based on the nonthermal photoablation phenomenon. Laser power levels have to be controlled even though it is assumed that inorganic materials are immune to the effects of this radiation. Results obtained by analyzing colored materials with conventional dispersive Raman can be improved by using Fourier transform Raman spectroscopy (FT-RS) with infrared excitation. Coupling of an optical microscope to a Raman spectrometer results in the micro-Raman spectroscopy (Fig. 37b). The high axial spatial resolution due to the confocality in the micro-Raman spectroscopes enables the analysis of samples smaller than $(5 \times 5) \mu \mathrm{m}$, thus reducing interferences from adjacent pigment particles. In surface-enhanced Raman scattering (SERS), the Raman signal together with fluorescence quenching is greatly enhanced (e.g. by Au nanoparticles). Solid-state lasers and fiber optic devices have enabled the development of mobile instrumentation.
Fig. 37 a Scheme of a Raman spectrometer and $\mathbf{b}$ scheme of a Raman microscope

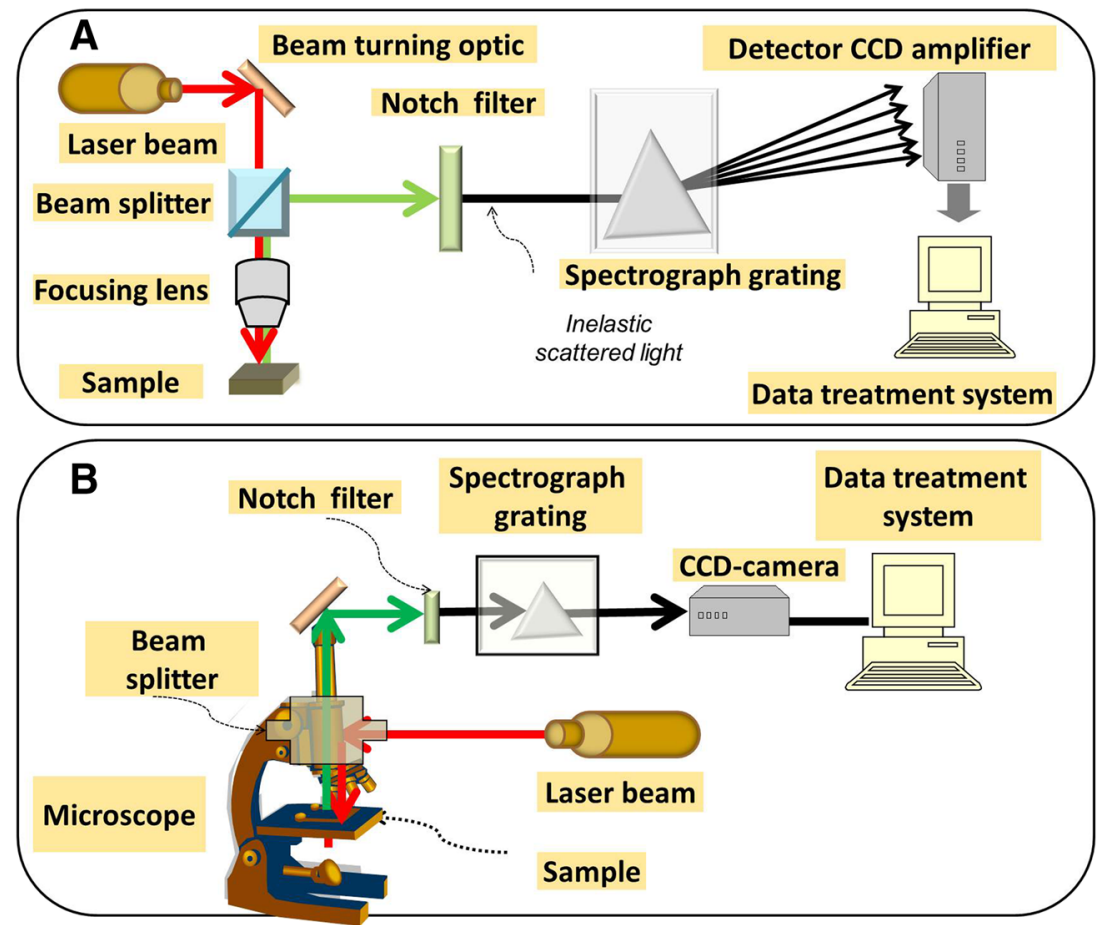




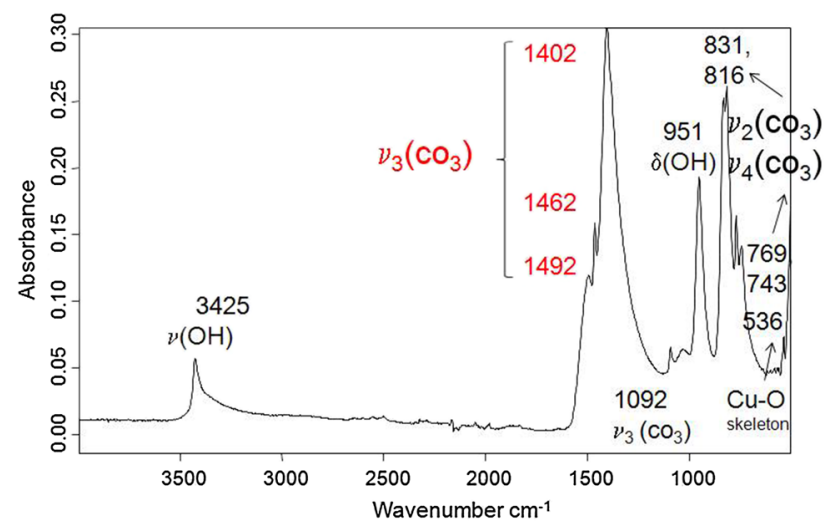

Fig. 38 IR spectrum of azurite. Most intense IR band ascribed to carbonate group is marked in red

\section{Spectral features of pigments}

In the application of Raman spectroscopy to Archaeology and Conservation Science, Raman spectra are used simply for identification of compounds. A characteristic pattern of bands, which are involved in the scattering of the incident monochromatic radiation, is composing the vibrational Raman spectrum of a pigment. This set of anti-Stokes and Stokes Raman bands that composes the spectrum is unique and serve to identify the chemical compounds present in the pigment. Identification of pigments is carried out by comparing the experimental spectrum of a paint sample with those obtained from reference minerals and historical pigments [15].
Identification of an unknown pigment by FTIR spectroscopy, similar to Raman spectroscopy, is carried out by matching the spectrum of the unknown with that of the reference pigment from databases. Apart from sulphide type pigments, inorganic pigments can be identified by FTIR spectroscopy owing to the spectral signatures characteristic of them, similar to Raman spectroscopy. Sulphide pigments do not absorb in the mid infrared region (MIR) and cause extensive scattering which results in the decrease in the intensity of the transmitted light on decreasing of the wavelength in the IR spectrum.

Identification of pigments by FTIR spectroscopy can also be carried out by ascription of IR bands appearing in the IR spectrum of the unknown to vibrational modes of specific groups of atoms. The first step in the interpretation of an IR spectrum (Fig. 38) is the ascription of the band that dominates the spectrum to a group of compounds characterized by a specific anion (carbonate, sulphate, etc.) as most of the artists' inorganic pigments are crystalline compounds formed by an anion (sometimes accompanied by hydroxyl or other anion) that is alternated with a metallic cation to form an ionic pattern. Table 8 and Fig. 39 summarize the wavenumber ranges of the main IR bands of common anions that compose pigments. Recognition of this band in the IR spectrum of a sample enables the identification of the prevalent anion present in the sample. In a second step, the rest of bands that appear in the IR spectrum (see Fig. 38) is examined and compared with the spectra stored in databases, thus enabling the

Table 8 Wavenumber ranges of the most intense IR band of the main anions that compose pigments

\begin{tabular}{|c|c|c|}
\hline Family & Wavenumber $\left(\mathrm{cm}^{-1}\right)$ & Pigments \\
\hline Sulphide & $<350$ & $\begin{array}{l}\text { Cadmium orange and red, cadmium yellow, lithopone, orpiment, realgar, } \\
\text { vermilion }\end{array}$ \\
\hline Stannate & $450-600$ & Cerulean blue, lead tin yellow \\
\hline Aluminate & $500-700$ & Thénard's blue \\
\hline Antimonate & 675 & Naples yellow \\
\hline Oxide & $<700$ & $\begin{array}{l}\text { Cobalt green, chromium oxide green, iron oxide, litharge, Mars black, } \\
\text { minium, ochre, titanium white, viridian, zinc white }\end{array}$ \\
\hline Chromate & $800-980$ & $\begin{array}{l}\text { Barium yellow, chrome orange, chrome yellow, molybdate orange, } \\
\text { strontium yellow, zinc yellow }\end{array}$ \\
\hline Molybdate & $850-950$ & Molybdate orange \\
\hline Silicate & $975-1150$ & $\begin{array}{l}\text { Earth pigments, Egyptian blue, chrysokolla, green earth, smalt, Maya blue, } \\
\text { ultramarine blue }\end{array}$ \\
\hline Phosphate & $950-1100$ & Bone black, cobalt violet dark, manganese phosphate, permanent violet \\
\hline Sulphate & $1000-1200$ & Baryte, gypsum, jarosite, lithopone \\
\hline Nitrite & $1300-1400$ & Cobalt yellow \\
\hline Carbonate, hydroxycarbonate & $1400-1450$ & Azurite, calcium carbonate white, lead white, malachite \\
\hline Acetate, aceto-arsenate & $1400-1560$ & Verdigris \\
\hline Aceto-arsenite/arsenite/arsenate & $800-850$ & Cobalt violet light, emerald green, Scheel's green, \\
\hline Ferrocyanide & 2100 & Prussian's blue \\
\hline
\end{tabular}




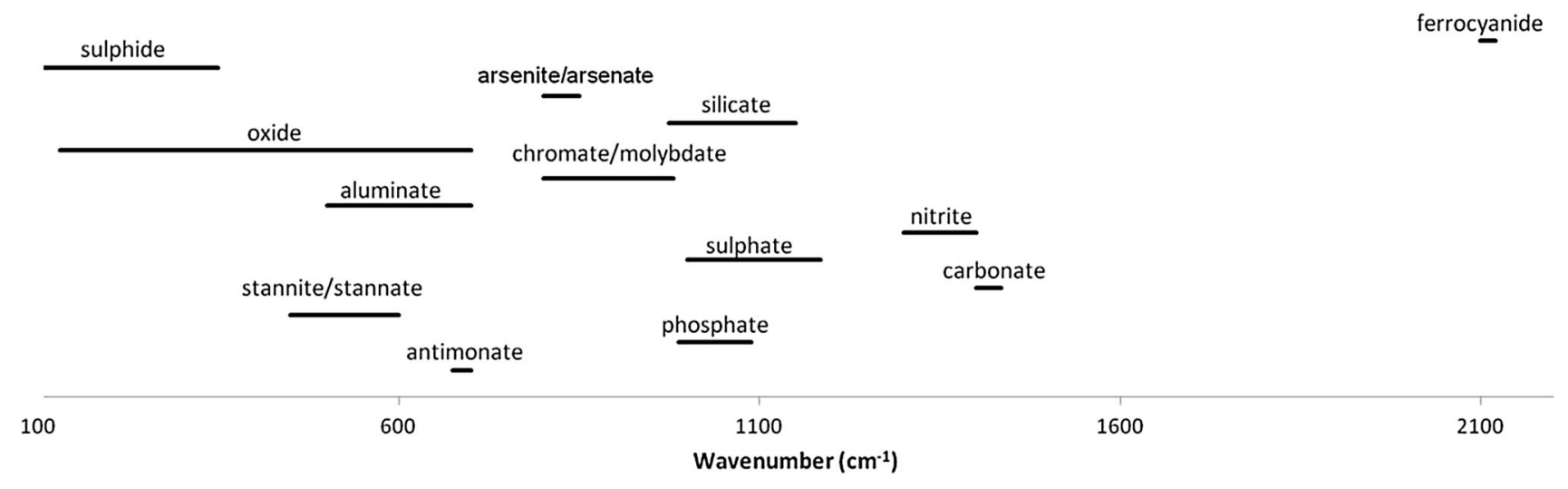

Fig. 39 Scheme of the wavenumber range of the most intense IR band of the main anions that compose artists' pigments

complete identification of compounds present in the sample (see examples in Sect. Examination of paint samples).

Sometimes, the pigment includes other compounds, apart from the coloring compound, such as accessory minerals or materials added as adulterations and sophistications. This is the case of earth pigments. Natural earth pigments and their synthetic analogs are colored principally by the oxides [hematite $\left(\alpha-\mathrm{Fe}_{2} \mathrm{O}_{3}\right)$ and, at lesser extent, magnetite $\left(\mathrm{Fe}_{3} \mathrm{O}_{4}\right)$ and maghemite $\left.\left(\gamma-\mathrm{Fe}_{2} \mathrm{O}_{3}\right)\right]$ and oxide hydroxides of iron (goethite $(\alpha-\mathrm{FeOOH})$, lepidocrocite $(\gamma-\mathrm{FeOOH})$, akaganeite $(\beta-\mathrm{FeOOH})$ and ferrihydrite), which are occasionally hydrated. Nevertheless, the IR spectra of earth pigments are dominated by absorptions due to accessory minerals rather than absorptions from the iron oxides or iron oxide hydroxides. The presence of clay minerals such as kaolin or quartz that masks the goethite signatures is common in yellow earths (see examples in Sect. Examination of paint samples). In addition to those, manganese oxide and organic matter are commonly found in raw sienna pigments along with the iron oxide. Manganese oxides, calcite, dolomite, mica, and quartz accompany to the oxide hydroxides of iron in umber pigments [72]. Water absorbed onto the surface of mineral particles or differences in crystallinity and particle size are also factors that modify the position of the iron oxide bands.

In the last decades, some effort has been made for collecting Raman and FTIR analytical data. Silva et al. [73] have developed a diffuse reflection FTIR spectral database of pigments and dyes that contains sixty diffuse reflectance spectra. IR spectra of pigments used for art and industrial applications are also available in encyclopedias of industrial chemistry [74]. A complete database of FTIR and Raman spectra of historical pigments has been developed by the Infrared and Raman Users Group (IRUG) [75]. e-VISART is also a complete database developed by Castro and Pérez-Alonso [76] that contains more than 229 FTIR, FT-Raman and Raman spectra of historical pigments. Other IR and Raman spectral libraries of pigments and minerals are also available in literature and internet $[15,77,78]$. Abundant case studies focused on the application of FTIR and Raman spectroscopy to the analysis of pigments can be found in literature [15, 79]. In particular, the series of monographs on artists' pigments edited by the National Gallery of Washington provides abundant analytical IR and Raman data on historical pigments [58-61]. IR spectra of a wide range of minerals used as pigments, since ancient times can be found in the Caltech database [80]. Raman spectra of the Caltech database are now part of the RRUFF project [81]. The latter is a large composite database that combines the American Mineralogist Crystal Structure Database with Raman spectra obtained at Arizona State University and Caltech. This database has chemical analyses, X-ray diffraction parameters, Raman spectra, and infrared spectra among other types of data.

Figure 19a, b shows the Raman and IR spectra of the historical pigment malachite $\left(\mathrm{CuCO}_{3} \cdot \mathrm{Cu}(\mathrm{OH})_{2}\right)$, as an example. List of the main IR and Raman bands found in the spectra is also provided (Fig. 19c) [82].

\section{Quantitative analysis and other analytical strategies}

Quantitative analysis Quantitative $( \pm 1 \%)$ or semiquantitative $( \pm 10 \%)$ analysis of pigments is based on the comparison of the intensity or area in absorbance unities of a specific band of the pigment in the unknown sample and the same band in a reference material of known concentration. Quantitative analysis is not frequently carried out in the field of Archaeometry and Conservation Science due to the variety of materials used by artists and the complex mixtures of pigments that often are present in the paint layers that makes difficult the calibration of the paint system. Nevertheless, an estimate of the relative content of pigments and minerals in a material can be easily 

in the $1600-800 \mathrm{~cm}^{-1}$ of two laboratory specimens prepared calcium carbonate and kaolinite.

Bands corresponding to the stretching vibrations of carbonate group (maximum at $1406 \mathrm{~cm}^{-1}$ ) for calcium carbonate and for the $\mathrm{Si}-\mathrm{O}$ bonds (maximum at $1002 \mathrm{~cm}^{-1}$ ) for clay and siliceous minerals have been used. a Specimen containing 7 wt\% kaolinite, b specimen containing $80 \mathrm{wt} \%$ kaolinite. Dashed line delimitates the portion of the band area measured
Fig. 40 Detail of the IR spectra by mechanical mixing of

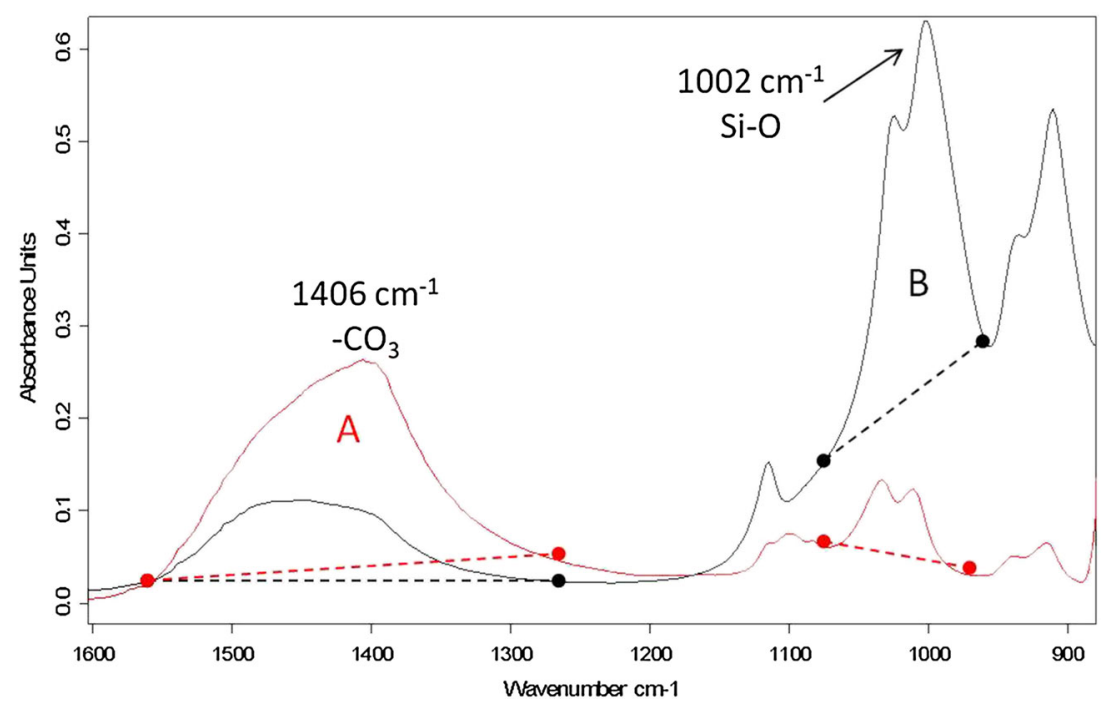

performed when the composition of the sample can be approximate to that of an ideal binary system using the absorbance ratio method [13]. This is the case of a natural earth pigment mainly composed of a clay with calcite also present in low amounts as accessory mineral or in a fresco ground composed of a microcrystalline matrix of calcium carbonate in which quartz and siliceous minerals are included (common dosages of slaked lime:sand are 1:3 and $1: 2, \mathrm{v} / \mathrm{v})$. In such instances, calculation of the relative amount of both components can be of great interest for establishing the purity of the pigment or for knowing the original dose lime:sand used by the artist for working with the fresco technique.

Figure 40 shows the IR spectra of two laboratory specimens prepared by mechanically mixing of calcium carbonate and kaolinite at different proportions. To build the calibration curve, the ratio of the measured area bands for kaolinite and calcium carbonate has been used. Dependence of the calculated quotients on the concentration of kaolinite is illustrated in the diagram shown in Fig. 41. It can be seen that a satisfactory linear dependence is obtained in a wide range of concentrations from 7-80 wt\% kaolinite.

Similar to FTIR spectroscopy, quantitative and/or semiquantitative analysis using Raman spectroscopy involves the calibration of the absolute intensity (determined from the measurement of the integrated area) of a specific band and its proportionality to the concentration of the pigment. A few works are found in the literature in which semiquantitative study of binary or ternary mineral systems such as jadeite-diopside or pyrope-almandinegrossular is reported [83].

Resolution-enhancement methods Several iterative optimization processes performed on the interferogram are of

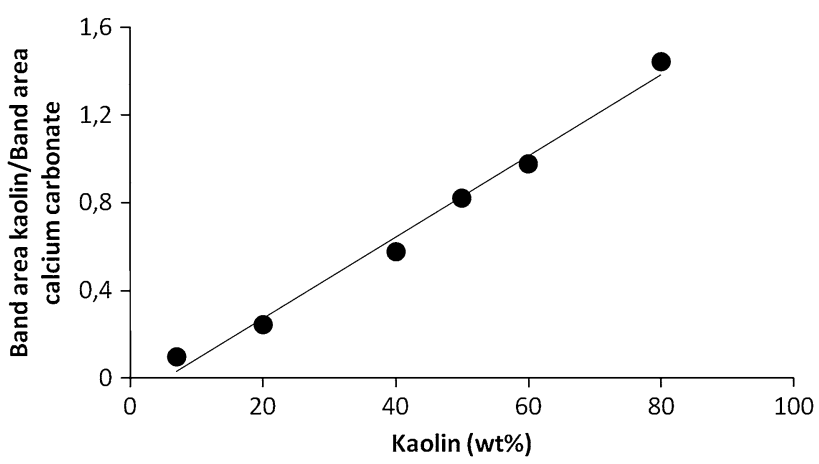

Fig. 41 Ratio of kaolinite band area and calcium carbonate band area vs. content of kaolinite expressed as weight percentage

interest in the analysis of materials from cultural artefacts. The second derivative is the most commonly used method of derivative spectroscopy. In this technique, the resultant spectrum has sharper bands than those of the original spectrum, so that the identification of the bands is carried out more accurately.

Fourier self-deconvolution (FSD) and curve fitting (CF) are mathematical data strategies which, used separately or combined, have become popular among FTIR spectroscopists due to their ability for discriminating bands that are overlapped in the original spectrum. Although these methods are commonly used in the study of the secondary structure of proteins, these treatments can also be applied to the study of inorganic materials used in Art such as bones, tooth and ivory and, eventually, in earth pigments for better discriminating overlapped bands corresponding to two different minerals. Figure 42 shows the original and the deconvolved band obtained by applying the FSD treatment. It can be seen that a better resolution of individual bands is achieved using this mathematical treatment. 


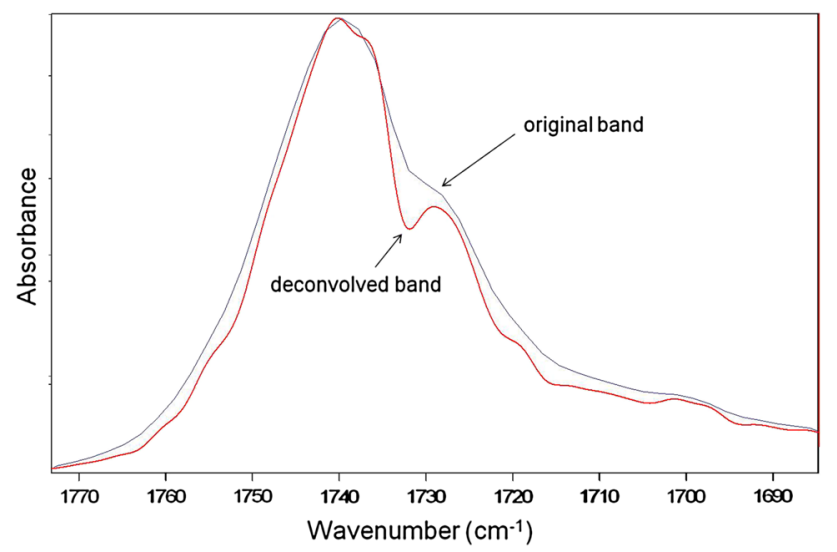

Fig. 42 Original and deconvolved band. Deconvolution conditions used are bandwidth at half height, $13 \mathrm{~cm}^{-1}$ and a resolution enhancement factor, 2.4

Curve fitting allows calculating single components in a system of overlapping bands. A model consisting of an estimated number of bands with a characteristic shape have to be established before the fitting iterative calculation is started. The result of this calculation highly depends on the model selected. Number of bands is established by the analyst in coherence with the chemical structure presumed for the material. Band shapes usually are defined by Lorentzian and Gaussian functions or by a mixture of both functions. Different algorithms are used for the curve fit that are based on the least squares method (i.e. LevenbergMarquardt, Local Least Squares, etc.). In these algorithms, the difference between the original and the calculated curve is kept as small as possible. Figure 43 shows a simple example of curve fit. The original band is supposed to be formed by overlapping of two individual bands A and B. The calculated curve is a combination of two single gaussian bands, which account for the 85 and $15 \%$ of the total calculated band area, and satisfactorily approaches the original curve.

Estimate of structural properties FTIR spectroscopy can also provide information on the extent of atomic order of the mineral phases of pigments and inorganic materials. A good example of this interesting application is provided by the Fourier transform splitting factor (FTSF) or Crystallinity Index [84]. This parameter is defined from a number of selected bands in the IR spectra of bone and tooth samples to qualify the degree of maturation/deterioration of the inorganic bioapatite. Bioapatite is mainly composed of crystalline grains of a calcium phosphate phase (apatite) with similar structure as hydroxyapatite $\left(\mathrm{Ca}_{10}\left(\mathrm{PO}_{4}\right)_{6}(\mathrm{OH})_{2}\right)$ in which carbonate ions $\left(\mathrm{CO}_{3}{ }^{2-}\right)$ are replacing to some extent both $\mathrm{OH}^{-}$groups (type A apatites) or $\mathrm{PO}_{4}^{3-}$ ions (type $\mathrm{B}$ apatites). The bioapatite ensures the rigidity of bone and teeth in the form of mineral crystallites, which are intimately joined at nanoscale with fibrous proteinaceous material, mainly collagen type I. A bone in a recent postmortem state contains, in general, a high concentration of non-stoichiometric apatite that adopts the form of nanometric needle and plate-like grains, denoting a low degree of crystallization. Diagenetic processes that take place in burial or underwater conditions over the time result in the decomposition of the organic matter and the recrystallisation of apatites. In parallel, other phenomena can take place such as precipitation of calcium carbonate or increase in fluorine concentration in the residual material, which modify the crystallinity of the bioapatite.

The degree of crystallinity of bioapatite can be quantified in terms of the degree of individualization of the IR bands that form the main doublet of the stretching vibration $v_{4}\left(\mathrm{PO}_{4}{ }^{3-}\right)$ at 565 and $600 \mathrm{~cm}^{-1}$ (see Fig. 44). This
Fig. 43 Original, calculated, and individual bands $\mathrm{A}$ and $\mathrm{B}$ obtained by curve fitting. Levenberg-Marquardt algorithm using Gaussian function for band shape has been used

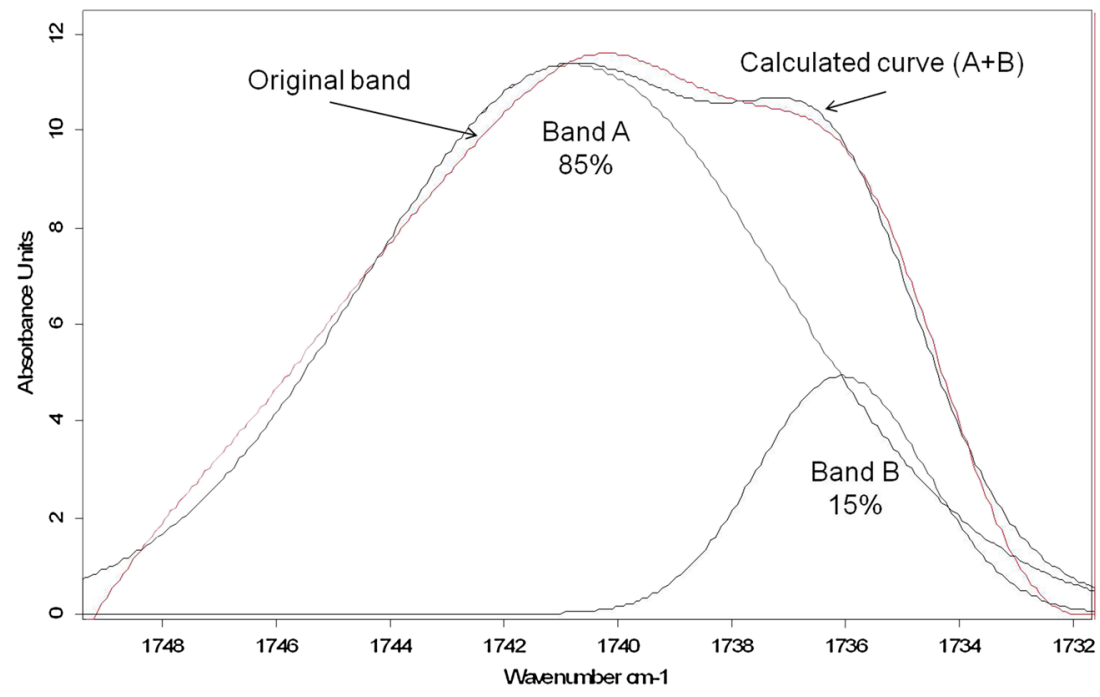




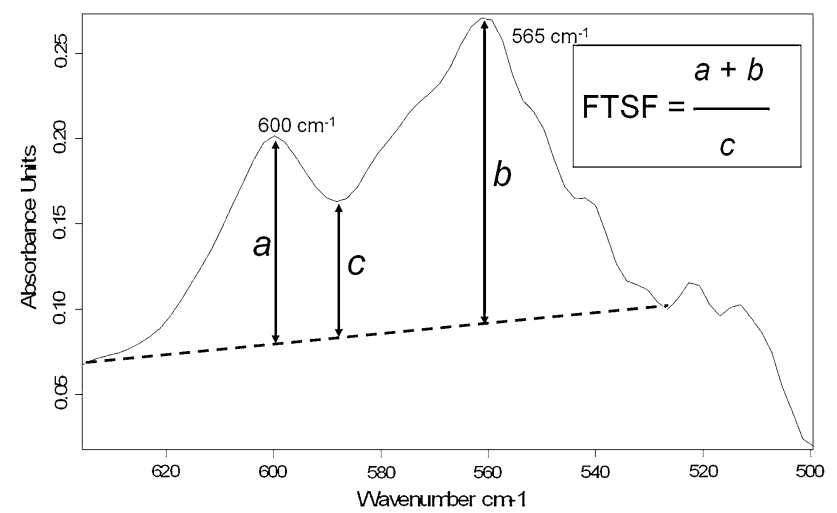

Fig. 44 Detail of the $v_{4}\left(\mathrm{PO}_{4}{ }^{3-}\right)$ band of a sample of archaeological ivory in which parameters $a, b$ and $c$ have been drawn. The value calculated for FTSF is 3.8

stretching vibration is particularly sensitive to the crystallinity degree of the bioapatite. Thus, the FTSF is defined by the mathematical expression:

$\mathrm{FTSF}=\frac{(a+b)}{c}$,

where $a$ and $b$ are the heights of the IR bands at 600 and $565 \mathrm{~cm}^{-1}$ corresponding to the $v_{4}\left(\mathrm{PO}_{4}{ }^{3-}\right)$. The value $c$ is the height in the valley that separates both IR bands. The baseline was drawn between the closest minima on either side of the measured peaks. Recent postmortem bones have a poorly crystallized bioapatite structure, and therefore, their IR spectra exhibit low separation between the two above IR bands, which provides low FTSF values that correspond to small crystalline domains and higher structural disorder. Typical values of FTSF in such instances are in the 2.0-3.0 range. Diagenesis processes that take place in burial or waterlogged conditions result in mineralised bones with higher FTSF values, FTSF $>3.0$.

Discriminating between minerals formed in different conditions In calcite, the three representative infrared absorption bands correspond to the asymmetric stretching $\left(v_{3}\right)$ at $1394 \mathrm{~cm}^{-1}$, out-of-plane bending at $872 \mathrm{~cm}^{-1}\left(v_{2}\right)$ and in-plane bending $\left(v_{4}\right)$ at $712 \mathrm{~cm}^{-1}$ vibrations of the carbonate ions, respectively (see Fig. 45) [85]. It has been observed that there is a correspondence between structural characteristics such as crystallinity and the $v_{2} / v_{4}$ band intensities ratio as the $v_{4}$ band is more influenced by atomic disorder than $v_{2}$ band [85-87]. Thus, this parameter can be used for discriminating between calcites with different structural characteristics as result of being formed in different conditions. $v_{2} / v_{4}$ band intensity ratio is calculated from the measurement of the height of the $v_{2}$ and $v_{4}$ bands. Baselines are drawn between the closest minima on either side of the measured band. To avoid the effect of grinding

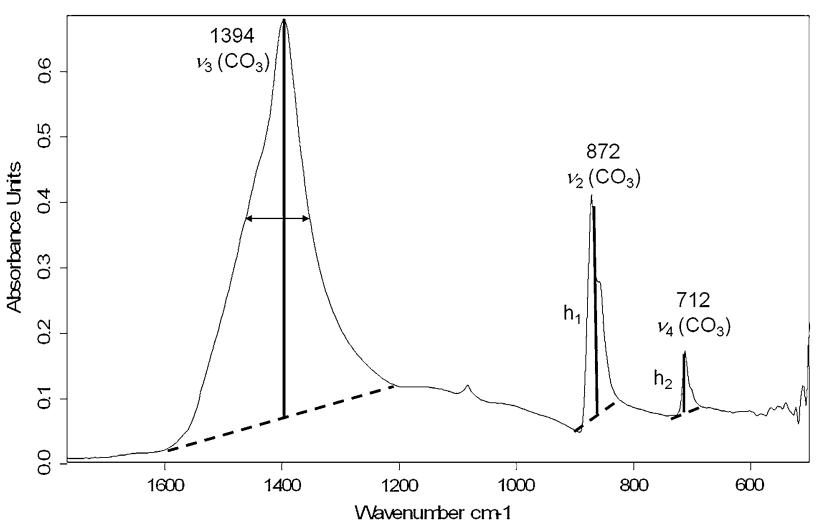

Fig. 45 Detail of the IR spectrum of a calcite showing the asymmetric stretch $\left(v_{3}\right)$ at $1394 \mathrm{~cm}^{-1}$, out-of-plane bending at $872 \mathrm{~cm}^{-1}\left(v_{2}\right)$ and in-plane bending $\left(v_{4}\right)$ at $712 \mathrm{~cm}^{-1}$ vibrations

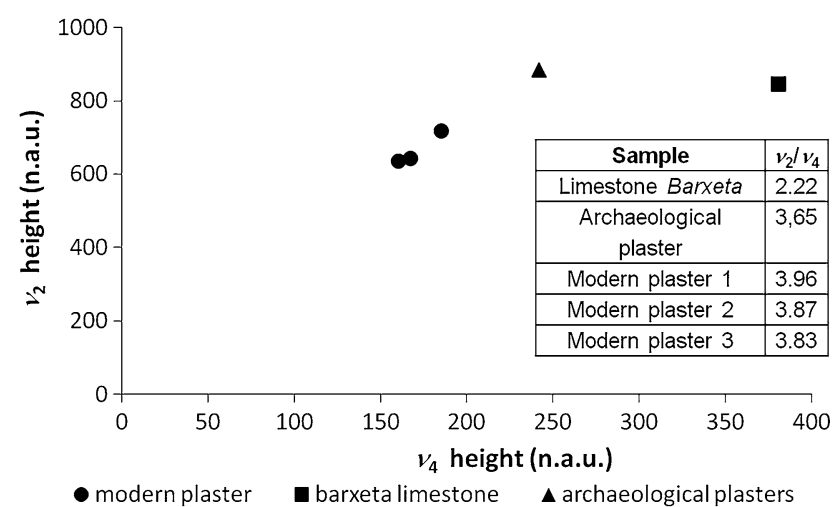

Fig. 46 Diagram $v_{2}$ band height vs. $v_{4}$ band height and values of $v_{2} / v_{4}$ band height ratio for calcite samples of geogenic and anthropogenic origin. n.a.u. normalized absorbance units

of samples on the measured bands, $v_{2} / v_{4}$ ratios are considered only in the IR spectra where the full width at half maximum (FWHM) of the $v_{3}$ band is in the range $110-130 \mathrm{~cm}^{-1}[86]$. In Fig. 46, are shown the diagram $v_{2}$ band height vs. $v_{4}$ band height and the values of $v_{2} / v_{4}$ band height ratio for calcite samples of geogenic (Barxeta limestone) and anthropogenic origin (archaeological and modern plasters). Values of $v_{2}$ and $v_{4}$ band height for each calcite in the diagram are normalized to a $v_{3}$ band height of 1000 , corresponding to 1.0 absorbance unit. Interestingly, points corresponding to all plasters (anthropogenic calcite) are aligned, whereas the point corresponding to the geogenic Barxeta calcite is depicted apart and is closer to the archaeological plaster. These results are coherent with the values calculated for $v_{2} / v_{4}$ band height ratio. Modern plasters exhibit $v_{2} / v_{4}$ band height ratio values in the range (3.96-3.83), which are higher than the archaeological plaster (3.65) and the geogenic calcite, which shows the lowest $v_{2} / v_{4}$ band height ratio value (2.22). The higher $v_{2} / v_{4}$ value found in plasters can be associated to the small sizes 
Fig. 47 IR spectrum of raw sienna pigment (Kremer 40400). Detail of the deconvolved band at $889 \mathrm{~cm}^{-1}$ ascribed to bending vibrations of $\mathrm{OH}$ groups in goethite (line in red)

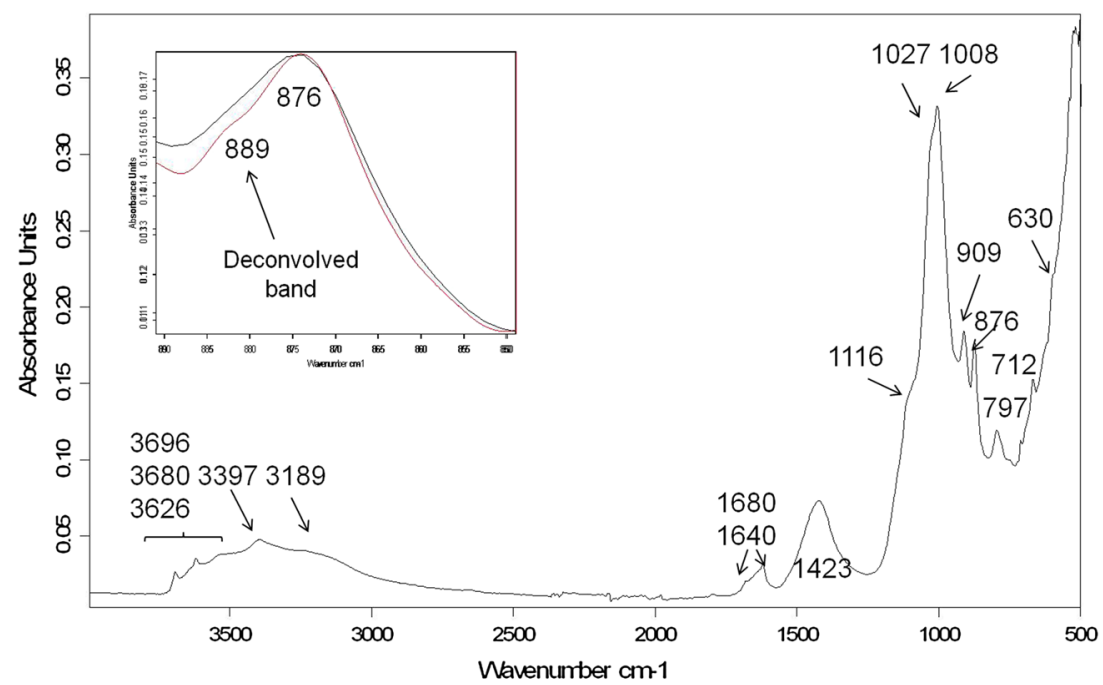

of the anthropogenic calcite crystals produced during the reaction of the slaked lime with atmospheric carbon dioxide thus increasing the proportion of disordered atoms close to the surface of the crystal. Larger crystals that form the geogenic Barxeta calcite result in lower $v_{2} / v_{4}$ band height ratio value. Interestingly, the archaeological plaster exhibits a $v_{2} / v_{4}$ band height ratio value closer to that of geogenic calcite than the modern plasters. This difference has diverse causes. The original limestone precursor of the slaked lime used in the plaster may not have been completely calcinated, so that the plaster finally formed should be a mix of geogenic and anthropogenic calcite. Second, aggregates of limestone may have been added to the plaster for improving its mechanical properties. Finally, processes of reprecipitation of the small and disordered crystals of calcite could take place in the plaster over time due to their lesser stability, thus resulting in larger and more ordered crystals.

\section{Examination of paint samples}

Pure pigments Figure 47 shows the IR spectrum of a sienna pigment. This natural pigment is mainly composed of iron oxide hydroxide and clay accompanied of calcite. The iron oxide hydroxide (goethite, $\alpha$-FeOOH), which is the compound mainly responsible for the yellowish color, is identified by bands at $3189 \mathrm{~cm}^{-1}$ ascribed to stretching vibrations of surface $\mathrm{OH}$ groups, band at $797 \mathrm{~cm}^{-1}$ assigned to bending vibrations of $\mathrm{OH}$ groups and shoulder at $630 \mathrm{~cm}^{-1}$ associated with stretching vibrations of $\mathrm{Fe}-\mathrm{O}$ bonds. Band at $889 \mathrm{~cm}^{-1}$ ascribed to bending vibrations of $\mathrm{OH}$ groups, which is also characteristic of goethite, has been identified after applying FSD treatment, as shown in Fig. 47. Noticeable amount of clay $[88,89]$ is present in the pigment that is clearly recognized in the IR spectrum by the sharp weak bands at 3696 and $3680 \mathrm{~cm}^{-1}$ ascribed to the stretching vibrations of surface hydroxyl groups and band at $3626 \mathrm{~cm}^{-1}$ assigned to inner hydroxyl groups. The band at $3397 \mathrm{~cm}^{-1}$ is assigned to the stretching vibrations of water, whereas the band at $1640 \mathrm{~cm}^{-1}$, with shoulder at $1680 \mathrm{~cm}^{-1}$, is assigned to the bending vibrations of hydroxyl groups. Strong bands at 1027 and $1008 \mathrm{~cm}^{-1}$ are attributed to $\mathrm{Si}-\mathrm{O}$ stretching vibrations. Band at $909 \mathrm{~cm}^{-1}$ is assigned to deformation vibrations of inner hydroxyl groups. Band at $797 \mathrm{~cm}^{-1}$ indicates the presence of amorphous silica accompanying to the clay [90]. Calcite is also easily recognized by characteristic vibrations of the carbonate ions, respectively, asymmetric stretching $\left(v_{3}\right)$ at $1423 \mathrm{~cm}^{-1}$, out-of-plane bending at $876 \mathrm{~cm}^{-1}\left(v_{2}\right)$ and inplane bending $\left(v_{4}\right)$ at $712 \mathrm{~cm}^{-1}$. The content of the accessory mineral calcite, at ca. $8 \%$, in the sienna pigment has been determined using the calibration curve obtained from a series of mixtures of calcium carbonate-kaolin.

Fresco painting FTIR spectroscopy Fresco technique has been applied for decorating walls and ceilings since the antiquity. In fresco painting pigments are applied on a ground layer (intonaco) of slaked lime and sand or other particulated inert material, whereas this plaster is not still completely hardened (fresco means fresh), so that the pigment grains are trapped in the more external part of the plaster ground providing to that of color simultaneously to the carbonation reaction of slaked lime to form calcium carbonate. This particular structure adds complexity to the analysis of pigments in fresco paintings as IR bands of the pigment appear in the IR spectrum together with IR bands of silica and calcium carbonate of the plaster. Figure 48 shows the IR spectrum of a sample of Egyptian blue excised from the Roman wall paintings of Cástulo (Jaen, Spain) [91]. This pigment is recognized by its intense IR 


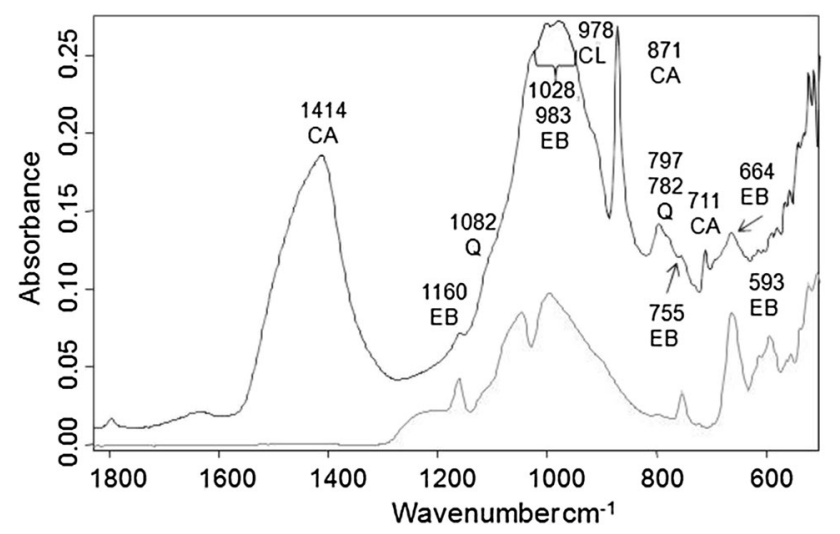

Fig. 48 Detail of the fingerprint region in the IR spectra of a sample of Egyptian blue excised from the Roman wall paintings of Cástulo (Jaen, Spain) and Egyptian blue pigment (Kremer). EB Egyptian blue, $C A$ calcium carbonate, $C L$ clayey materials, $Q$ quartz

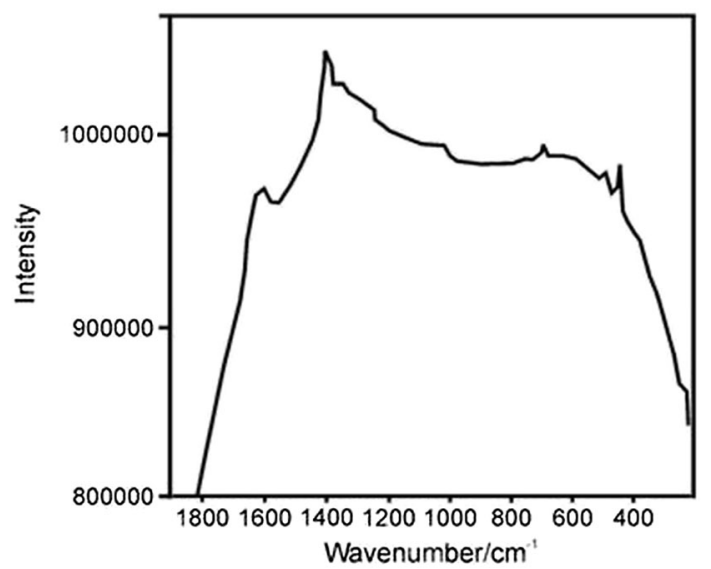

Fig. 49 Raman spectrum of a sample of carbon black pigment in Sant Joan del Mercat church (eighteenth century, Valencia, Spain) frescoes. Acquisition conditions: $785 \mathrm{~nm}$ excitation, $\times 50$ objective, 10 scans accumulated, $2 \mathrm{~cm}^{-1}$ spectral resolution, wavenumber range $300-1850 \mathrm{~cm}^{-1}$ [92]. Reproduced by permission from DoménechCarbó et al. Copyright (2012) Wiley bands at 1046 and $996 \mathrm{~cm}^{-1}$ and moderate bands at 755, 664, and $593 \mathrm{~cm}^{-1}$ ascribed to the stretching and bending vibrations of the $\mathrm{Si}-\mathrm{O}$ bond. Although the former are overlapped with IR bands at 1028 and $983 \mathrm{~cm}^{-1}$ ascribed to clayey materials, the latter are clearly discernible in the spectrum. Shoulder at $1082 \mathrm{~cm}^{-1}$ and bands at 1414,871 , and $711 \mathrm{~cm}^{-1}$ are assigned, respectively, to the stretching vibrations of $\mathrm{Si}-\mathrm{O}$ bonds of quartz from the sand and the stretching and bending vibrations of the $\mathrm{CO}_{3}$ group of microcrystalline calcium carbonate formed during the hardening of the intonaco.

Raman spectroscopy Figure 49 shows the Raman spectrum of a sample of carbon black pigment from the frescoes of the Sant Joan del Mercat church (eighteenth century, Valencia, Spain) [92]. This pigment, used since Prehistoric times, has a problematic identification and often its presence is deduced from the failure to identify other type of black pigments. Nevertheless, carbon black pigment is easily recognized by means of Raman spectroscopy by its characteristic $\mathrm{D}$ and $\mathrm{G}$ bands of amorphous $s p^{3}$ and $s p^{2}$ carbon that can be seen at 1590 and $1320 \mathrm{~cm}^{-1}$, respectively. In addition, the Raman spectrum does confirm the vegetable origin of this carbon pigment by the absence of phosphate signal in the Raman spectrum at $960 \mathrm{~cm}^{-1}$ characteristic of bone black pigment obtained from the calcination of bones.

Oil painting Oil painting is an artistic technique widely used in Europe since the late fifteenth century when canvas painting became popular. Similar to that observed for fresco painting, the IR spectra of samples of an oil paint are a combination of IR bands belonging to both pigment and drying oil used as binding medium. Figure 50 shows the IR spectrum of the white oil paint used by the Spanish painter José Benlliure (1855-1937) together with lead white and
Fig. 50 IR spectra of a sample of white paint excised from the Benlliure's palette, white lead (Aldrich) and linseed oil (Kremer). $L W$ lead white, $L O$ linseed oil, $M C$ metal carboxylate

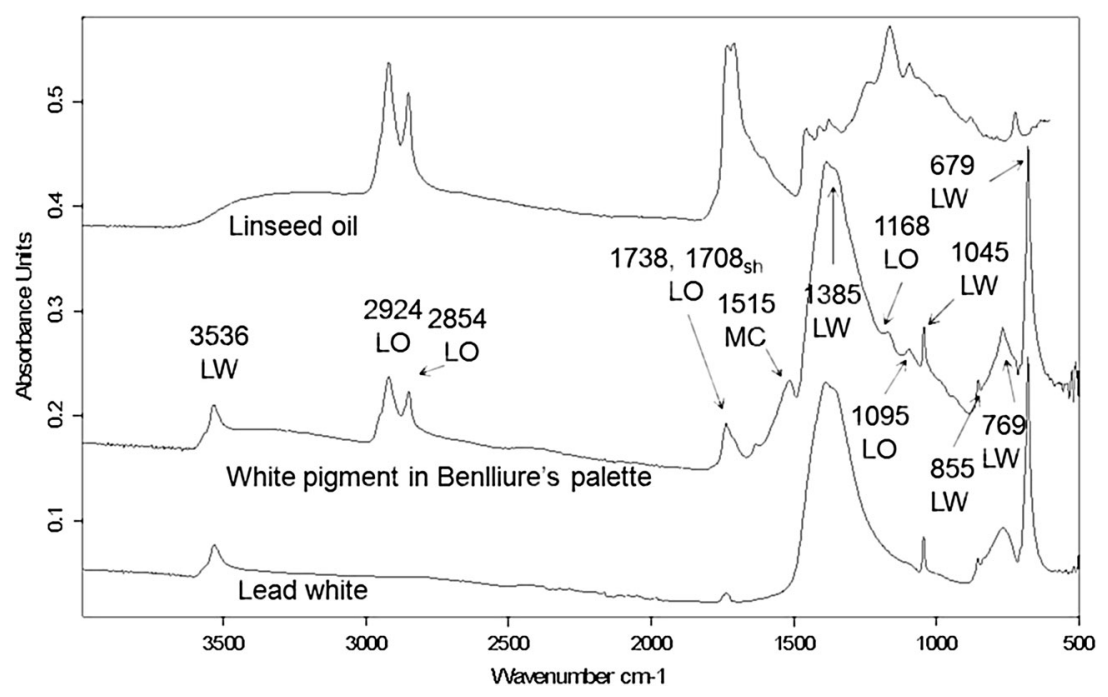


linseed oil used as reference materials. This pigment is recognized by its characteristic bands at $3536 \mathrm{~cm}^{-1}(\mathrm{OH}$ stretch), 1385, 1045, 855, 769, and $679 \mathrm{~cm}^{-1}\left(\mathrm{CO}_{3}\right.$ stretch and bend). Linseed oil is also recognized by bands at 2924 and $2854 \mathrm{~cm}^{-1}$ (-CH stretch), 1738 and $1708 \mathrm{~cm}^{-1}(-\mathrm{C}=\mathrm{O}$ stretch of esterified and free fatty acids hydrolysed from the polymerized oil) and 1168 and $1095 \mathrm{~cm}^{-1}$ (-C-O stretch). Interestingly, band at $1515 \mathrm{~cm}^{-1}$ ascribed to the stretching vibrations of the $\mathrm{Pb}$-carboxylate group is an evidence of the formation of lead soaps from the hydrolysed fatty acids and $\mathrm{Pb}^{2+}$ ions from the pigment. This reaction takes place together with the hydrolysis of triacylglycerols that form the network of polymerized oil. These reactions are typically taking place during aging of the oil paint contributing to its loss of chemical and physical properties.

\section{Voltammetry of microparticles}

\section{Fundamentals of the technique}

This instrumental technique is based on the electrochemical identification of the electroactive components of a powdered solid sample $\left(10^{-6}-10^{-11} \mathrm{~mol}\right)$ that is attached to an inert graphite electrode by abrasion and then immersed in a suitable electrolyte, so that the response of this sample-modified electrode becomes phase-characteristic $[14,46]$. This instrumental technique is based on the theoretical model developed by Lovric and Scholz [39, 93] and Oldham [94] for the redox reactivity of noncfonducting solids able to be permeated by cations and anions. According to this model, the reactive process is initiated at the three-phase junction between the electrode, the electrolyte and the solid particle and then expanded via charge diffusion across the solid particle. Fluxes of electrons and electrolyte ions across the electrolyte/particle interface take place, in parallel (Fig. 51).

\section{Instrumentation}

VMP is performed on conventional voltammetric instruments in which a three-electrode arrangement is performed (Fig. 52). Here, a voltage is applied between a working

\section{Electrolite}

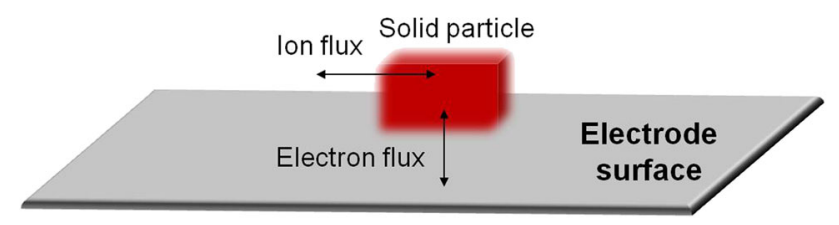

Fig. 51 Scheme of the reactive process at the three-phase junction between the electrode

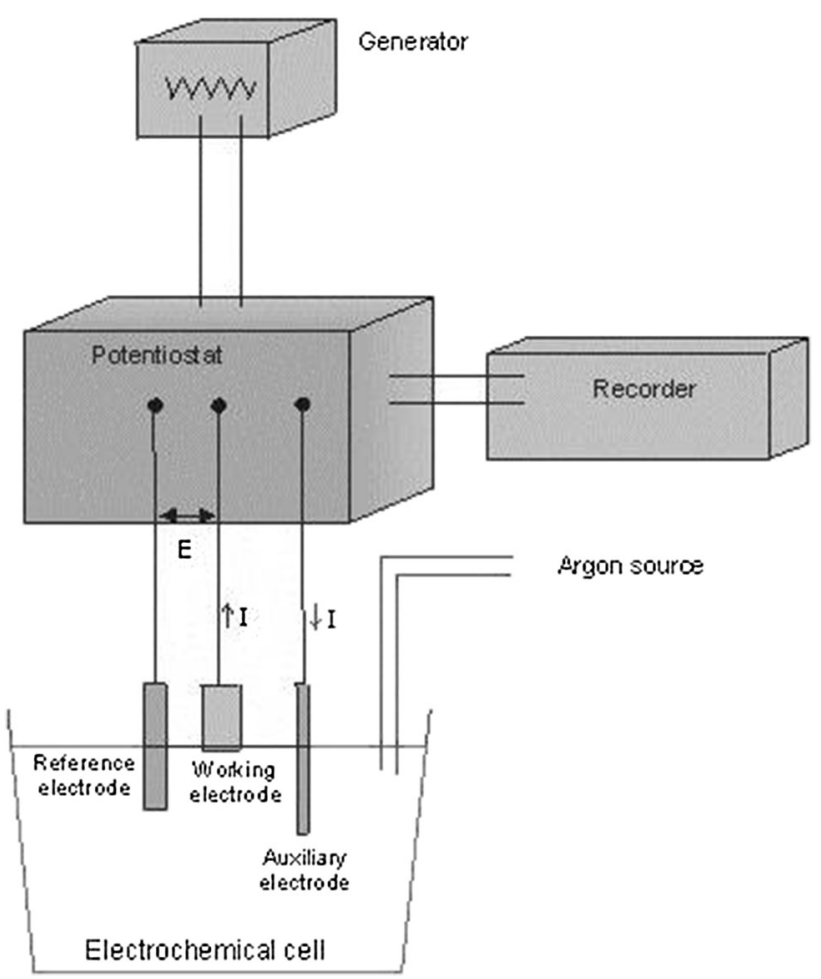

Fig. 52 Scheme of a voltammetric analyzer with a three-electrode arrangement

electrode and an auxiliary electrode. The potential of the former is controlled by the reference electrode, which is maintained at a constant known potential. During the analysis, the current $I$, which flows across the electrochemical cell as consequence of the application of a timedepending potential $E$, is measured. The obtained graphs $I$ vs. $E$ enable a rapid recognition of the oxidative and reductive processes that take place at the working electrode, which involve the pigment particles. Routine computer-assisted data processing treatments such as integration of peak areas, deconvolution, and convolution are also included as part of the instrumentation.

Different types of voltammetry can be performed depending on the form in which the applied potential varies on time. In cyclic and linear voltammetry, the excitation potential is linearly swept between two extreme values in a single direction (linear voltammetry) and sweeping up and down in cyclic voltammetry (Fig. 53). In differential pulse voltammetry (DPV), the excitation signal is applied as a combination of pulses superimposed to a linear potential scan, whereas in square wave voltammetry (SQWV), a square wave signal is used. This signal comprises the sum of a symmetrical square wave of half peak-to-peak amplitude and a staircase of the same period.

The electrolyte used can contribute to improve the result of the analysis. Acetic acid/sodium acetate buffer (total 


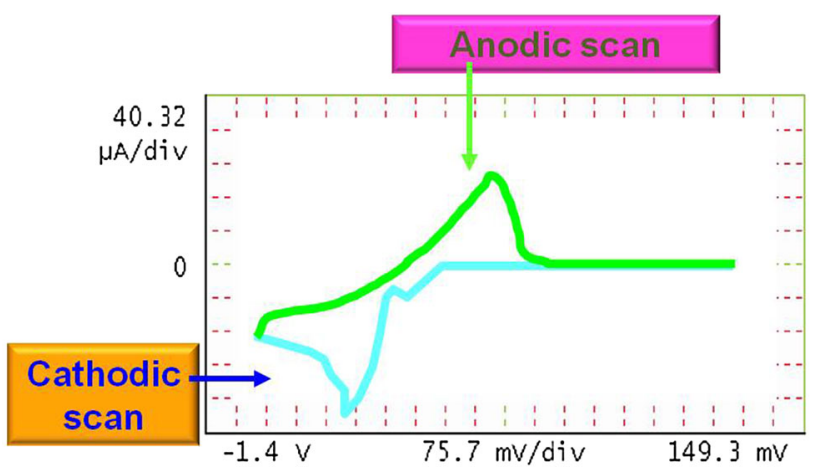

Fig. 53 Cyclic voltammogram of a pigment

acetone conc. $0.50 \mathrm{M}, \mathrm{pH} 4.85)$, phosphate buffer $(0.10 \mathrm{M}$, $\mathrm{pH}$ 7.0) or $0.10 \mathrm{M} \mathrm{HCl}$ solutions are commonly used.

Different types of working electrodes can be used in VMP. Carbon paste electrodes (PEs), which consist of a conducting paste formed by graphite powder and a binder such as Nujol or paraffin oil, have the disadvantage of generating large background currents. Pigments transferred by abrasion to the surface of a paraffin impregnated graphite electrodes (PIGEs) result in large signal-to-background responses and excellent repeatability. Less frequently are used electrodes prepared with graphitepolymer composites [95] or conventional graphite electrodes in which the pigment is deposited on the surface of the electrode by evaporation of a suspension of the pigment in a diluted polymer solution (polymer film electrodes, PFEs) [96].

\section{Analytical strategies}

Identification of individual species Identification of individual species from artists' pigments can be easily carried out using VMP. Each pigment, according to its composition, develops a specific reaction when is abrasively deposited on an inert electrode in contact with an electrolyte. Pigments such as lead white, minium, litharge, Naples yellow, cadmium yellow, vermilion, zinc oxide, cobalt blue or smalt, among others, undergo a reaction of reduction of the metal oxide or salt to the corresponding metal in the cathodic scan and a subsequent oxidation of the metallic deposit to the corresponding ion in solution in the anodic scan, the so-called oxidative stripping. Metal particles of bronze or tin, which are sometimes applied as pigment in altarpieces or wall paintings, display highly sensitive oxidative dissolution processes with characteristic stripping peaks. Natural earth pigments iron oxide-rich exhibit electrochemical processes involving their reductive dissolution of the solid $\mathrm{Fe}_{2} \mathrm{O}_{3}$ or $\mathrm{FeO}(\mathrm{OH})$ to $\mathrm{Fe}^{2+}$ ions in solution. In these cases, the shape of the voltammetric curves depends on the mineralogical composition and the shape and size distribution of the particles so that the voltammograms of different pigments have different profiles. The oxidative dissolution process of $\mathrm{Cr}_{2} \mathrm{O}_{3}$ to $\mathrm{Cr}_{2} \mathrm{O}_{7}^{2-}$ is used for identifying viridian and chrome oxide green. Finally, Prussian blue or Turnbull's blue [iron(III) hexacyanoferrate(II) or potassium-iron(III) hexacyanoferrate(II)] is an example of solid state redox process involving transformation of one solid compound in another. Solidstate processes are exhibited by a number of organic pigments. The electrochemical process can be described as:

$\mathrm{A}_{(\mathrm{s})}^{\mathrm{ox}}+n \mathrm{H}_{(a q)}^{+}+n \mathrm{e}^{-} \rightarrow \mathrm{H}_{n} \mathrm{~A}_{(\mathrm{s})}^{\mathrm{rd}}$,

where $\mathrm{A}^{\mathrm{ox}}$ is the oxidated form of the pigment and $\mathrm{H}_{n} \mathrm{~A}^{\mathrm{rd}}$ is the $n$-protonated reduced form.

Figure 19d shows the voltammogram of the historical pigment malachite, as an example. A database containing voltammograms from up to 75 historical pigments has recently been published by Doménech et al. [97, 98]. This database also includes UV-VIS, IR and X-ray spectra as well as electron images of most of the pigments. Case studies concerning analysis of historical pigments are also available in special features of scientific journals devoted to the solid state electrochemistry [99].

Multicomponent systems Analysis of paintings and polychromed objects often involves the characterization of multicomponent systems as the painter could use several pigments in a same paint layer or owing to the difficulty of mechanically separate the different strata that compose the sample excised from the painting. Resolution of multicomponent systems using VMP enables the simultaneous identification of the electroactive species present in the sample [14]. That can be achieved by applying different methods: (a) chemical methods based on the selective election of experimental conditions and parameters $(\mathrm{pH}$, electrolyte, electrode type), (b) electrochemical methods based on the variation of electrochemical parameters and further processing of data. Among the latter strategies, are included the Tafel analysis and cluster analysis.

Tafel analysis Tafel analysis is based on the assumption that the rising portion of the voltammogram can be approached by an exponential dependence of the current $(i)$ on the potential $(E)$ irrespectively of the electrochemical mechanism (Fig. 54a). Thus, a linear dependence between ln $I$ and $E$ can be established for pigments A and B in a binary sample containing both so that the slope (SL) and the ordinate at the origin $(\mathrm{OO})$ of the curve obtained from experimental data are intermediate between those from individual plots of A and B. Diagram depicting Tafel SL vs. OO (Fig. 54b) enables a satisfactory discrimination between pure pigment $\mathrm{A}$, pure pigment $\mathrm{B}$ and paints prepared as mixtures of A plus B. 
Fig. 54 a Tafel plots for pigment $\mathrm{A}, \mathrm{B}$ and binary sample $\mathrm{A}+\mathrm{B}$; b Tafel SL vs. OO diagram

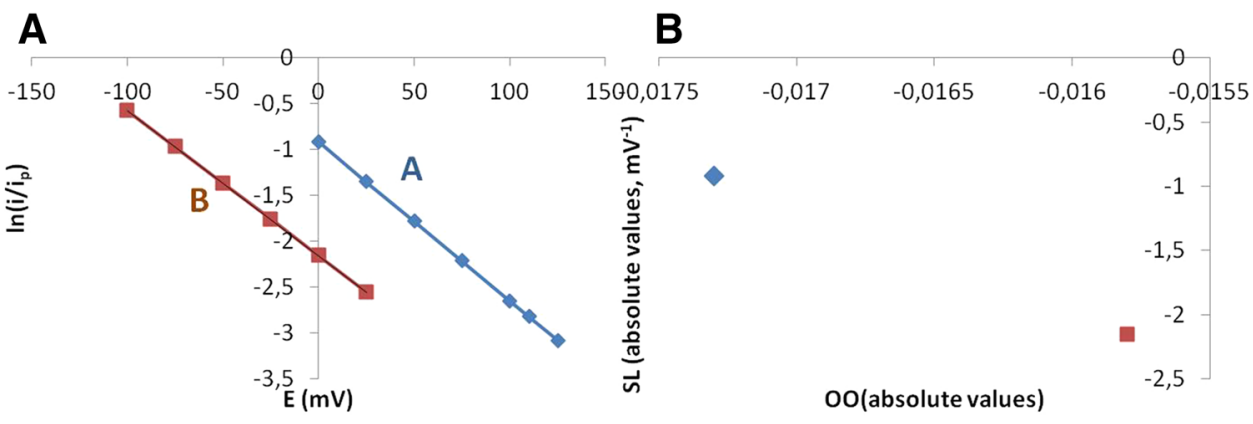

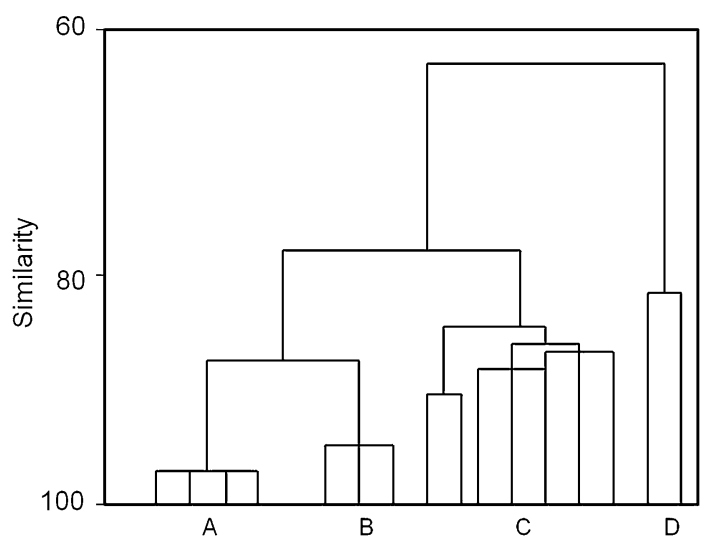

Fig. 55 Hierarchical cluster diagram that shows the Euclidean distances of the autoscaled variables applied to voltammetric parameters recorded for earth pigments

Hierarchical cluster analysis Analytical strategies based on multivariate methods can also be applied in VMP. In particular, earth pigments can be satisfactorily discriminated using multivariate methods. As previously mentioned, earth pigments exhibit varied mineralogical composition, shape, and size distribution of the particles, which hamper a satisfactory discrimination of those pigments when the analysis is performed with analytical techniques such as XRD. In contrast, application of VMP enables the identification of different holotypes based on the different values exhibited by the normalized peak current intensity [100]. Figure 55 shows the hierarchical cluster diagram that shows the Euclidean distances of the autoscaled variables applied to voltammetric parameters recorded for earth pigments. Four main holotypes can be discriminated according to their degree of similarity: holotype $\mathrm{A}$ is formed by pigments mainly composed of highly crystalline anhydrous iron oxide, holotype $\mathrm{B}$ includes pigments that contain amorphous highly hydrated iron oxide forms, and holotypes $\mathrm{C}$ and D include pigments composed of iron oxides with different degree of hydration and crystallinity accompanied of clays and manganese oxides as accessory minerals, respectively.

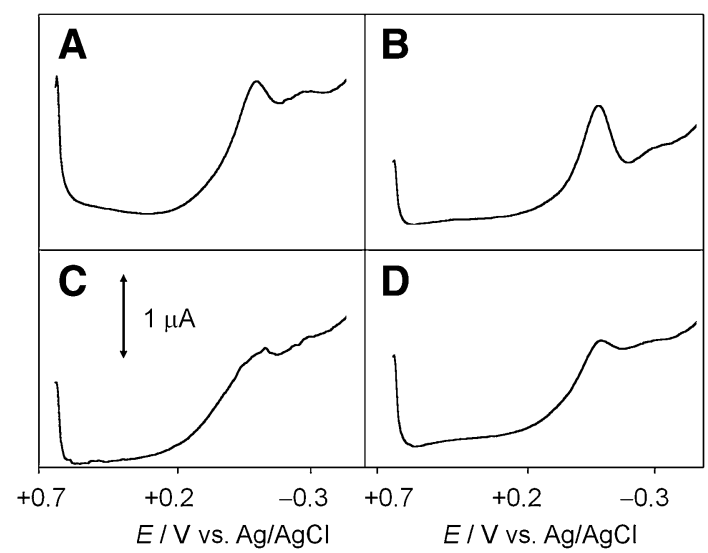

Fig. 56 SWVs of graphite electrode modified with: a azurite; b Ploss blue; c Han blue; $\mathbf{d}$ Egyptian blue in contact with $0.10 \mathrm{M}$ aqueous phosphate buffer. Potential scan initiated at $+0.65 \mathrm{~V}$ in the negative direction; potential step increment $4 \mathrm{mV}$; square wave amplitude $25 \mathrm{mV}$; frequency $5 \mathrm{~Hz}$ [91]. Reproduced by permission from Doménech-Carbó et al. Copyright (2013) Wiley

\section{Examination of paint samples}

Fresco painting Identification of pigment from fresco paintings is properly carried out by VMP, because the calcium carbonate, which acts as the inorganic binding medium in the intonaco, scarcely interferes the electroanalysis. Figure 56 shows the SWVs of a graphite electrode modified with: (a) azurite $\left(\mathrm{Cu}_{3}\left(\mathrm{CO}_{3}\right)_{2}(\mathrm{OH})_{2}\right)$; (b) ploss blue $\left((\mathrm{CuCa})\left(\mathrm{CH}_{3} \mathrm{COO}\right)_{2} \cdot 2 \mathrm{H}_{2} \mathrm{O}\right)$; (c) Han blue $\left(\mathrm{BaCuSi}_{4} \mathrm{O}_{10}\right)$, and (d) Egyptian blue $\left(\mathrm{CaCuSi}_{4} \mathrm{O}_{10}\right)$ in contact with $0.10 \mathrm{M}$ aqueous phosphate buffer. These reference materials enabled the unambiguous identification of Egyptian blue from the Roman wall paintings of Cástulo (Jaen) by recognition of main cathodic peak at $-0.15 \mathrm{~V}$ vs. $\mathrm{Ag} / \mathrm{AgCl}$ followed by a shoulder at ca. $-0.75 \mathrm{~V}$ (Fig. 56d) and an anodic stripping peak at $+0.15 \mathrm{~V}$ in the reverse scan [91].

Maya blue Maya blue is an outstanding indigo-based pigment produced by the ancient Mayas that has attracted attention of scientists over the years. Maya blue has a 


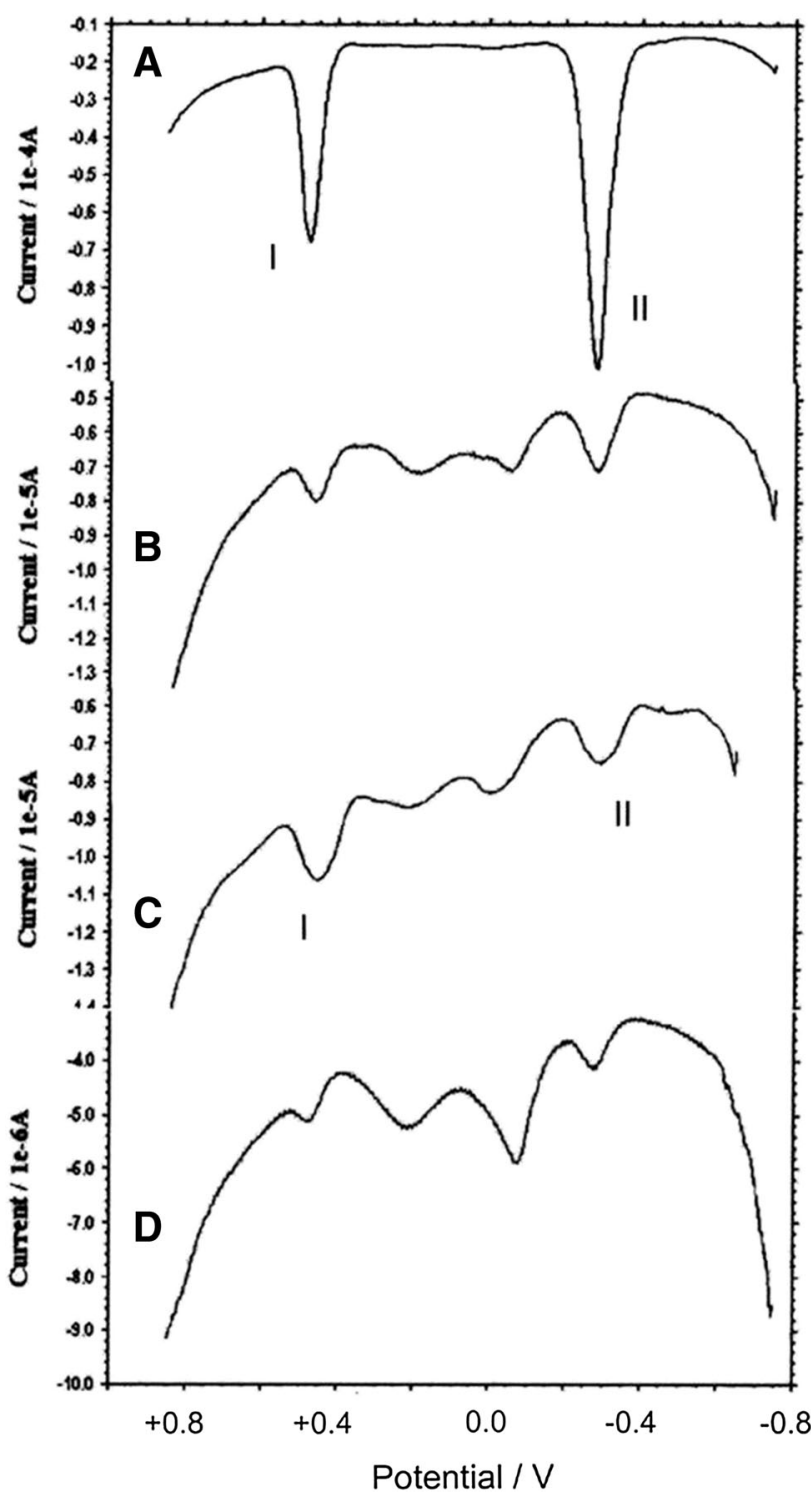

Fig. 57 SQWVs of a indigo microparticles, and samples from b Calakmul, Substructure II-C, Late Preclassical period; c Dzibilnocac-2, Late Classical period; d Mayapán-2, Early Postclassical period. Electrolyte $0.50 \mathrm{M}$ acetate buffer, $\mathrm{pH} 4.85$. Potential scan initiated at $-750 \mathrm{mV}$ in the positive direction. Potential step increment $4 \mathrm{mV}$; square wave amplitude $25 \mathrm{mV}$; frequency $5 \mathrm{~Hz}$ [101]. Reproduced by permission from Doménech-Carbó et al. Copyright (2006) American Chemical Society

peculiar color and significant stability because of its inorganic-organic hybrid nanostructure whose elucidation is being a challenge for chemists and conservators. There exists a general agreement in which the association of indigo to a local clay, palygorskite determines the stability of the pigment. Despite the procedure of preparation of Maya blue is unknown, it is assumed that this pigment was prepared by crushing indigo (obtained from Indigofera species) and palygorskite with a moderate thermal treatment. However, the nature of the indigo-palygorskite association has been in the past controversial, because the studies performed on samples and laboratory paint reconstructions of this pigment did not provide satisfactory structural data for justifying the characteristic hue and notable stability of the pigment.

In this context, application of VMP, further confirmed by application of a multi-technique methodology that included UV-Vis spectrophotometry, FTIR and Raman spectroscopy, MNR, SEM-EDX, TEM, AFM, GC-MS, Py-GC-MS, UTLC-MS, and HPLC-DAD, has provided experimental evidences of the existence of redox tuning in Maya blue-type materials and, in particular, of the presence not only of indigo but also of dehydroindigo attached to palygorskite [101-106]. The co-existence of different organic molecules attached to the palygorskite in variable concentration depending on the thermal treatment applied during the preparation of the pigment justify the different hue found in Maya wall paintings, which ranges from yellow to blue and green.

Figure 57 shows the SQWVs of indigo microparticles (a) and samples from Calakmul, Substructure II-C, Late Preclassical period (b), Dzibilnocac, Late Classical period (c) and Mayapán, Early Postclassical period (d). It can be seen that SQWVs of Maya Blue samples exhibit significant differences with those of indigo microparticles, namely, small but consistent differences in peak potentials, peak broadening and remarkably different peak current ratio for processes I and II ascribed, respectively, to the oxidation of indigo to dehydroindigo and the reduction of indigo to leucoindigo. These results fit well with current models on the electrochemistry of ion insertion solids and indicate that a significant amount of dehydroindigo accompanies indigo in Maya blue samples.

Acknowledgments Financial support is gratefully acknowledged from Spanish "I+D+I MINECO" projects CTQ2011-28079-CO3-01 and CTQ2014-53736-C3-1-P supported by ERDEF funds. The authors also wish to thank Mr. Manuel Planes and Dr. José Luis Moya, technical supervisors of the Electron Microscopy Service of the Universitat Politècnica de València.

\section{References}

1. Wilks H (ed) (1987) Science for conservators: a conservation science teaching series. The Conservation Unit Museums and Galleries Commission, London

2. San Andrés Moya M, Viña Ferrer S (2004) Fundamentos de química y física para la conservación y restauración. Síntesis, Madrid

3. Doménech-Carbó MT (2013) Principios físico-químicos de los materiales integrantes de los bienes culturales, Universitat Politècnica de València

4. Mills JS, White R (1987) The organic chemistry of museum objects. Butterworths, London, pp 141-159

5. Matteini M, Moles A (1991) La Quimica nel Restauro. I materiali dell'arte pittorica. Nardini, Firenze 
6. Gomez MA (1998) La Restauración. Examen científico aplicado a la conservación de obras de arte. Cátedra, Madrid

7. Taft WS Jr, Mayer JW (2000) The science of paintings. Springer, New York

8. Allen RO (ed) (1989) Archaeological chemistry IV; Advances in chemistry. American Chemical Society, Washington, DC

9. Aitken MJ (1990) Science-based dating in archaeology. Longman Archaeology Series, New York

10. Ciliberto E, Spoto G (eds) (2000) Modern analytical methods in art and archaeology. Wiley, New York

11. Matteini M, Moles A (1986) Sciencia e Restauro. Metodi di Indagine, 2nd edn. Nardini, Firenze

12. Odegaard N, Carroll S, Zimmt W (2000) Material characterization tests for objects of art and archaeology. Archetype Publications, London

13. Derrick MR, Stulik DC, Landry MJ (1999) Infrared spectroscopy in conservation science. Getty Conservation Institute, Los Angeles

14. Doménech-Carbó A, Doménech-Carbó MT, Costa V (2009) Electrochemical methods in archaeometry, conservation and restoration. In: Scholz F (ed) Series: Monographs in electrochemistry. Springer, Berlin

15. Edwards HGM, Chalmers JM (eds) (2005) Raman spectroscopy in archaeology and art history. The Royal Society of Chemistry, Cambridge

16. Lahanier C (1991) Scientific methods applied to the study of art objects. Mikrochim Acta II:245-254

17. Bitossi G, Giorgi R, Salvadori BM, Dei L (2005) Spectroscopic techniques in cultural heritage conservation: a survey. Appl Spectrosc Rev 40:187-228

18. Odlyha M (2000) Special feature: preservation of cultural heritage. The application of thermal analysis and other advanced analytical techniques to cultural objects. Thermochim Acta 365

19. Feature Special (2003) Archaeometry. Meas Sci Technol 14:1487-1630

20. Aitken MJ (1961) Physics and archaeology. Interscience, New York

21. Olin JS (ed) (1982) Future directions in archaeometry. A round table. Smithsonian Institution Press, Washington, DC

22. Townsend JH (2006) What is conservation science? Macromol Symp 238:1-10

23. Nadolny J (2003) The first century of published scientific analyses of the materials of historical painting and polychromy, circa 1780-1880. Rev Conserv 4:39-51

24. Montero Ruiz I, Garcia Heras M, López-Romero E (2007) Arqueometría: cambios y tendencias actuales. Trabajos de Prehistoria 64:23-40

25. Fernandes Vieira G, Sias Coelho LJ (2011) Arqueometría: Mirada histórica de una ciencia en desarrollo. Revista CPC 13:107-133

26. Rees-Jones SG (1990) Early experiments in pigment analysis. Stud Conserv 35:93-101

27. Allen RO (1989) The role of the chemists in archaeological studies. In: Allen RO (ed) Archaeological chemistry IV. Advances in chemistry. American Chemical Society, Washington DC, pp 1-17

28. Plesters J (1956) Cross-sections and chemical analysis of paint samples. Stud Conserv 2:110-157 and references therein

29. Gilberg M (1987) Friedrich Rathgen: the father of modern archaeological conservation. J Am Inst Conserv 26:105-120

30. Olin JS, Salmon ME, Olin CH (1969) Investigations of historical objects utilizing spectroscopy and other optical methods. Appl Optics 8:29-39

31. Feller RL (1954) Dammar and mastic infrared analysis. Science 120:1069-1070
32. Hall ET (1963) Methods of analysis (physical and microchemical) applied to paintings and antiquities. In: Thomson G (ed) Recent advances in conservation. Butterworths, London, pp 29-32

33. Feigl F, Anger V (1972) Spot tests in inorganic analysis, 6th English edition, translated by Oesper RE. Elsevier, Amsterdam

34. Locke DC, Riley OH (1970) Chemical analysis of paint samples using the Weisz ring oven technique. Stud Conserv 15:94-101

35. Mairinger F, Schreiner M (1986) Analysis of supports, grounds and pigments. In: van Schoute R, Verougstracte-Marcq H (eds) PACT 13, Xth Anniversary Meeting of PACT Group. Louvainla Neuve, pp 171-183 (and references therein)

36. Vandenabeele P, Edwards HGM (2005) Overview: Raman spectrometry of artefacts. In: Edwards HGM, Chalmers JM (eds) Raman spectroscopy in archaeology and art history. The Royal Society of Chemistry, Cambridge, pp 169-178

37. Tykot RH (2004) Scientific methods and applications to archaeological provenance studies. In: Proceedings of the International School of Physics "Enrico Fermi". IOS Press, Amsterdam, pp 407-432

38. Doménech-Carbó A, Doménech-Carbó MT, Valle-Algarra FM, Domine ME, Osete-Cortina L (2013) On the dehydroindigo contribution to Maya Blue. J Mat Sci 48:7171-7183

39. Lovric M, Scholz F (1997) A model for the propagation of a redox reaction through microcrystals. J Solid State Electrochem $1: 108-113$

40. Fitzgerald AG, Storey BE, Fabian D (1993) Quantitative microbeam analysis. Scottish Universities Sumer School in Physics and Institute of Physics Publishing, Bristol

41. Doménech-Carbó A (2015) Dating: an analytical task. ChemTexts 1:5

42. Mairinger F, Schreiner M (1982) New methods of chemical analysis-a tool for the conservator. Science and Technology in the service of conservation, IIC, London, pp 5-13

43. Malissa H, Benedetti-Pichler AA (1958) Anorganische qualitative Mikroanalyse. Springer, New York

44. Tertian R, Claisse F (1982) Principles of quantitative X-ray fluorescence analysis. Heyden, London

45. Mantler M, Schreiner M (2000) X-ray fluorescence spectrometry in art and archaeology. X-Ray Spectrom 29:3-17

46. Scholz F (2015) Voltammetric techniques of analysis: the essentials. ChemTexts 1:17

47. Inzelt G (2014) Crossing the bridge between thermodynamics and electrochemistry. From the potential of the cell reaction to the electrode potential. ChemTexts 1:2

48. Milchev A (2016) Nucleation phenomena in electrochemical systems: thermodynamic concepts. ChemTexts $2: 2$

49. Milchev A (2016) Nucleation phenomena in electrochemical systems: kinetic models. ChemTexts 2:4

50. Seeber R, Zanardi C, Inzelt G (2015) Links between electrochemical thermodynamics and kinetics. ChemTexts 1:18

51. Feist M (2015) Thermal analysis: basics, applications, and benefit. ChemTexts 1:8

52. Stoiber RE, Morse SA (1994) Crystal identification with the polarizing microscope. Springer, Berlin

53. Goldstein JI, Newbury DE, Echlin P, Joy DC, Lyman CE, Echlin P, Lifshin E, Sawyer L, Michael JR (2003) Scanning electron microscopy and X-ray microanalysis. Plenum Press, New York

54. Doménech-Carbó A, Doménech-Carbó MT, Más-Barberá X (2007) Identification of lead pigments in nanosamples from ancient paintings and polychromed sculptures using voltammetry of nanoparticles/atomic force microscopy. Talanta 71:1569-1579

55. Reedy TJ, Reedy ChL (1988) Statistical analysis in art conservation research. The Getty Conservation Institute, Los Angeles 
56. Eastaugh N, Walsh V, Chaplin T, Siddall R (2004) Pigment compendium, optical microscopy of historical pigments. Elsevier, Oxford

57. Feller RL, Bayard M (1986) Terminology and procedures used in the systematic examination of pigment particles with polarizing microscope. In: Feller RL (ed) Artists' pigment. A handbook of their history and characteristics, vol 1 . National Gallery of Art, Washington, pp 285-298

58. Feller RL (ed) (1986) Artists' pigment. A handbook of their history and characteristics, vol 1. National Gallery of Art, Washington

59. Roy A (ed) (1993) Artists' pigments. A handbook of their history and characteristics, vol 2. National Gallery of Art, Washington

60. FitzHugh EW (ed) (1997) Artists' pigments. A handbook of their history and characteristics, vol 3. National Gallery of Art, Washington

61. Berrie BH (ed) (2007) Artists' pigment. A handbook of their history and characteristics, vol 4. National Gallery of Art, Washington

62. Haynes WN (ed) (2015) CRC handbook for physics and chemistry, 96th edn. Taylor and Francis Group, UK

63. Fiedler I, Bayard MA (1986) Cadmium yellows, oranges and reds. In: Feller RL (ed) Artists' pigment. A handbook of their history and characteristics, vol 1. National Gallery of Art, Washington, pp 65-108

64. Domenech-Carbó MT, de Agredos Vazquez, Pascual ML, Osete-Cortina L, Domenech A, Guasch-Ferré N, Manzanilla LR, Vidal C (2012) Characterization of Pre-hispanic cosmetics found in a burial of the ancient city of Teotihuacan (Mexico). J Archaeol Sci 39:1043-1062

65. Mühlethaler B, Thissen J (1993) Smalt. In: Roy A (ed) Artists' pigments. A handbook of their history and characteristics, vol 2. National Gallery of Art, Washington, pp 113-130

66. Musumarra G, Fichera M (1998) Chemometrics and cultural heritage. Chemometr Intell Lab Syst 44:363-372

67. Hochleitner B, Schreiner M, Drakopoulos M, Snigireva I, Snigirev A (2005) Analysis of paint layers by light microscopy, scanning electron microscopy and synchrotron induced X-ray micro-diffraction. In: Van Grieken R, Janssens K (eds) Cultural heritage conservation and environment impact assessment by non-destructive testing and micro-analysis. AA Balkema Publishers, London, pp 171-182

68. Švarcová S, Kočí E, Bezdička P, Hradil D, Hradilová J (2010) Evaluation of laboratory powder X-ray micro-diffraction for applications in the fields of cultural heritage and forensic science. Anal Bioanal Chem 398:1061-1076

69. Van de Voorde L, Vekemans B, Verhaeven E, Tack P, DeWolf R, Garrevoet J, Vandenabeele P, Vincze L (2015) Analytical characterization of a new mobile X-ray fluorescence and X-ray diffraction instrument combined with a pigment identification case study. Spectrochim Acta B 110:14-19

70. Hochleitner B, Desnica V, Mantler M, Schreiner M (2003) Historical pigments: a collection analyzed with $\mathrm{X}$-ray diffraction analysis and X-ray fluorescence analysis in order to create a database. Spectrochim Acta B 58:641-649

71. Middleton PS, Ospitali F, Di Lonardo F (2005) Case study: painters and decorators: Raman spectroscopic studies of five Romano-British villas and the Domus Coiedii at Suasa, Italy. In: Edwards HGM, Chalmers JM (eds) Raman spectroscopy in archaeology and art history. The Royal Society of Chemistry, Cambridge, pp 97-120

72. Helwig K (1993) Iron oxide pigments: natural and synthetic. In: Roy A (ed) Artists' pigments. A handbook of their history and characteristics, vol 2. National Gallery of Art, Washington, pp 39-95
73. Silva CE, Silva LP, Edwards HGM, de Oliveira LFC (2006) Diffuse reflection FTIR spectral database of dyes and pigments. Anal Bioanal Chem 386:2183-2191

74. Hummel DO (ed) (1985) Atlas of polymer and plastic analysis, vol 1, Polymers, structures and spectra. Hanser VCH, Münich

75. http://www.irug.org (consulted: 1 Feb 2016)

76. http://www.ehu.es/udps/database/database.html (consulted: 1 Feb 2016)

77. Burgio L, Clark RJH (2001) Library of FT-Raman spectra of pigments, minerals, pigment media and varnishes, and supplement to existing library of Raman spectra of pigments with visible excitation. Spectrochim Acta A 57:1491-1521

78. http://www.chem.ucl.ac.uk/resources/raman/speclib.html (consulted: 1 Feb 2016)

79. Madariaga JM, Bersani D (2012) Special feature: Raman spectroscopy in art and archaeology. J Raman Spectrosc 43(11): 1523-1844

80. http://minerals.gps.caltech.edu/ (consulted: 1 Feb 2016)

81. http://www.rruff.info (consulted: 1 Feb 2016)

82. Frost RL, Martens WN, Rintoul L, Mahmutagic E, Kloprogge JT (2002) J Raman Spectrosc 33:252-259

83. Smith D (2005) Overwiew: jewellery and precious stones. In: Edwards HGM, Chalmers JM (eds) Raman spectroscopy in archaeology and art history. The Royal Society of Chemistry, Cambridge, pp 335-378

84. Weiner S, Bar-Yosef O (1990) States of preservation of bones from prehistoric sites in the Near East: a survey. J Archaeol Sci 17:187-196

85. Chu V, Regev L, Weiner S, Boaretto E (2008) Differentiating between anthropogenic calcite in plaster, ash and natural calcite using infrared spectroscopy: implications in archaeology. J Archaeol Sci 35:905-911

86. Beniash E, Aizenberg J, Addadi L, Weiner S (1997) Amorphous calcium carbonate transforms into calcite during sea-urchin larval spicule growth. Proc R Soc Lond Ser B 264:461-465

87. Regev L, Poduska KM, Addadi L, Weiner S, Boaretto E (2010) Distinguishing between calcites formed by different mechanisms using infrared spectrometry: archaeological applications. J Archaeol Sci 37:3022-3029

88. Farmer C (ed) (1974) The infrared spectra of mineral, Monograph 4. Mineralogical Society, London

89. Madejová J, Kečkéš J, Pálková H, Komadel P (2002) Identification of components in smectite/kaolinite mixtures. Clay Miner 37:377-388

90. Šucha V, Środoń J, Clauer N, Elsass F, Eberl DD, Kraus I, Madejová J (2001) Weathering of smectite and illite-smectite under temperate climatic conditions. Clay Miner 36:403-419

91. Doménech-Carbó A, Doménech-Carbó MT, López-López F, Valle-Algarra FM, Osete-Cortina L, Arcos-Von Haartman E (2013) Electrochemical characterization of egyptian blue pigment in wall paintings using the voltammetry of microparticles methodology. Electroanalysis 25:2621-2630

92. Doménech-Carbó MT, Edwards HGM, Doménech-Carbó A, del Hoyo-Meléndez JM, de la Cruz-Cañizares J (2012) An authentication case study: Antonio Palomino vs. Vicente Guillo paintings in the vaulted ceiling of the Sant Joan del Mercat church (Valencia, Spain). J Raman Spectrosc 43:1250-1259

93. Lovric M, Scholz F (1999) A model for the coupled transport of ions and electrons in redox conductive microcrystals. J Solid State Electrochem 3:172-175

94. Oldham KB (1998) Voltammetry at a three phase junction. J Solid State Electrochem 2:367-377

95. Doménech A, Doménech-Carbó MT, Gimeno-Adelantado JV, Bosch-Reig F, Saurí-Peris MC, Sánchez-Ramos S (2001) Electrochemical identification of iron oxide pigments (earths) from 
pictorial microsamples attached to graphite/polyester composite electrodes. Analyst 126:1764-1772

96. Doménech A, Doménech-Carbó MT, Moya-Moreno MCM, Gimeno-Adelantado JV, Bosch-Reig F (2000) Identification of inorganic pigments from paintings and polychromed sculptures immobilized into polymer film electrodes by stripping differential pulse voltammetry. Anal Chim Acta 407:275-289

97. Doménech-Carbó A, Doménech-Carbó MT, Valle-Algarra FM, Gimeno-Adelantado JV, Osete-Cortina L, Bosch-Reig F (2016) On-line database of voltammetric data of immobilized particles for identifying pigments and minerals in archaeometry, conservation and restoration (ELCHER database). Anal Chim Acta 927:1-12

98. http://www.elcher.info (consulted: 1 July 2016)

99. Scholz F, Doménech-Carbó A (2010) Special feature: electrochemistry for conservation science. J Solid State Electrochem 14

100. Domenech-Carbó A, Domenech-Carbó MT, Edwards HGM (2007) Identification of earth pigment by hierarchical cluster applied to solid state voltammetry. Application to a severely damaged frescoes. Electroanalysis 19:1890-1900

101. Domenech-Carbó A, Domenech-Carbó MT, Vázquez de Agredos-Pascual ML (2006) Dehydroindigo: a new piece into the Maya Blue puzzle from the voltammetry of microparticles approach. J Phys Chem B 110:6027-6039
102. Doménech-Carbó A, Doménech-Carbó MT, Vázquez de Agredos-Pascual ML (2007) Chemometric study of Maya Blue from the voltammetry of microparticles approach. Anal Chem 79:2812-2821

103. Doménech-Carbó A, Doménech-Carbó MT, Vázquez de Agredos-Pascual ML (2011) From Maya Blue to 'Maya Yellow': a connection between ancient nanostructured materials from the voltammetry of microparticles. Angew Chem Int Edit 50:5741-5744

104. Doménech-Carbó A, Doménech-Carbó MT, Vidal-Lorenzo C, Vázquez de Agredos-Pascual ML (2012) Insights into the Maya Blue Technology: greenish pellets from the ancient city of La Blanca. Angew Chem Int Ed 51:700-703

105. Doménech-Carbó A, Doménech-Carbó MT, Osete-Cortina L, Montoya N (2012) Application of solid-state electrochemistry techniques to polyfunctional organic-inorganic hybrid materials: the Maya Blue problem. Micropor Mesopor Mater 166:123-130

106. Doménech-Carbó MT, Osete-Cortina L, Doménech-Carbó A, Vázquez de Agredos-Pascual ML, Vidal-Lorenzo C (2014) Identification of indigoid compounds present in archaeological Maya blue by pyrolysis-silylation-gas chromatography-mass spectrometry. J Anal Appl Pyrol 105:355-362 